\title{
Modernization of Technical Requirements for Licensing of Advanced Non-Light Water Reactors: Probabilistic Risk Assessment Approach
}

Wayne L Moe

March 2020

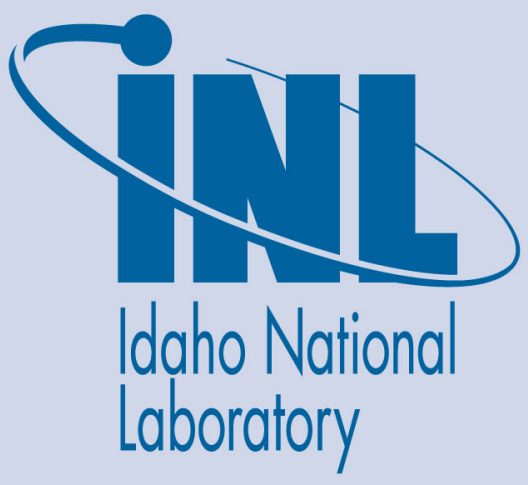

The INL is a U.S. Department of Energy National Laboratory operated by Battelle Energy Alliance 


\title{
Modernization of Technical Requirements for Licensing of Advanced Non-Light Water Reactors: Probabilistic Risk Assessment Approach
}

\author{
Wayne L Moe
}

March 2020

Idaho National Laboratory Idaho Falls, Idaho 83415

http://www.inl.gov

Prepared for the

U.S. Department of Energy

Under DOE Idaho Operations Office

Contract DE-AC07-05ID14517 


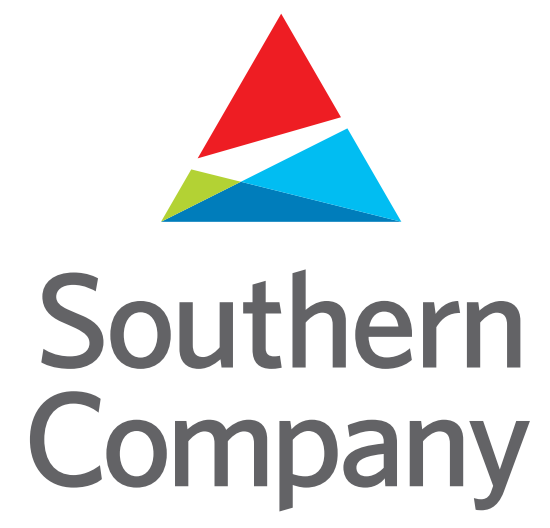

Modernization of Technical Requirements

for Licensing of Advanced Non-Light Water Reactors:

Probabilistic Risk Assessment Approach

Document Number

SC-29980-101 Rev 1

March 2020

Prepared for:

U.S. Department of Energy

Office of Nuclear Energy

Under DOE Idaho Operations Office

Contract DE-AC07-05ID14517 


\section{$\Delta$ \\ Southern Company}

Modernization of Technical Requirements for Licensing of Advanced Non-Light Water Reactors:

Probabilistic Risk Assessment Approach

Document Number

SC-29980-101 Rev 1

Issued by:

Amir Afzali, Next Generation Licensing and Policy Director Southern Company Services

Date 


\section{Disclaimer}

This report was prepared as an account of work sponsored by an agency of the United States (U.S.) Government. Neither the U.S. Government nor any agency thereof, nor any of their employees, nor Southern Company Services, Inc., nor any of its employees, nor any of its subcontractors, nor any of its sponsors or co-funders, makes any warranty, expressed or implied, or assumes any legal liability or responsibility for the accuracy, completeness, or usefulness of any information, apparatus, product, or process disclosed, or represents that its use would not infringe privately owned rights. Reference herein to any specific commercial product, process, or service by trade name, trademark, manufacturer or otherwise, does not necessarily constitute or imply its endorsement, recommendation, or favoring by the U.S. Government or any agency thereof. The views and opinions of authors expressed herein do not necessarily state or reflect those of the U.S. Government or any agency thereof. 


\begin{abstract}
This report, "Modernization of Technical Requirements for Licensing of Advanced Non-Light Water Reactors: Probabilistic Risk Assessment Approach," represents a key element in the development of a methodology for the efficient licensing of advanced non-light water reactors (non-LWRs). It is the result of a Licensing Modernization Project (LMP) led by Southern Company and cost-shared by the U.S. Department of Energy (DOE). The LMP has developed detailed proposals for establishing licensing technical requirements to facilitate risk-informed and performance-based design and licensing of advanced non-LWRs. Such a methodology acknowledges enhancements in safety achievable with advanced designs and reflects more recent states of knowledge regarding safety and design innovation, creating an opportunity for reduced regulatory complexity with increased levels of safety. The project builds on best practices, as well as previous activities through DOE and industry-sponsored advanced reactor licensing initiatives.
\end{abstract}

The LMP objective is to assist the Nuclear Regulatory Commission (NRC) in developing regulatory guidance for licensing advanced non-LWR plants.

This report outlines the approach to develop a PRA for advanced non-LWR plants in support of risk-informed and performance-based (RIPB) applications including:

- Evaluation of design alternatives and incorporation of risk insights into early and continuing development of the design

- Selection and evaluation of LBEs

- Safety classification and performance targets for SSCs

- Development of SSC performance targets for preventing and mitigating LBEs

- Evaluation of defense-in-depth adequacy

Key elements of this report have been incorporated into industry guidance for implementing the LMP methodology for preparing license applications for future advanced non-LWRs that are being considered for NRC endorsement.

Companion reports developed as part of the LMP address how the PRA is used to support each of the above listed risk-informed and performance-based applications.

Future advanced non-LWR license applications will include a design-specific PRA that is capable of supporting the above listed applications. When introduced at an early stage of the design, the PRA is expected to result in a more efficient risk management process. This report outlines the relevant regulatory policy and guidance for this type of PRA, describes the approach to be followed for the development of the PRA, and sets forth PRA topics that need to be addressed in order to facilitate successful design and more safety focused preparation and review of the license application. 
Key elements discussed in this report include the PRA scope and objectives, regulatory guidance used in the formulation of these objectives, and the methodology for factoring the objectives into the LMP methodology. These PRA elements are first described in terms of a TI framework supplemented with examples of PRA models for specific non-LWR designs including a modular high temperature gas-cooled reactor, a pool-type sodium-cooled fast reactor, and a molten salt reactor.

The PRA approach that will be used to support the advanced non-LWR license design is broadly applicable to both single reactor and multi-reactor module plants and is intended to support both design certification and site-specific license applications. As described herein, the PRA is introduced at an early stage in the design, and subsequently upgraded in terms of scope and level of detail at various design and licensing stages as the design matures and the design and siting details are defined. At each stage of the design maturation, information from the PRA that is available at that design stage will be used to support decisions on the selection and evaluation of design options, selection and evaluation of LBEs, to help formulate requirements on the capability and reliability of SSCs in the prevention and mitigation of accidents, and to evaluate defense-in-depth adequacy. 


\section{Acknowledgments}

The LMP acknowledges the invaluable input received from the B. John Garrick Institute for the Risk Sciences, which was tasked with reviewing the Next Generation Nuclear Plant (NGNP) and LMP draft white papers on PRA development, LBE selection, SSC safety classification and riskinformed evaluation of defense-in-depth. In their review of the PRA papers, the Garrick Institute noted that the referenced examples from the modular high temperature gas-cooled reactor and sodium cooled fast reactor communities already benefit from a long history of PRA development, whereas other advanced non-LWRs are at a much earlier stage of developing a supporting probabilistic and deterministic safety basis. In response to this input, additional guidance has been incorporated into this report on how to begin the PRA development for a new reactor that may not benefit from a rich PRA history. In addition to this input, John Garrick has provided his personal review comments on an earlier draft of this report that reflects his vast experience with developing and applying PRA over many decades and covering a wide spectrum of industries. His review includes counsel to avoid delays in addressing external hazards, to embrace the full quantification of uncertainty, and to heed the lessons from the Fukushima Daiichi accident. A summary of the Garrick Institute review is provided in Section 4.3 of this report. 


\section{Table of Contents}

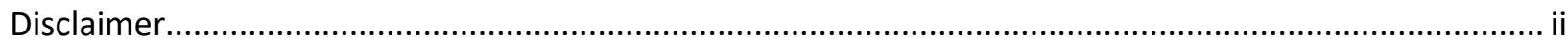

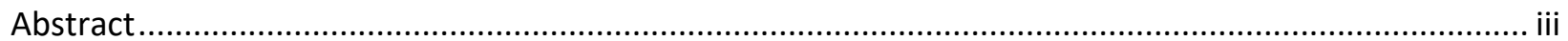

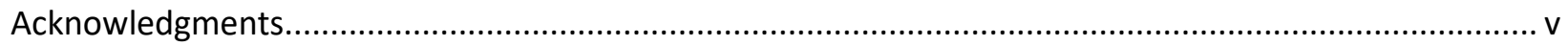

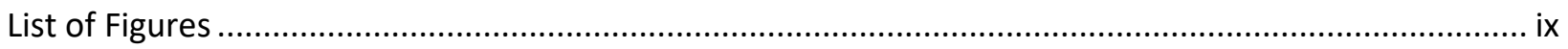

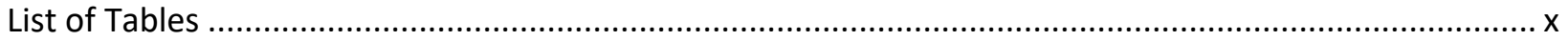

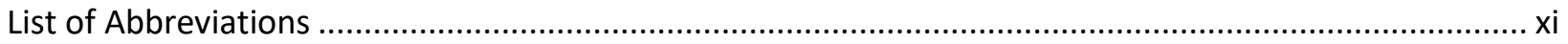

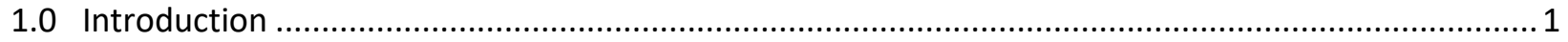

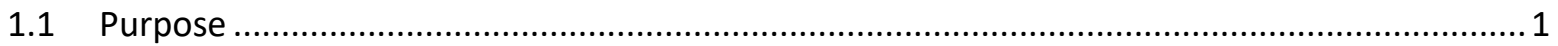

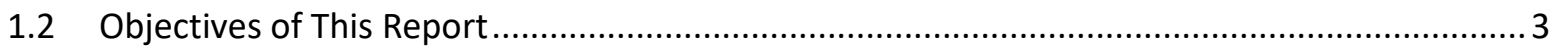

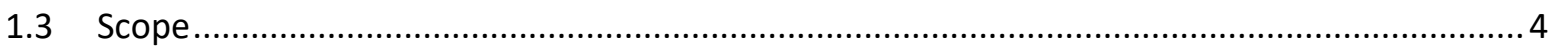

1.4 Summary of PRA Objectives within LMP Methodology ................................................... 5

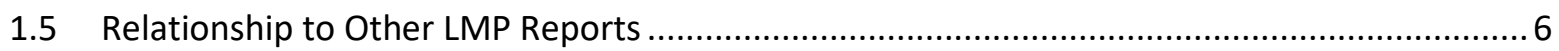

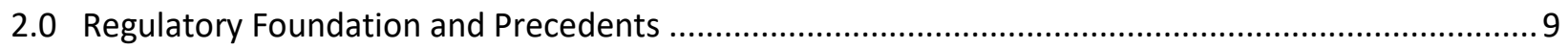

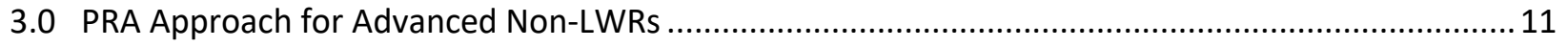

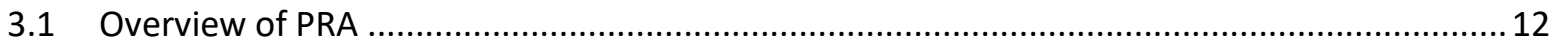

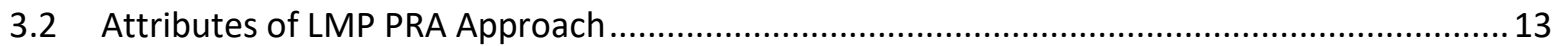

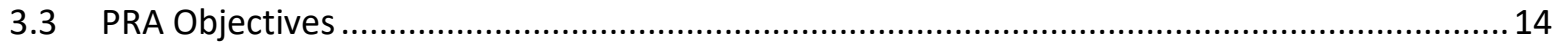

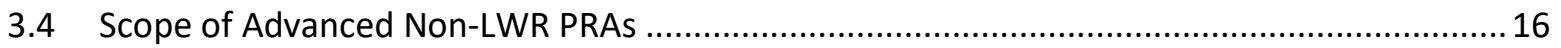

3.5 Roadmap for PRA Development as the Design Matures ...................................................... 17

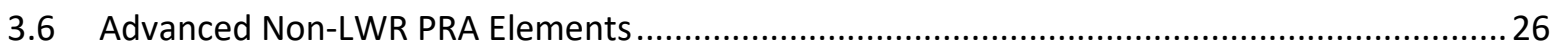

3.7 Selection of Risk Metrics for PRA Model Development...................................................... 28

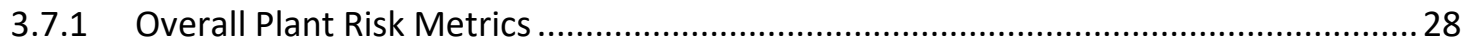

3.7.2 Risk Metrics for Selection of Licensing Basis Events .................................................... 30

3.7.3 Contributors to Risk and Risk Importance Measures ................................................ 31

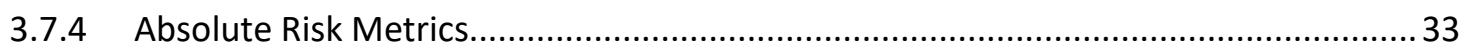

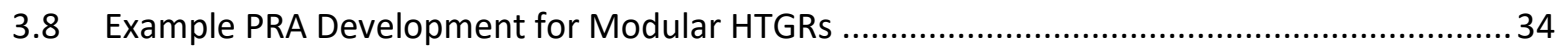

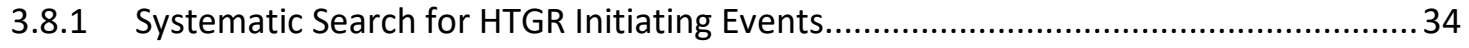

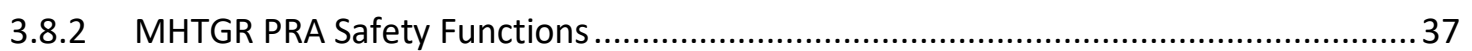

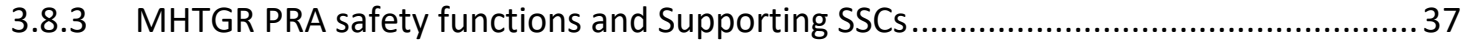

3.8.4 Development of Event Sequence Models.............................................................. 41

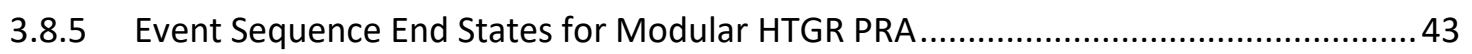

3.8.6 LBEs as Event Sequence Families ............................................................................ 44 
3.8.7 Example Modular HTGR Event Sequence Model for Slow Depressurization Event .... 45

3.8.7.1 Definition of Initiating Event.................................................................... 45

3.8.7.2 Safety Design Mitigation Strategy ............................................................. 46

3.8.7.3 Key Assumptions Regarding Plant Response and SSC Capabilities ............. 46

3.8.7.4 Event Sequence Diagram Development................................................. 47

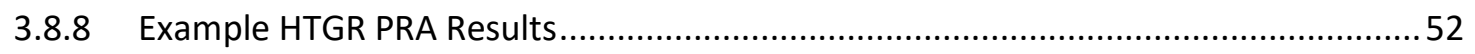

3.9 Example PRA Development for PRISM Sodium-Cooled Fast Reactor .....................................5 53

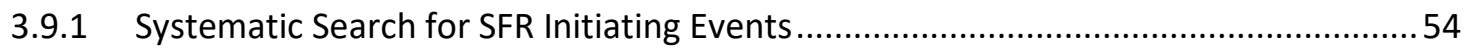

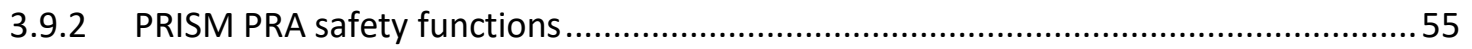

3.9.3 PRISM PRA safety functions and Supporting System Development...........................57

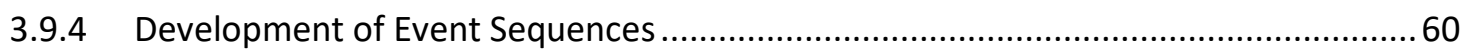

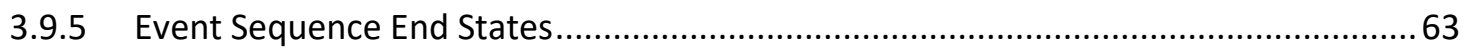

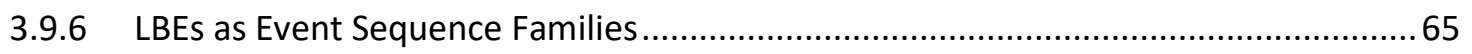

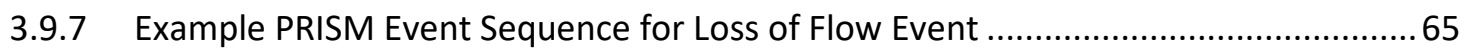

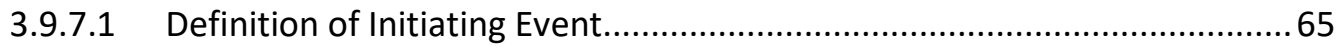

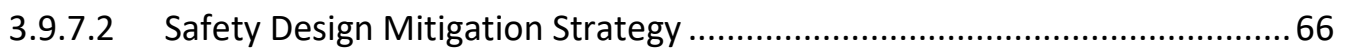

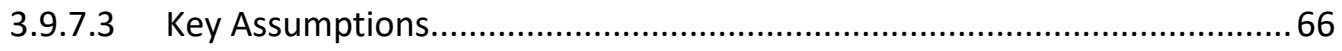

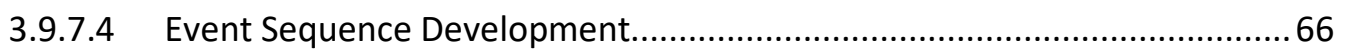

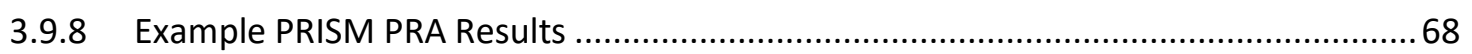

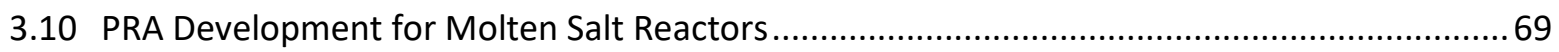

4.0 Advanced Non-LWR PRA Technical Adequacy for Risk-Informed and Performance-Based

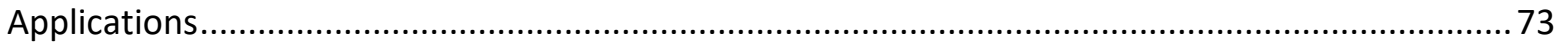

4.1 Technical Issues and Challenges for Advanced non-LWR PRA........................................... 73

4.1.1 PRA Treatment of Multi-Reactor Module Plants ........................................................ 73

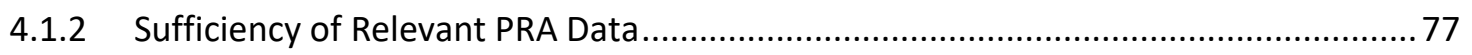

4.1.3 Identification of Initiating Events for New Reactor Designs ....................................... 80

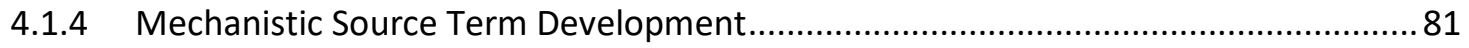

4.1.5 Treatment of Inherent and Passive Safety Features................................................ 81

4.1.6 Need to Address New Risk-Informed Applications ................................................. 82

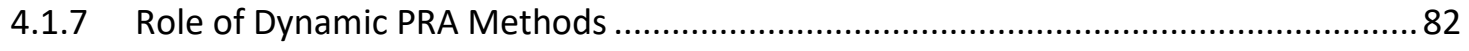

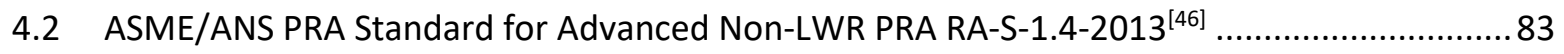

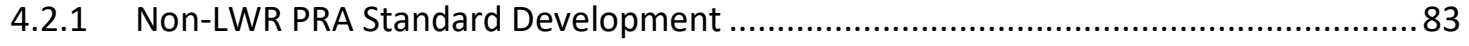

4.2.2 Role of PRA Standard in Supporting LMP Methodology .......................................... 87

4.2.3 Additional Guidance for PRA Technical Adequacy.................................................... 88

4.3 Insights from B. John Garrick Institute for the Risk Sciences............................................... 88

4.4 NRC Roles in Ensuring PRA Technical Adequacy............................................................ 90 


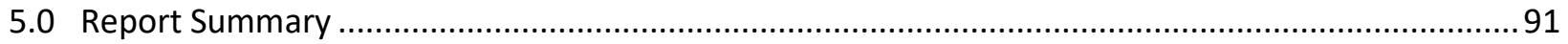

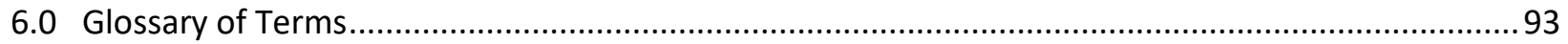

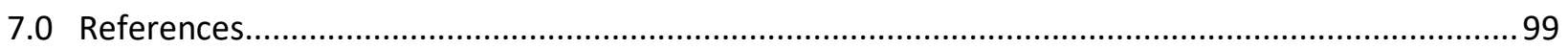

Appendix A-LMP Documentation and Frequently Asked Questions................................................A-1 


\section{List of Figures}

Figure 1-1. Elements of TI-RIPB Licensing Modernization Methodology ............................................. 2

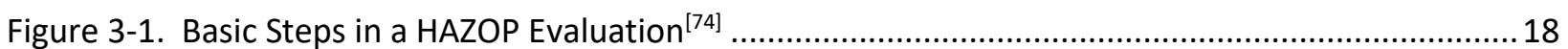

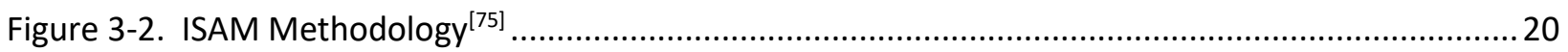

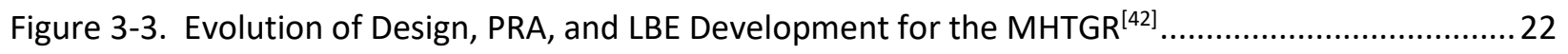

Figure 3-4. Flow Chart for Initial PRA Model Development................................................................23

Figure 3-5. Use of Process Hazards Analysis to Inform PRA Building Blocks ........................................25

Figure 3-6. Overview of Advanced non-LWR PRA Model Elements ....................................................2 27

Figure 3-7. Use of the LMP F-C Target to Define Risk-Significant LBEs.................................................. 30

Figure 3-8. Master Logic Diagram Guiding the Steps to Selection of MHTGR Initiating Events ............... 35

Figure 3-9. Event Sequence Modeling Framework for a Modular HTGR PRA .........................................42

Figure 3-10. End State Codes for HTGR Event Sequences …............................................................. 44

Figure 3-11. Event Sequence Diagram Symbols.............................................................................. 47

Figure 3-12. Event Sequence Diagram for HTGR Small (Slow) Depressurization Event (Page 1 of 2) ....... 49

Figure 3-13. Event Sequence Diagram for HTGR Small (Slow) Depressurization Event (Page 2 of 2) .......50

Figure 3-14. Event Tree for HTGR Small (Slow) Depressurization Event ................................................ 51

Figure 3-15. PBMR LBE Results Compared with NGNP Frequency-Dose Criteria ..................................53

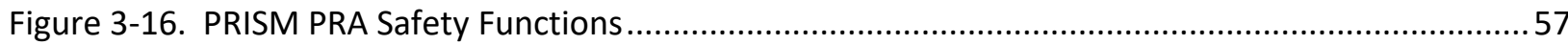

Figure 3-17. Example Event Sequence Overview Diagram .............................................................61

Figure 3-18. Simplified Event Tree for PRISM Loss of Flow Event ........................................................67

Figure 3-19. Example PRISM LBEs Compared with TLRC Frequency-Dose Evaluation Criteria .................69

Figure 3-20. Sample Event Tree for the Loss of Power Conversion Unit in an FHR From

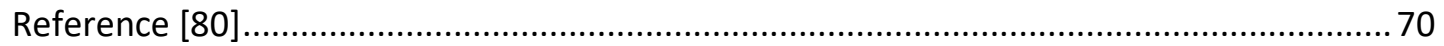

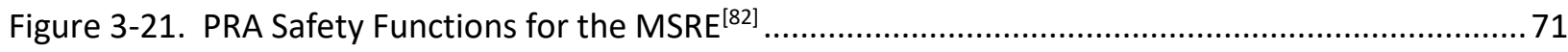

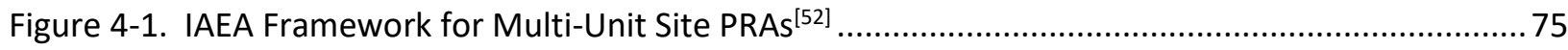

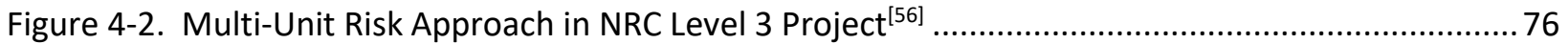

Figure 4-3. Failure Rate vs. Rupture Size for 250 mm Carbon Steel Pipe Weld on PBMR HPB ${ }^{[61]}$............. 79 


\section{List of Tables}

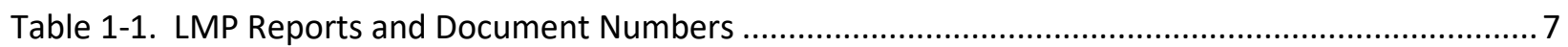

Table 2-1. Documents Reviewed for Regulatory Bases and Precedents .................................................. 9

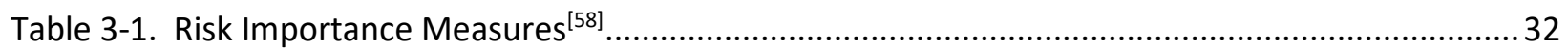

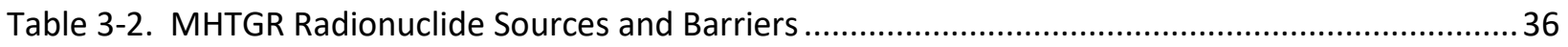

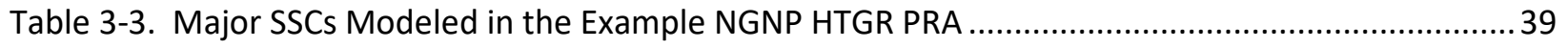

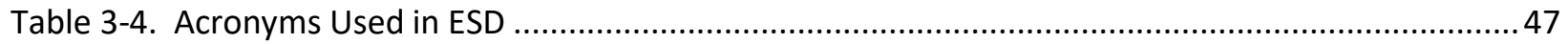

Table 3-5. LBEs for Small Depressurization Initiating Event in a Modular HTGR …................................52

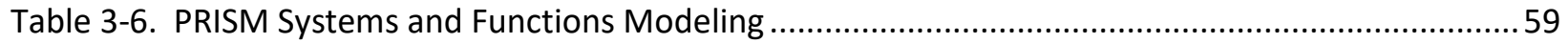

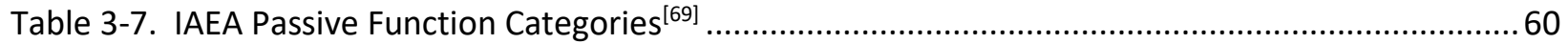

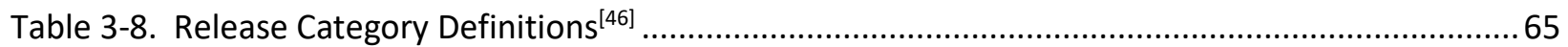

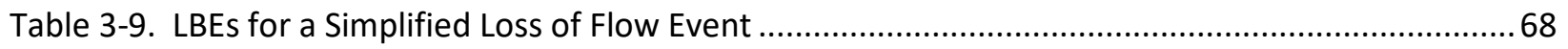

Table 3-10. Preliminary List of Initiating Events Selected for the FHR From Reference [80] ................... 70

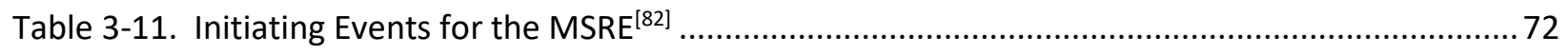

Table 4-1. References for Multi-Module PRA Development …............................................................ 74

Table 4-2. Elements of ASME/ANS Non-LWR PRA Standard and Comparison with LWR PRA

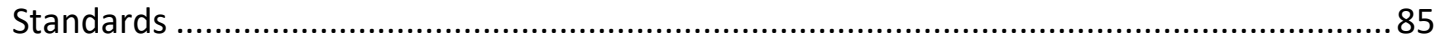




\section{List of Abbreviations}

\begin{tabular}{|c|c|}
\hline ACRS & Advisory Committee on Reactor Safeguards \\
\hline ANS & American Nuclear Society \\
\hline ANSI & American National Standards Institute \\
\hline AOO* & Anticipated Operational Occurrence \\
\hline ASME & American Society of Mechanical Engineers \\
\hline BDBE* & Beyond Design Basis Event \\
\hline BOP & balance-of-plant \\
\hline CDF & core damage frequency \\
\hline CFR & Code of Federal Regulations \\
\hline COL & Combined License \\
\hline $\mathrm{DBA}^{*}$ & Design Basis Accident \\
\hline DBE* & Design Basis Event \\
\hline DBEHL & Design Basis External Hazard Level \\
\hline DID & defense-in-depth \\
\hline DOE & Department of Energy \\
\hline ES & Event Sequence \\
\hline ESD & event sequence diagram \\
\hline $\mathrm{F}-\mathrm{C}^{*}$ & Frequency-Consequence \\
\hline F-C Target* & Frequency-Consequence Target \\
\hline FMEA & failure modes and effects analysis \\
\hline FHR & Fluoride-Salt-Cooled, High-Temperature Reactor \\
\hline FR & Federal Register \\
\hline FSF & Fundamental Safety Function \\
\hline HAZOP & Hazard and Operability Study \\
\hline HPB & helium pressure boundary \\
\hline HBFT & Heat Balance Fault Tree \\
\hline HRA & human reliability analysis \\
\hline HTGR & high temperature gas-cooled reactor \\
\hline HVAC & heating, ventilation, and air-conditioning \\
\hline IAEA & International Atomic Energy Agency \\
\hline IE & Initiating Event \\
\hline IHTS & Intermediate Heat Transport System \\
\hline $\mathrm{IHX}$ & Intermediate Heat Exchanger \\
\hline IPS & Investment Protection System \\
\hline IRF & inherent reactivity feedback \\
\hline ISAM & Integrated Safety Assessment Methodology \\
\hline JCNRM & Joint Committee on Nuclear Risk Management \\
\hline $\mathrm{LBE}^{*}$ & Licensing Basis Event \\
\hline LERF & large early release frequency \\
\hline LMP & Licensing Modernization Project \\
\hline LOCA & loss of coolant accident \\
\hline LOF & loss of primary forced flow \\
\hline LOHS & Loss of heat sink \\
\hline LWR & light water reactor \\
\hline mHTGR & modular high temperature gas-cooled reactor \\
\hline MHTGR & a specific mHTGR designed by General Atomics \\
\hline MLD & Master Logic Diagram \\
\hline MSR & molten salt reactor \\
\hline MSRE & Molten Salt Reactor Experiment \\
\hline
\end{tabular}




\begin{tabular}{|c|c|}
\hline MST & mechanistic source term \\
\hline non-LWR & non-light water reactor \\
\hline NGNP & Next Generation Nuclear Plant \\
\hline NRC & Nuclear Regulatory Commission \\
\hline NSRST & Non-Safety-Related with Special Treatment \\
\hline NSSS & Nuclear Steam Supply System \\
\hline NST & Non-Safety-Related with no Special Treatment \\
\hline PB & performance-based \\
\hline PBMR & Pebble Bed Modular Reactor \\
\hline PHA & process hazard analysis \\
\hline PIRT & Phenomena Identification and Ranking Table \\
\hline POS & plant operating state \\
\hline PRA & probabilistic risk assessment \\
\hline PRISM & Power Reactor Innovative Small Module \\
\hline PSA & Probabilistic Safety Assessment \\
\hline PSF & PRA Safety Function \\
\hline $\mathrm{QHO}$ & Quantitative Health Objective \\
\hline $\mathrm{RB}$ & reactor building \\
\hline RCCS & Reactor Cavity Cooling System \\
\hline RI & risk-informed \\
\hline RIPB* & risk-informed and performance-based \\
\hline RIPB-DM* & risk-informed and performance-based decision-making \\
\hline RPS & Reactor Protection System \\
\hline RFDC & Required Functional Design Criteria \\
\hline RSF & Required Safety Function \\
\hline RVACS & Reactor Vessel Auxiliary Cooling System \\
\hline SAP & Safety Assessment Principle \\
\hline SCS & Shutdown Cooling System \\
\hline SFR & sodium-cooled fast reactor \\
\hline SR & Safety-Related \\
\hline SRDC & Safety-Related Design Criteria \\
\hline SRM & Staff Requirements Memorandum \\
\hline SSC & structures, systems, and components \\
\hline SU/SD & Startup/Shutdown \\
\hline TEDE & Total Effective Dose Equivalent \\
\hline $\mathrm{TI}$ & technology-inclusive \\
\hline TI-RIPB & technology-inclusive, risk-informed, and performance-based \\
\hline TLRC & Top Level Regulatory Criteria \\
\hline ULOF & unprotected loss of primary forced flow \\
\hline ULOHS & unprotected loss of heat sink \\
\hline UTOP & unprotected transient overpower \\
\hline U.S. & United States \\
\hline USS & Ultimate Shutdown System \\
\hline
\end{tabular}

*These terms have special meanings defined in this document and in the glossary. 


\subsection{INTRODUCTION}

\subsection{Purpose}

Many of the current regulatory requirements for U.S. nuclear power plants are based on light water reactor (LWR) technology used for generation of electricity, necessitating changes to the LWR framework ${ }^{*}$ to facilitate efficient, effective, and predictable licensing expectations for a spectrum of novel, advanced, non-light water reactors (non-LWRs). The Licensing Modernization Project (LMP), led by Southern Company and cost-shared by the U.S. Department of Energy (DOE) and other industry participants, has proposed changes to specific elements of the current licensing framework ${ }^{\dagger}$ and a methodology for implementation of the changes. The LMP objective is to assist the Nuclear Regulatory Commission (NRC) in developing regulatory guidance for licensing advanced non-LWR plants.

These proposals are described in a series of reports (including this report), which will collectively lead to modernization and adaptation of the current licensing framework through issuance of NRC regulatory guidance that supports licensing of advanced non-LWRs. These proposals are intended to lead to a high degree of nuclear safety, establish stable performancebased acceptance criteria, and enable near-term implementation of non-LWR design development, in support of national and industrial strategic objectives.

These proposals are technology-inclusive, risk-informed, and performance-based (TI-RIPB). The modernized framework is technology-inclusive (TI) to accommodate the variety of technologies expected to be developed (implementation will inherently be technology-specific). It is risk-informed because it employs an appropriate blend of deterministic and probabilistic inputs to each decision. Rather than being expressed in the form of a list of new requirements, it is presented as a methodology for developing a design and preparing a license application for advanced non-LWRs as a means of meeting applicable regulatory requirements. This LMP methodology is performance-based because it uses quantitative risk metrics to evaluate the risk significance of events and leads to formulation of performance requirements on the capability and reliability of structures, systems, and components (SSCs) to prevent and mitigate accidents. By utilizing a risk-informed, performance-based approach for the Licensing Basis Event (LBE) selection process, the design and licensing efforts are more closely aligned with the safety outcome objectives. The goal is efficient and effective development, licensing, and deployment of non-LWRs on aggressive timelines with even greater margins of safety than prior generations

\footnotetext{
* "Framework" as used in the LMP products, refers to the interrelated elements that form the basis for the NRC's oversight of the use of radioactive materials, including the Atomic Energy Act and enabling legislation; licenses, orders, and regulations in Title 10 of the Code of Federal Regulations; regulatory guides, review plans, and other documents that clarify and guide the application of NRC requirements and amplify agency regulations; and licensing and inspection procedures and enforcement guidance. The focus of the LMP effort is primarily on amended regulatory guidance and implementation proposals (i.e., nearterm changes in actual regulation are not anticipated as part of LMP initiatives).

†The regulatory framework was defined in SECY-2000-0191, "High-Level Guidelines for Performance-Based Activities" to include the regulation and its supporting regulatory guides, standard review plans, technical specifications, NUREGs, and inspection guidance. It is in this context that the term is generally used in this report.
} 
of technology. These goals fully support and reflect DOE and NRC visions for licensing and deploying advanced non-LWR plants.

The LMP methodology consists of elements including establishment of TI-RIPB LBE selection, classification of SSCs, and establishment of predictable means to determine and evaluate adequate defense-in-depth (DID). These process tasks are facilitated and informed by reports describing approaches and methods for: risk-informed decision making; the conduct and application of probabilistic risk assessments (PRAs) as part of the early and continuing lifecycle of new designs; and establishment of performance-based licensing criteria in lieu of LWRcentric prescriptive requirements. These elements are supported by reviews of past regulatory precedents and policies to make maximum use of existing approaches and NRC decisions, as well as assessments of current state of the art analytical tools. Gap analyses are used to identify where new or revised requirements are needed for a TI-RIPB framework and propose changes in language or approach to allow the framework changes to be used effectively.

The relationship between the main topics described above is represented in Figure 1-1. This figure is intended to provide a generalized context for the major activities and how they fit into the overall framework.

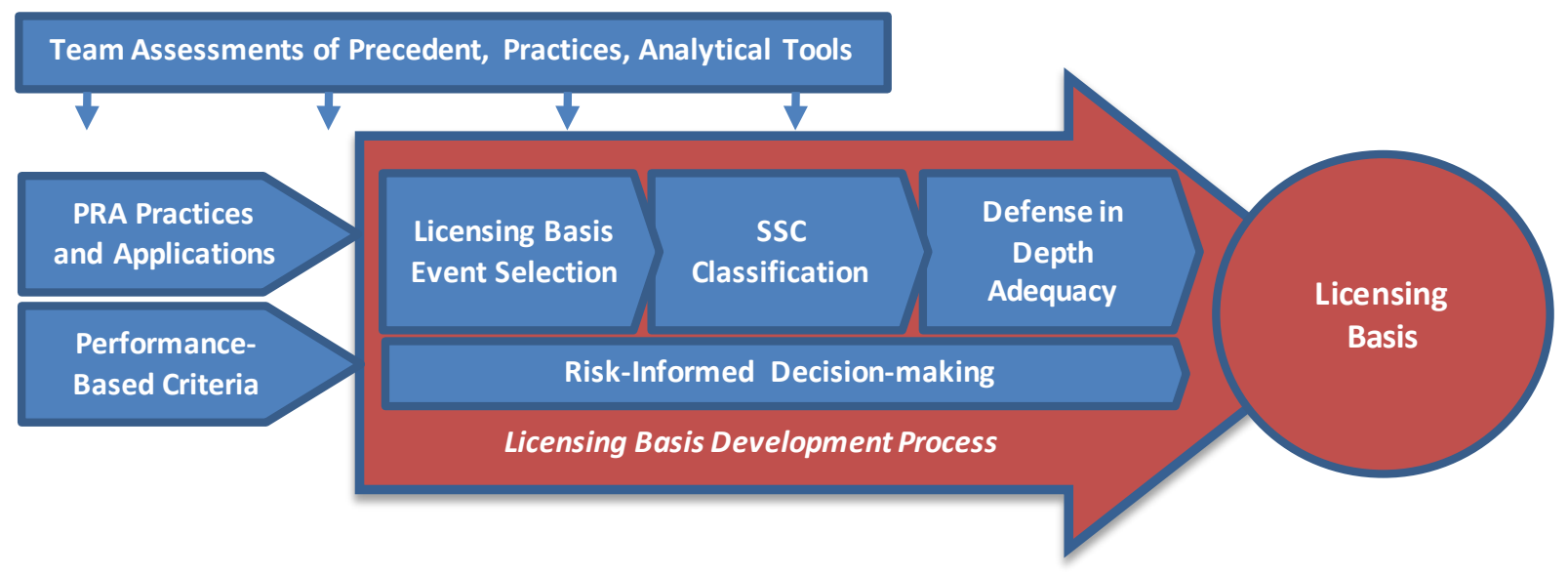

Figure 1-1. Elements of TI-RIPB Licensing Modernization Methodology

This report reviews the relevant regulatory precedents for guidance in the development of a PRA to support a TI-RIPB design and licensing process. Inputs from the PRA are used in:

1. Supporting and evaluating the development of the design

2. Identifying the spectrum of LBEs to be considered

3. Evaluating the risk significance of LBEs against Frequency-Consequence (F-C) Targets derived from Top Level Regulatory Criteria (TLRC)

4. Performing an integrated risk assessment of advanced non-LWR plants that may be comprised of two or more reactor modules and associated non-core sources of radioactive material 
5. Safety classification of SSCs

6. Development of performance targets for the reliability and capability of SSCs in the prevention and mitigation of accidents

7. Determining integrated plant performance margins compared to TLRC performance-based objectives

8. Exposing and evaluating sources of uncertainty in the identification of LBEs and in the estimation of their frequencies and consequences, and providing key input to the evaluation of the adequacy of DID

9. Providing risk and performance-based insights into the evaluation of the design DID adequacy

10. Supporting other risk-informed and performance-based (RIPB) decisions

It is noted that PRA is not developed in a single step, but rather in an iterative process that proceeds with the successive stages in the development of the design. Each of the decisions associated with the above applications is reviewed as the PRA is updated and upgraded and revised as needed to incorporate changes to the state of knowledge about risks.

The focus of this report is the development process for the PRA that addresses the first five of the above applications associated with design support, identifying and evaluating LBEs, and safety classification of SSCs. Each of the above applications is an example of RIPB decision making under the LMP methodology.

A draft of this report was submitted for NRC review in 2017, and the NRC staff comments from this review are documented in Reference [1]. A guidance document for implementing the LMP methodology has been published in NEI 18-04, ${ }^{[2]}$ which includes a discussion on the role of the PRA in implementing the methodology that addresses the NRC comments on the draft PRA white paper. This version of the PRA report reflects the clarifications on the role of the PRA identified in NEI 18-04. Applications of the PRA to support selection and evaluation of Licensing Basis Events (LBEs), safety classification and performance requirements of structures, systems, and components (SSCs), and evaluation of DID adequacy within the LMP methodology are discussed in References [3], [4], and [5], respectively.

This report builds on the development of the PRA white paper for DOE's Next Generation Nuclear Plant (NGNP) ${ }^{[6]}$ and is intended for use with a spectrum of advanced non-LWRs including modular high temperature gas-cooled reactors (mHTGRs), molten salt reactors, sodium-cooled fast reactors, and other advanced non-LWR concepts.

\subsection{Objectives of This Report}

This report describes a technology-inclusive approach for the development and use of a PRA to support RIPB decisions associated with design and licensing of advanced non-LWR plants. The objectives of this PRA report are to: 
- Identify supporting regulatory guidance, precedents, and available references providing the bases of the proposed PRA approach.

- Identify the similarities and differences between the LMP approach to PRA development and use and the approach that has been followed for LWRs.

- Identify the key technical issues that will need to be resolved in the advanced non-LWR PRAs for the successful application of the LMP methodology.

- Describe the approach for using available guides, standards, and peer review processes to assure the technical adequacy of the PRA during design development and licensing.

- Define the approach to developing the PRA so that it can be used to provide input to the selection of LBEs, information to select the safety classification of SSCs and associated safety-related design criteria, the formulation of special treatment requirements, and to perform a risk-informed evaluation of defense-in-depth.

- Describe the approach to the PRA treatment of the integrated risk from operation of a multi-reactor module plant.*

\subsection{Scope}

The PRA approach described in this report applies to a spectrum of advanced non-LWR designs including mHTGRs, molten salt reactors, and liquid metal-cooled fast reactors and is intended to be reactor technology-inclusive. This report discusses the use of the PRA in the selection and classification of LBEs using criteria that focus on acceptable risks to the public health and safety. Risks to the worker will be discussed at a later date, as will security-related events. Worker and security-related risks are not included in the scope of the PRA. Such risks may be addressed using deterministic criteria consistent with operating advanced LWRs under the proposed LMP methodology.

Section 2 of this report provides an overview of the regulations and guidance considered during development of the proposed PRA approach. The TI-RIPB approach to PRA is described in Section 3 and builds upon an approach that was developed for DOE's NGNP. ${ }^{[6]}$ This is accomplished by incorporating insights from NRC and Advisory Committee on Reactor Safeguards (ACRS) reviews of the NGNP approach and by considering PRA applications in using a TI process. This review also considers events and developments in the intervening period following the NGNP work, such as new insights from the Fukushima accident, and more recent developments in the incorporation of RIPB elements into the regulatory framework.

Section 3 includes a TI approach to performing a PRA with specific examples of PRA models that have been developed for the MHTGR (a specific mHTGR designed by General Atomics), ${ }^{[8]}$ the Power Reactor Innovative Small Module (PRISM) liquid-metal reactor, ${ }^{[9]}$ the Fluoride-Salt-

\footnotetext{
* The term "plant," as it is used in this document means a nuclear plant that may or may not employ a modular design. A "modular design" indicates a nuclear power station that consists of two or more essentially identical nuclear reactors (modules), and each module is a separate nuclear reactor capable of being operated independent of the state of completion or operating condition of any other module co-located on the same site, even though the nuclear power station may have some shared or common systems. ${ }^{[6]}$
} 
Cooled, High-Temperature Reactor (FHR) ${ }^{[80]}$ and the Molten Salt Reactor Experiment (MSRE) ${ }^{\left[{ }^{[2]}\right.}$ In Section 4, key challenges and technical issues to performing the non-LWR PRA are discussed. The approach to achieving technical adequacy in light of these issues is presented. Section 5 summarizes the top priority licensing topics to be discussed with the NRC staff and examines how the proposed approach to PRA meets the existing regulatory foundation for RIPB decision-making.

The PRA development process described in this report is intended for use on advanced nonLWR designs, and it is intended to be applied at different stages along the entire reactor designoperation life cycle. It is intended that the PRA be introduced at an early stage of design and noted that the scope and level of detail of the PRA will be consistent with the level of detail of the evolving design and site characteristics.

\subsection{Summary of PRA Objectives within LMP Methodology}

The LMP objective is to assist the NRC to develop regulatory guidance for licensing advanced non-LWR plants. The objective of this report is to document how the LMP approach to PRA development supports the LMP objectives. More specifically, this report is intended to demonstrate that:

- The scope and technical approach for advanced non-LWR PRAs outlined in this report are appropriate for the intended applications of the PRA in the design, construction, and operating license application for advanced non-LWR plants including mHTGRs, molten salt reactors, sodium reactors, and other advanced non-LWR concepts. These PRA applications include input to:

- Evaluation of design alternatives and incorporation of risk insights into the design

- Selection of LBEs* including the Design Basis Accidents (DBAs)

- SSC safety classification and special treatment requirements

- Selection of performance-based targets for the reliability and capability of SSCs within the scope of the PRA

○ RIPB evaluation of DID adequacy

- The road-map presented in this report for introducing the PRA at an early stage in the design and progressively increasing the scope and level of detail of the PRA models and documentation consistent with the scope and level of detail of the supporting design and siting characterization is appropriate. The iterative nature of the PRA development and design maturation process creates a need to review and revise the supported RIPB decisions in order to incorporate new risk insights.

\footnotetext{
${ }^{*}$ As explained more fully in the LBE report, LBEs include all the events considered as part of the design and licensing basis including Anticipated Operational Occurrences (AOOs), Design Basis Events (DBEs), Beyond Design Basis Events (BDBEs) and Design Basis Accidents. AOOs, DBEs, and BDBEs are derived from the PRA results and DBAs are deterministically derived to conservatively bound the events within the design basis.
} 
- The TI approaches to initiating event (IE) selection, event sequence development, end-state definition, definition of risk metrics, definition of risk importance measures, and risksignificance determination included in this report are technically adequate for the intended PRA applications.

- The TI approaches to the treatment of inherent characteristics and passive SSCs outlined in this report are appropriate.

- The TI approach to using deterministic engineering analyses * for assessing the plant response to IEs and event sequences, success criteria, and mechanistic source terms (MSTs) is appropriate for the proposed risk-informed advanced non-LWR design and licensing approach.

- The TI approach to the development of PRA data outlined in this report, including the use of applicable data from non-nuclear sources, LWRs, expert opinion, and treatment of uncertainty, is a technically adequate approach for the advanced non-LWR PRA.

- The TI process for treatment of uncertainties in the estimation of accident frequencies and the quantification of MSTs and consequences in the development of the PRA is a technically adequate approach for the purpose of developing and analyzing the results of the PRA and to support the evaluation of defense-in-depth adequacy.

- The TI approach for the treatment of multi-unit or multi-module plants including the delineation of accidents involving single and multiple reactor modules and radiological sources in PRA development is technically adequate to support licensing of single and multi-module plant configurations. It is recognized that case studies in the application of PRA to non-core source of radioactive material are lacking.

- For non-LWRs, the guidance in the ASME/ANS RA-S-1.4 provides an acceptable means to establish the scope and technical adequacy of the PRA. The scope and level of detail of the PRA models align with the state of definition of the design, the safety design approach, and systems design concepts. As the design matures and more design information becomes available for different types of risk evaluations, the scope of the PRA can be broadened to address other plant conditions and progressively confirm the plant capability to meet safety objectives.

\subsection{Relationship to Other LMP Reports}

The LMP approach to PRA has significant interrelationships to other topics within the scope of the LMP methodology as described below.

The LMP team prepared independent reports on each of the four major LMP elements. Additionally, the LMP team produced a narrative report describing the processes, events, and documents involved in producing the ultimate project deliverable product, NEI 18-04 "RiskInformed Performance-Based Technology Inclusive Guidance for Non-Light Water Reactor

\footnotetext{
${ }^{*}$ Deterministic engineering analyses referred to here include reactor physics, thermo-fluid analyses, structural analyses, etc. that are necessary to predict the plant response to events, success criteria development, analysis of physical processes and phenomena to resolve the event sequence end states and develop mechanistic source terms.
} 
Licensing Basis Development." Finally, the LMP team produced a report based on the experiences of early adopters of the LMP RIPB process which includes best practices, lessons learned, and frequently asked questions and responses. See Table 1-1 for the Southern Company document numbers of each of these reports.

Table 1-1. LMP Reports and Document Numbers

\begin{tabular}{|c|c|c|}
\hline Report Title & $\begin{array}{l}\text { Southern Company } \\
\text { Document Number }\end{array}$ & $\begin{array}{l}\text { DOE OSTI } \\
\text { Document Number }\end{array}$ \\
\hline Selection and Evaluation of Licensing Basis Events & SC-29980-100 Rev 1 & TBD \\
\hline Probabilistic Risk Assessment Approach & SC-29980-101 Rev 1 & TBD \\
\hline $\begin{array}{l}\text { Safety Classification and Performance Criteria for } \\
\text { Structures, Systems, and Components }\end{array}$ & SC-29980-102 Rev 1 & TBD \\
\hline $\begin{array}{l}\text { Risk-Informed and Performance-Based Evaluation of } \\
\text { Defense-in-Depth Adequacy }\end{array}$ & SC-29980-103 Rev 1 & TBD \\
\hline Final Project Report & SC-29980-105 Rev. 1 & TBD \\
\hline $\begin{array}{l}\text { LMP Lessons Learned, Best Practices, and Frequently } \\
\text { Asked Questions }\end{array}$ & SC-29980-106 Rev 0 & TBD \\
\hline
\end{tabular}

\section{Licensing Basis Event Selection Approach}

Key inputs to the selection of LBEs are derived from a PRA evaluation of the advanced nonLWR plant. These inputs together with deterministic inputs are used as part of a TI-RIPB approach for the selection and evaluation of LBEs. ${ }^{[3]}$

\section{SSC Safety Classification and Performance Requirements Approach}

Information developed from and used in the development of the PRA to define event sequences and evaluate their frequencies and consequences is an input to the SSC safety classification and development of SSC performance targets. Information from the PRA is used to establish the necessary and sufficient conditions of SSC capability and reliability in order for LBE frequencies, consequences, and uncertainties to stay within the frequency-consequence evaluation criteria derived from the TLRC and to implement risk management strategies to control the total integrated risk of the plant. Reliability targets for SSCs are determined based on the need to maintain each LBE within its LBE category (Anticipated Operational Occurrence, Design Basis Event, or Beyond Design Basis Event). RIPB SSC capability targets are defined in part by the selected design margins between the LBE frequencies and dose limits for that LBE category. Special treatment requirements for SSCs are derived to achieve the necessary and sufficient degree of reliability and capability of the SSCs. This is discussed in a companion report on the LMP SSC safety classification approach. ${ }^{[4]}$ 


\section{Defense-in-Depth Adequacy}

The PRA models and supporting assumptions are based in part on the plant capabilities for DID reflected in the design, as well as assumptions about the limits placed on design and operation of the plant by assumed programmatic DID measures. Information developed in the PRA is used to help evaluate the SSCs responsible for preventing and mitigating accidents. The PRA also plays an important role in the identification of key sources of uncertainty, and this supports a feedback loop to identify possible enhancements to plant capability and programmatic aspects of DID. Hence, the PRA provides important input to the risk-informed evaluation of DID, complements the NRC's deterministic approach and traditional DID philosophy, and provides a more objective, RIPB means to systematically demonstrate DID adequacy and preservation. This is discussed in a companion report on the LMP approach to evaluating DID adequacy. ${ }^{[5]}$

\section{LMP Final Report}

The LMP team produced a narrative report describing the processes, events, and documents involved in producing the ultimate project deliverable product, NEI 18-04 "Risk-Informed Performance-Based Technology Inclusive Guidance for Non-Light Water Reactor Licensing Basis Development." This report contains a wealth of references to documents that future users of the LMP RIPB process may find useful. Tables within the report provide references to the NRC Agencywide Document Management System (ADAMS) Accession Numbers of many industry and NRC documents that future permit and license applicants may wish to reference in their own applications.

\section{LMP Lessons Learned, Best Practices, and Frequently Asked Questions and Responses}

The LMP team produced a report based on the experiences of early adopters of the LMP RIPB process which includes best practices, lessons learned, and frequently asked questions with responses. This report provides guidance to reactor designers on how to efficiently implement the LMP RIPB processes within their own organization and answers to thirty-two frequently asked questions from reactor designers. 


\subsection{REGULATORY FOUNDATION AND PRECEDENTS}

There is a substantial set of prior activities, policies, practices and precedents stretching more than 30 years back in time that support RIPB processes and uses. NRC and international regulations, policies, guidance, and other precedents that are relevant to the use of PRA to support RIPB decisions were reviewed. NRC and ACRS feedback on previous efforts to define a RIPB design and licensing approach for NGNP are also reviewed for guidance. Insights from use of PRA to support the design and licensing of advanced LWRs as well as NRC pre-licensing reviews of advanced non-LWRs are included.

This regulatory precedent review builds on the regulatory review in the NGNP uses of PRA ${ }^{[6]}$ by incorporating more recent developments and precedents and by considering the need to have a reactor technology-inclusive approach for performing a PRA rather than one focused on the specific high temperature gas-cooled reactor (HTGR) technology.

A summary of the documents reviewed for regulatory guidance and insights from relevant precedents is provided in Table 2-1. The regulatory documents include the U.S. Code of Federal Regulations (CFR), NRC policies and policy statements, NRC Staff Requirements Memoranda, regulatory guides, the Standard Review Plan (NUREG-0800), and relevant Advisory Committee on Reactor Safeguards letters. The relevant regulatory precedents include the initiatives to develop RIPB licensing approaches for the MHTGR, PRISM, Pebble Bed Modular Reactor (PBMR), and NGNP projects, as well as the NRC staff and ACRS reviews and feedback on those initiatives. International perspectives were incorporated into the review based on relevant documents from the International Atomic Energy Agency (IAEA) and the regulatory authority in the United Kingdom.

Table 2-1. Documents Reviewed for Regulatory Bases and Precedents

\begin{tabular}{|c|c|c|}
\hline Category & Document & Applicable Content \\
\hline \multirow{3}{*}{$\begin{array}{l}\text { NRC } \\
\text { Regulations }\end{array}$} & 10 CFR 50.71(h) & PRA requirements for Combined License (COL) applications \\
\hline & 10 CFR 52 & PRA requirements for Design Certification Application \\
\hline & 10 CFR 52.1 & License terms definitions \\
\hline \multirow{4}{*}{ NRC Policies } & 73 Federal Register (FR) 60612 & Policy on regulation of advanced reactors \\
\hline & $60 \mathrm{FR} 42622$ & Policy on use of PRA \\
\hline & 51 FR 28044 & Safety goal policy \\
\hline & 50 FR 32138 & Severe accident policy \\
\hline \multirow{6}{*}{$\begin{array}{l}\text { NRC Policy } \\
\text { Statements }\end{array}$} & SECY/SRM 2003-0047 & Policy issues related to non-LWR licensing \\
\hline & SECY 2005-0006 & Regulatory structure and policy issues for new plant licensing \\
\hline & SECY/SRM 2006-0007 & $\begin{array}{l}\text { Advanced notice of Proposed Rulemaking for TI-RIPB process } \\
\text { for advanced reactors }\end{array}$ \\
\hline & SECY/SRM 2007-0101 & Decision to defer rulemaking until new applicant \\
\hline & SECY/SRM 2011-0089 & NRC Level 3 PRA project status \\
\hline & SECY/SRM 2015-0168 & $\begin{array}{l}\text { Disposition of NUREG-2150 Risk Management Task Force } \\
\text { recommendations }\end{array}$ \\
\hline
\end{tabular}




\begin{tabular}{|c|c|c|}
\hline \multirow{7}{*}{ NRC Guidance } & Reg. Guide 1.206 & COL requirements for Chapter 19 and PRA \\
\hline & NUREG-0800, Chapter 19 & PRA evaluation review guidance \\
\hline & Reg. Guide 1.174 & Use of PRA in risk-informed decisions approach \\
\hline & Reg. Guide 1.200 & Technical adequacy of PRA \\
\hline & NUREG-1860 & RIPB regulatory structure feasibility study \\
\hline & NUREG-2150 & Proposed risk management regulatory framework \\
\hline & Near Term Task Force Report & Review of Fukushima Daiichi accident \\
\hline ACRS & ACRS letter April 22,2004 & $\begin{array}{l}\text { ACRS views on risk metrics for non-LWRs and interpretation } \\
\text { of safety goal Quantitative Health Objectives }\end{array}$ \\
\hline \multirow{7}{*}{ NGNP } & INL/EXT-09-17139 & Defense-in-Depth White Paper \\
\hline & INL/EXT-10-19521 & Licensing Basis Event White Paper \\
\hline & INL/EXT-11-21270 & PRA White Paper \\
\hline & INL/EXT-13-28205 & NRC licensing status summary \\
\hline & ACRS Letter May 15, 2013 & ACRS views on NGNP proposed licensing approach \\
\hline & NRC Letter June 20, 2013 & NRC staff response to May 15, 2013 ACRS letter \\
\hline & NRC Letter July 17, 2014 & $\begin{array}{l}\text { NRC report to DOE on NRC staff assessment of NGNP white } \\
\text { papers }\end{array}$ \\
\hline \multirow{4}{*}{ PBMR } & Exelon Letter March 15, 2002 & PBMR RIPB licensing approach \\
\hline & NRC Letter Sept. 24, 2007 & RAls regarding PBMR white papers \\
\hline & PBMR Letter March 21, 2008 & Response to RAls from Sept. 24, 2007 \\
\hline & NRC Letter March 26, 2002 & NRC preliminary findings on licensing approach \\
\hline \multirow{4}{*}{ MHTGR } & DOE-HTGR-86-024 & Preliminary safety information for MHTGR \\
\hline & DOE-HTGR-86-011 & PRA for MHTGR \\
\hline & DOE-HTGR-86-034 & Licensing basis events for MHTGR \\
\hline & NUREG-1338 & Draft Pre-application safety evaluation for MHTGR \\
\hline \multirow{2}{*}{ PRISM } & NUREG-1368 & Pre-application safety evaluation for PRISM \\
\hline & GE-Hitachi 2017 report & Development and modernization of PRISM PRA \\
\hline \multirow{4}{*}{$\begin{array}{l}\text { Industry } \\
\text { Consensus } \\
\text { Standards }\end{array}$} & ASME/ANS RA-Sb-2013 & PRA standard for operating LWR plants \\
\hline & ASME/ANS RA S-1.4-2013 & Trial use PRA standard for advanced non-LWR plants \\
\hline & ANS/ANSI-53.1-2011 & $\begin{array}{l}\text { Nuclear safety design process for modular helium cooled } \\
\text { reactors }\end{array}$ \\
\hline & AlChE & Guidelines for Hazards Evaluation Procedures, $3^{\text {rd }}$ Edition \\
\hline \multirow{6}{*}{$\begin{array}{l}\text { International } \\
\text { Guidance }\end{array}$} & IAEA TECDOC-626 & Safety-related terms for advanced reactors \\
\hline & IAEA TECDOC-1804 & Nuclear safety design requirements \\
\hline & IAEA SRS-04 & Multi-unit PRA technical approach \\
\hline & $\begin{array}{l}\text { United Kingdom Safety Assessment } \\
\text { Principals (SAPs) }\end{array}$ & United Kingdom SAPs \\
\hline & $\begin{array}{l}\text { Canadian Nuclear Safety } \\
\text { Commission Multi-reactor unit PRA } \\
\text { Workshop }\end{array}$ & Technical issues in multi-unit PRA \\
\hline & GIF/RWSG/ISAM Report & $\begin{array}{l}\text { Integrated Safety Assessment Methodology for Generation IV } \\
\text { Nuclear Systems }\end{array}$ \\
\hline
\end{tabular}




\subsection{PRA APPROACH FOR ADVANCED NON-LWRS}

It is well known in the field of PRA that the risks associated with reactor accidents, as assessed in a PRA, are highly design, plant, and site specific. This is true for any type of reactor, but the range of variabilities in assessed risks is much larger when advanced non-LWR reactor concepts are concerned. The use of different materials for the reactor fuel, moderator, and coolant, and the different safety design approaches for the deployment of radionuclide barriers create fundamental differences in the physical processes and plant responses associated with reactor transients and accidents when compared with an LWR. These differences are reflected in the definition of event sequences, end states, and risk metrics that provide the framework for the advanced non-LWR PRA model within the LMP methodology.

Despite these differences among the reactor technologies, the PRA approach that has been successfully applied in the U.S. for risk-informed applications of LWR plants and for meeting PRA requirements for licensing advanced LWRs is fundamentally the same approach that is used for advanced non-LWR technologies. Although the predominant use of PRA in U.S. regulatory activities has been with operating and evolutionary LWR designs, there is a long history of PRA development for non-LWR concepts such as HTGRs and sodium-cooled fast reactors (SFRs). Some preliminary steps toward completing PRAs for the FHR and the MSRE have also been completed.

Another distinction to make between LWR and advanced non-LWR PRAs is that the former have been introduced after the plants were designed and licensed, limiting the risk-informed applications to incremental changes to plants that were already built and operated. By contrast, advanced non-LWRs have been primarily used as tool to support the design and to formulate the safety design approaches. Early introduction of the PRA greatly expands the range of riskinformed decisions to include the design itself.

The fact that risk is plant, site, and design specific is a primary justification for using information from a plant, site, and design specific PRA to inform decisions that may impact the level of safety of operating a nuclear power plant. This conclusion is amplified when considering advanced non-LWR technologies. Use of generic models and approaches to inform safety decisions, especially those formulated for LWRs, fail to capture the design and technology specific safety issues associated with the advanced non-LWRs. Hence, before the safety and licensing decisions can be effectively made for advanced non-LWRs, it is imperative that design and technology specific safety and risk insights are developed by performing a plant, site, and design specific PRA.

The purpose of this section is to describe the approach to PRA development that has been developed for advanced non-LWRs within the LMP methodology. This includes the approach to establish the fit-for-purpose technical adequacy of the PRA for RIPB decisions within the LMP methodology. The PRA approach is described in terms of a technology-inclusive approach for building a non-LWR PRA model, a roadmap for expanding the scope and level of detail of the PRA as the design matures, and use of consensus standards for advanced non-LWRs. To demonstrate the capabilities of the approach, example PRA models are described for four advanced non-LWRs: one for a modular HTGR, the General Atomics MHTGR, ${ }^{[8]}$ a second for a 
modular pool-type SFR, the PRISM liquid-metal reactor developed by GE-Hitachi, ${ }^{[9]}$ a third for the FHR, ${ }^{[80]}$ and the fourth for the MSRE. ${ }^{[82]}$ These examples were selected to cover a spectrum of advanced non-LWR concepts that exhibit significant differences among them and are all fundamentally different from an LWR.

The focus of this section is to describe the TI approach to performing a PRA within the LMP methodology with a view towards the early applications of the PRA, namely incorporating risk insights into the design, providing input to the selection of LBEs early in the design, and for supporting design decisions on the safety classification of SSCs. Additional reports developed in the LMP will provide additional information on the applications of the PRA for other RIPB decisions including formulation of SSC performance requirements and risk-informed evaluation of DID.

Following their early introduction in a simplified fit-for-purpose form, the PRAs will be expanded and refined as the design, operation, maintenance, and siting considerations are better defined. Early RIPB decisions will be reviewed and revised as needed to incorporate enhancements in the evolving safety and risk states of knowledge. Once the plants are constructed and put into operation it is expected that the PRAs will be maintained, updated, and upgraded as needed for newly licensed plants, to incorporate insights from service experience any changes to the PRA model inputs, consistent with accepted PRA standards. Consistent with the principles and practices of risk-informed and performance-based regulation, any RIPB decisions supported by previous iterations of the PRA will be reviewed and revised as needed to preserve the technical bases of the safety case.

\subsection{Overview of PRA}

The advanced non-LWR PRA provides a logical and structured method to guide the design and evaluate its safety characteristics. This is accomplished by systematically enumerating a sufficiently complete set of reactor design specific event sequences and assessing the frequencies, and consequences of those sequences individually and in the aggregate to identify challenges to the plant's safety functions and to quantify the overall risk profile. As discussed more fully in the LMP LBE report, the PRA is selected as a tool to help identify the LBEs, in part because of its structured process of identifying event sequences and its ability to account for the dependencies and interactions among SSCs, operators, and the internal and external plant hazards that may perturb the operation of the plant and potentially lead to an accidental release of radioactive material. It is the only approach currently known that has the capability to define the reactor specific event sequences in a systematic and exhaustive manner and using methods supported by industry standards.

Rather than limit the quantification to point estimates of selected risk metrics, the PRA will be structured to give emphasis to the treatment of uncertainties. The quantification of both frequencies and consequences of event sequences and sequence families address uncertainties through the performance of quantitative uncertainty analysis where information is available to perform this function and sensitivity analyses to address other sources of uncertainty that are more difficult to quantify. This uncertainty treatment will be used as an input to a risk-informed evaluation of DID as will be discussed in a companion report on that topic. The treatment of 
uncertainties for the advanced non-LWR design will address the available applicable reactor service experience. The quantification of frequencies and consequences of event sequences and the associated quantification of uncertainties will provide an objective means of comparing the likelihood and consequence of different scenarios and of comparing the assessed level of safety against the applicable performance-based requirements. The sources of uncertainty identified in the uncertainty analysis will be given visibility for deterministic treatment in the selection of LBEs and in the development of principal design criteria.

The PRA will be structured to be able to examine the risk significance of design features and SSCs in the performance of safety functions as called for in the NRC advanced reactor policy statement. ${ }^{[28]}$

\subsection{Attributes of LMP PRA Approach}

PRA is selected as an analysis tool because of its capabilities to:

- Provide a systematic identification and enumeration of design-specific plant operating states, hazard groups, IEs, and event sequences

- Provide a basis for the quantification of risk to public health and safety, and serve as an appropriate and acceptable input to optimization of the design, selection of LBEs, ${ }^{*} \mathrm{SSC}$ safety classification, and risk-informed evaluation of DID

- Provide a reasonable and sufficient degree of completeness in the enumeration of reactor technology and design-specific event sequences, and the treatment of appropriate combinations of failure modes beyond prescriptive single failure assumptions, including consideration of the potential for multiple failures necessary to determine risk levels, identify LBEs, and perform safety classification of SSCs

- Provide a systematic examination of dependencies and interactions and the role that SSCs and operator actions play in the development of each event sequence and accident scenario

- Provide the capability to display the cause and effect relationships between the plant characteristics and the resulting risk levels that are sufficient to support the identification of LBEs and the safety classification of SSCs and their associated performance-based requirements

- Assess the integrated risks for advanced non-LWRs including event sequences involving two or more reactor modules or radionuclide sources when the design employs a modular reactor concept

- Provide quantitative estimates of accident frequencies and consequences under a realistic set of assumptions with a full quantitative treatment of uncertainties that is supported by available data, expert opinion, and other objective evidence

\footnotetext{
${ }^{*}$ As the term is used in this document, LBEs are defined broadly to include all events used to support the radiological safety aspects of the design and to meet licensing requirements. The LMP LBE report provides a more comprehensive discussion of the categories of LBEs and their use in different RIPB licensing decisions.
} 
- Define an appropriate set of technology-inclusive and reactor-specific risk metrics that have the capability to define the significant contributions to risk and provide information to demonstrate DID adequacy

- Apply risk-metrics to the evaluation of potential remedial plant changes or programmatic actions as part of risk-informed decision-making process

- Identify the sources of uncertainty for use in the implementation of DID evaluations and resulting risk management strategies and quantify the impacts of uncertainties on the risk results

- Determine the cause and effect relationships between elements of the safety design approach and the risk profile, including the risk significance of SSCs and design features to support the selection of LBEs and perform safety classification of SSCs

- Provide insights into the provision of special treatments of SSCs commensurate with their safety significance in any given event sequence

- Provide input to the selection of reliability and capability performance targets for SSCs

- Demonstrate compliance with applicable NRC regulations, guidance, and standards associated with plant safety objectives as well as the performance of PRA for an advanced non-LWR license application

Key assumptions that are used to develop success criteria, to develop and apply probability and consequence models, and to select elements for incorporation into the models will be clearly documented. Assumptions that are made in lieu of as-built and as-procured characteristics for the advanced non-LWR design will also be identified and documented.

\subsection{PRA Objectives}

The objectives of the PRA are to:

- Provide risk insights into the design of the advanced non-LWR, including the design of SSCs that perform PRA safety functions ${ }^{*}$ responsible for the prevention and mitigation of accidents

- Provide an acceptably complete set of event sequences from which to select the LBEs for early introduction into the design and subsequently in the license application

- Assess the integrated risks for advanced non-LWRs including event sequences involving two or more reactor modules or radionuclide sources when the design employs a modular reactor concept

\footnotetext{
* The term "PRA safety function" as used in this report broadly refers to any function by any SSC that is responsible for preventing or mitigating a release of radioactive material from any radioactive material source within the plant within the scope of the PRA. This includes functions performed by SSCs classified as "safety-related" which are credited during DBAs and those performed by any other SSC that is modeled in the PRA. Since the PRA is performed initially prior to the safety classification of SSCs, it is not known a priori which modeled SSCs will be considered safety-related when the PRA is initially developed. Hence PRA modeled safety functions should not be confused with the safety classification made in the licensing context.
} 
- Provide information needed to effectively manage the risks of multi-module and multiradionuclide source event sequences to ensure such sequences are not risk significant

- Confirm that the applicable requirements, including the safety goal Quantitative Health Objectives (QHOs) for individual and societal risks, are capable of being met at the site selected for the license application

- Provide input for the development of reactor-specific principal design criteria for the plant

- Support the determination of safety classification, safety-related design criteria and special treatment requirements of SSCs

- Support the identification of emergency planning specifications, including the location of the site boundary as well as the goal of appropriately sizing the emergency planning zones

- Support the development of technical specifications

- Provide insight on the role of advanced non-LWR SSCs in the prevention and mitigation of event sequences as part of the risk-informed evaluation of DID

- Determine the risk significance of design features and SSCs to the extent needed to support LBE selection, safety classification of SSCs, special treatments, and riskinformed and performance-based evaluation of defense-in-depth adequacy

- Provide PRA information to support a more integrated approach to a broad range of design and licensing decisions including DID adequacy, operational programs, technical specifications, reliability assurance programs, preparation of environmental reports, siting decisions, emergency planning, and evaluation of severe accident management alternatives. These evaluations incorporate deterministic inputs as well as inputs from the relevant event families represented in the PRA derived LBEs.

- Meet applicable codes, guides, and standards that ensure the technical adequacy of the PRA

- Provide a PRA maintenance and update process that supports risk-informed decisions at appropriate stages in the design, licensing, commissioning, and operation of the advanced non-LWR facility throughout the lifetime of the plant

It is useful to identify the boundaries between the PRA and the RIPB applications that information developed in the PRA will support. The primary role of the PRA is to provide the answers to the three fundamental questions: "What can go wrong?", "How likely is it?"; and "What are the consequences?" The PRA is then responsible to provide a reasonably complete set of event sequences and accident scenarios, estimates of the frequencies and consequences of these sequences and scenarios, a characterization of the uncertainties in the frequency and consequence estimates, and a comprehensive evaluation of risk insights in terms of the principle contributors to risk, risk significance of accident sequences, and their causes including internal and external hazards, equipment failures, and human errors. 
The RIPB decisions supported by the PRA, such as selection of LBEs, safety classification of SSCs, and development of design criteria involve many other non-PRA other inputs to the decision such as application of deterministic safety principles including defense-in-depth and conservative judgements to address issues not fully resolved in the PRA.

For LBEs not supported by the PRA, such as physical security threats and external hazards not supported by sufficient hazard analysis data, analyses and evaluations based on deterministic rules will be used similar to those employed for existing and advanced LWRs.

The above objectives cover a broad spectrum of expected PRA applications. The focus of the technical approach in this section is on the early applications of design support, LBE selection, and SSC safety classification. NRC agreement on the PRA objectives is an important outcome of this report.

\subsection{Scope of Advanced Non-LWR PRAs}

The advanced non-LWR PRA will provide a primary source of candidate event sequences for the selection of LBEs, be a key input to the safety classification and design of SSCs, and provide information to support a risk-informed evaluation of the plant's DID. In view of these applications, completeness and design specificity in the enumeration of event sequences are viewed as especially important outcomes of the PRA. The emphasis placed on the roles of inherent and passive capabilities in the safety design approach of typical advanced non-LWRs requires a comprehensive set of challenges to the advanced non-LWR inherent features and passive SSCs be included. Such a comprehensive set includes a full spectrum of internal events and external hazards that pose challenges to the inherent and passive capabilities of the plant.

The PRA at the time of the advanced non-LWR license application will include the following aspects of a full-scope PRA:

- Definition of a spectrum of event sequences that is sufficient to identify and evaluate the LBEs as defined in the LMP LBE report, to support the safety classification and performance criteria for SSCs as defined in the LMP SSC safety classification report, and to support the evaluation of DID adequacy as defined in the LMP DID report

- PRA models sufficient to meet regulatory requirements for any license applicant

- The potential sources of release of radioactive material as needed to delineate MSTs, radionuclide consequences, and determination of risk-significant event sequences

- All planned operating and shutdown modes, including plant configurations expected for planned maintenance, tests, and inspections as needed to identify risk-significant event sequences

- A full range of potential causes of IEs, including internal plant hardware failures, human operator and staff errors, internal plant hazards such as fires and floods, and external plant hazards such as seismic events, transportation accidents, and any nearby industrial facility accidents 
Quantification of the frequencies and radiological consequences of each of the significant event sequences modeled in the PRA. This quantification includes mean point estimates and an appropriate quantification of uncertainty in the form of uncertainty probability distributions that account for quantifiable sources of parameter and model uncertainty in the accident frequencies, MSTs, and offsite radiological consequences. An appropriate set of sensitivity analyses will also be performed to envelope sources of uncertainty that are not quantifiable, as described below.

- For advanced non-LWR plants covered under license applications that are comprised of multiple reactor modules, event sequences that impact reactor modules independently as well as those that impact two or more reactor modules concurrently will be defined. The frequencies will be calculated on a per-plant-year basis, and the consequences will consider the number of reactor modules and sources involved in the definition of the MSTs.

- To support the development of reactor specific performance targets and design criteria, the PRA will have the capability of evaluating the cause and effect relationships between design characteristics and risk, supporting a structured evaluation of sensitivities to examine the risk impact of adding and removing selected design capabilities, and setting and adjusting SSC reliability requirements.

- Future advanced non-LWRs are expected to have multiple reactor modules to be located at the same site, with the potential for sharing of systems and structures among modules. The PRA will account for the integrated risk of multiple modules and multiple radionuclide sources to help identify design and operational strategies to effectively manage the risks in a multi-module facility. The existence of multiple modules increases the site-wide likelihood of scenarios that impact a single module independently and creates the potential for scenarios that involve multiple modules, as well as the potential for a mechanistic source term involving releases from two or more reactors. These modular reactor considerations will impact the scope and level of detail of the PRA.

\subsection{Roadmap for PRA Development as the Design Matures}

When the PRA is initially introduced at an early stage in the design, the PRA scope will be focused on internal events and full power initial conditions and event sequences involving the reactor sources of radioactive material. The scope and level of detail of the PRA models will also be simplified to be in alignment with the state of knowledge regarding the definition of the design, the safety design approach, and systems design concept. As the design matures and more design definition and details become available, the scope of the PRA will be broadened to address other plant conditions and progressively confirm the plant capability to meet safety objectives. The PRA will only achieve a full scope status prior to plant operation when all the design and testing information (most of it confirmatory) is included. However, the PRA at the completion of the conceptual design should be sufficient to identify an appropriate set of LBEs. When available to support pre-licensing interactions, an understanding of how risk insights have been incorporated into the design will help set the foundation for subsequent risk-informed licensing decisions. 
Prior to first introduction of the PRA, it is necessary to develop a technically sound understanding of the potential failure modes of the reactor concept, how the reactor plant would respond to such failure modes, and how protective strategies will be incorporated into formulating the safety design approach. The incorporation of safety analysis methods appropriate to early stages of design, such as process hazard analysis (PHA) tools, provides industry-standardized methods to ensure that such early stage evaluations are systematic, reproducible and as complete as the current stage of design permits. A suitable reference for performing such PHA evaluations is Reference [74]. PHA methods include hazard and operability assessment and failure modes and effects analysis (FMEA) which are recognized by in the ASME/ANS advanced non-LWR PRA standard ${ }^{[46]}$ as systematic and reproducible methods for comprehensive hazard assessment. PHA may be regarded as a precursor to the development of the PRA and is actually recognized as an integral part of the PRA methodology. Basic steps in a Hazard and Operability Study (HAZOP) evaluation are shown in Figure 3-1 adapted from Reference [74].

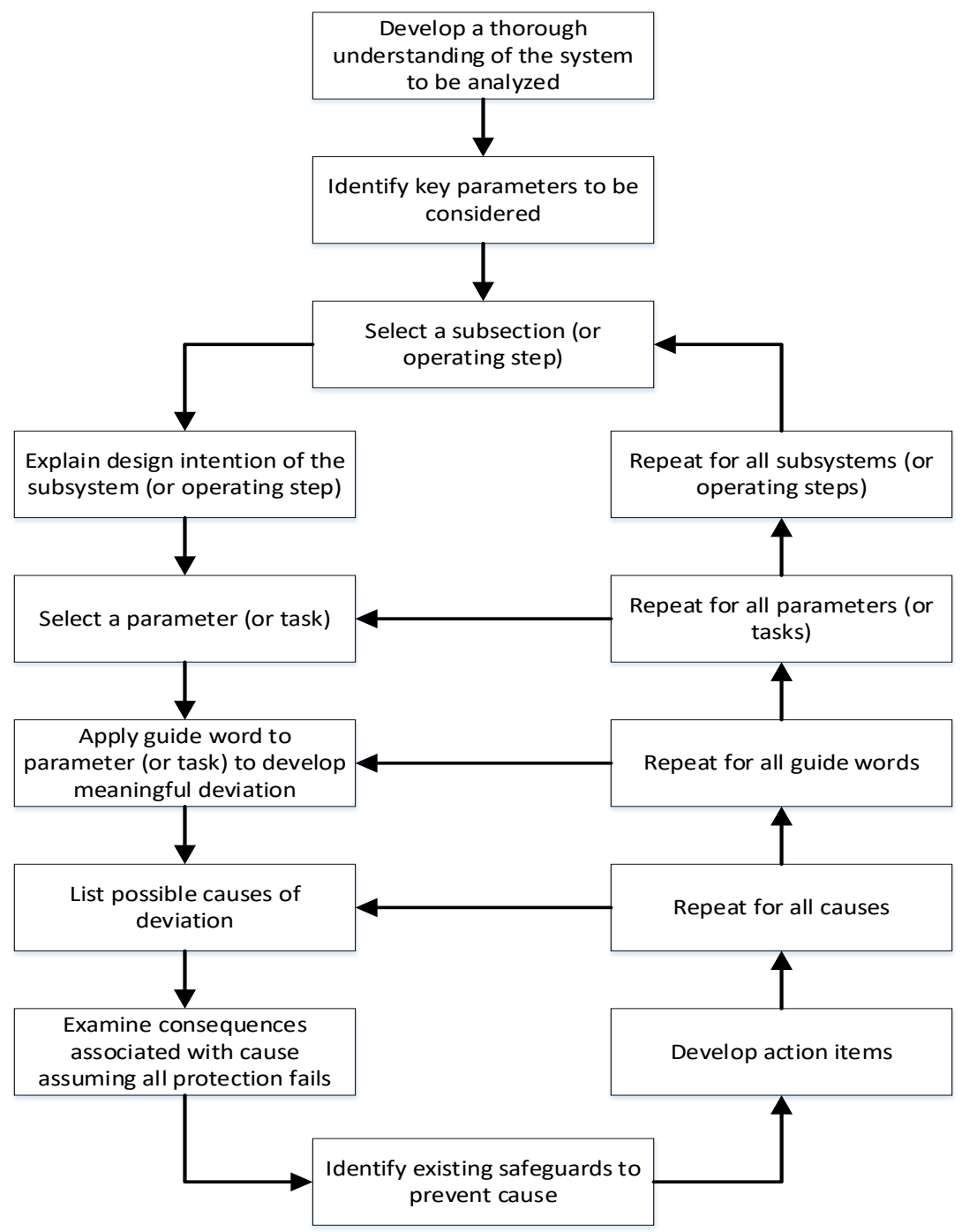

Figure 3-1. Basic Steps in a HAZOP Evaluation ${ }^{[7]}$ 
During the process of the developing the PRA, questions raised are framed around the fundamental risk question "What can go wrong?" will be considered by the design team to assist in defining the challenges that need to be considered to complete the design. These challenges are reflected in the PRA approaches for the systematic and exhaustive enumeration of IEs, event sequences, and logic models for identifying the cause of each event. This enables a structured way to address the remaining two risk questions of "How likely is it" and "What are the consequences?" As such, the scope of the PRA and level of detail of the PRA mature as the design evolves in an iterative manner.

To meet current regulatory requirements for a new plant license, the PRA will include a full treatment of internal and external events and hazards initiated from applicable plant operating states consistent with then applicable NRC endorsed PRA standards. However, beyond meeting these requirements in this application, the PRA is introduced at a sufficiently early stage of the design to enable the designer to identify the expected LBEs that need to be considered to minimize the potential for costly back-fits later. This approach to using the results of the early PRA to inform the LBE selection process is used to make the LBE selection process systematic, reproducible, and sufficient to identify reactor specific and unique safety issues. This is explained more fully in the companion LMP report on LBE selection and evaluation.

Given the fundamental differences in the design and selection of materials with unique inherent safety characteristics among the advanced non-LWRs and between those and the existing LWRs the current approach of having the applicant propose a list of LBEs with the design for NRC to review yields too much uncertainty in planning, scheduling, and budgeting a design and license application. The iterative nature of the design evolution and PRA maturity means that the initial set of LBEs determined at an early stage of design will be refined and updated periodically and finally confirmed before the application is submitted. However, this approach is expected to converge more quickly on a successful design and licensing outcome rather than trying to derive LBEs from the current LWR-centric requirements. Additional guidance for developing the initial knowledge base for a PRA model can be found in a report on an Integrated Safety Assessment Methodology (ISAM) developed by the Generation IV Risk and Safety Working Group. ${ }^{[75]}$ The ISAM approach includes the following elements that are illustrated in Figure 3-2, which was reproduced from the report:

- Qualitative Safety Features Review

- Phenomena Identification and Ranking Table

- Objective Provision Tree (a DID evaluation)

- Probabilistic Safety Assessment*

- Deterministic and Phenomenological Analysis

\footnotetext{
* International documents frequently use the term "Probabilistic Safety Assessment," which has the same meaning as PRA.
} 


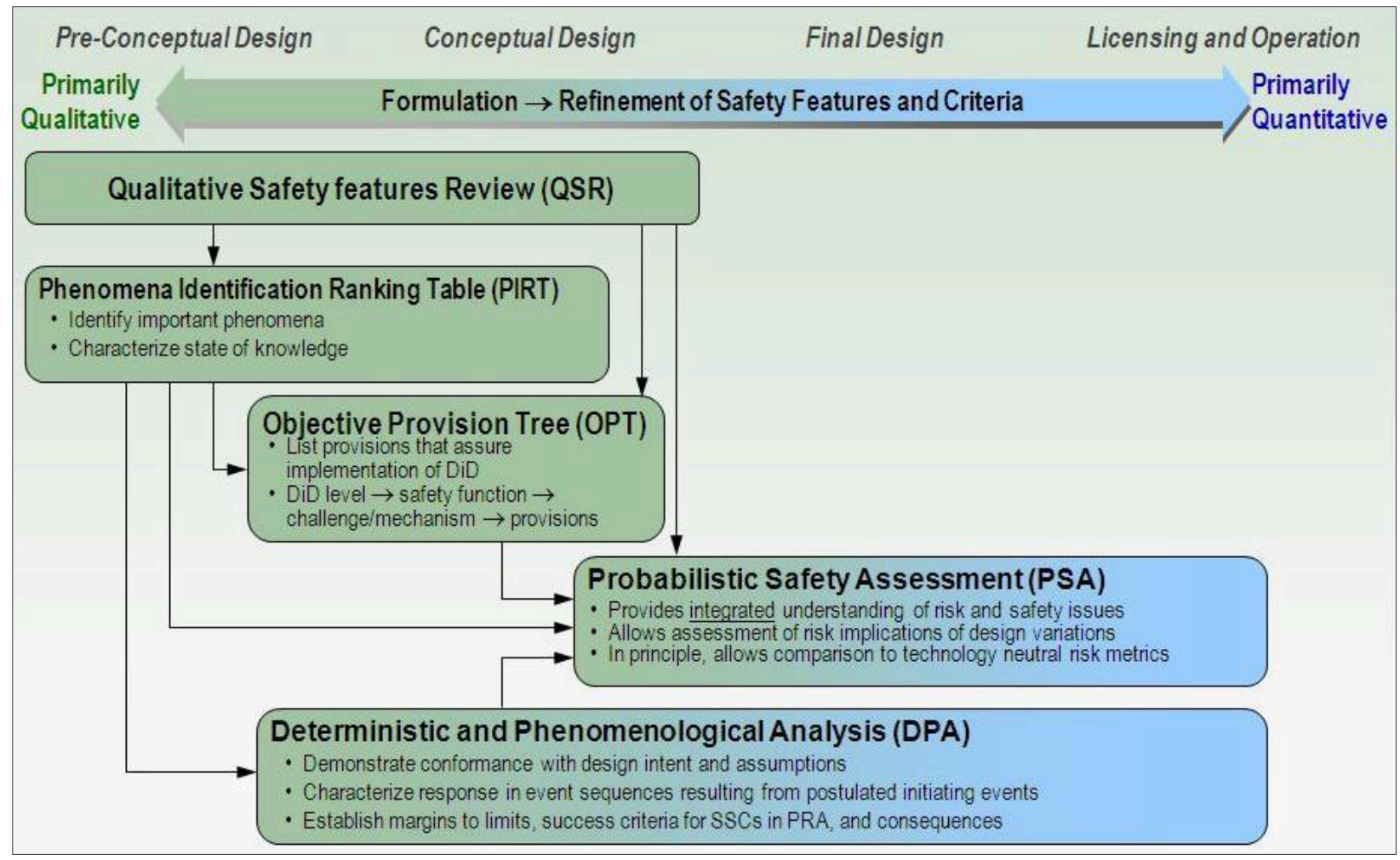

Figure 3-2. ISAM Methodology ${ }^{[75]}$

The ISAM approach is generally consistent with the approach to PRA advanced in this report with the following observations:

- The LMP approach recommends an earlier introduction of PRA than does the ISAM approach.

- The Probabilistic Safety Assessment presentation in ISAM retains several LWR-specific concepts, such as the Level 1-2-3 PRA framework, and does not explicitly identify the role of a simplified high-level PRA that would be used to guide the conceptual design development.

- ISAM recognizes the need for technology-inclusive risk metrics. However, it attempts to redefine core damage frequency $(\mathrm{CDF})$ in a way that applies to all reactors, which is problematic for many advanced non-LWRs. Even when a core damage state can be defined, there is no basis for applying the acceptance criteria for CDF which have been established for large LWRs.

- All the non-PRA elements of the ISAM including the Qualitative Safety Features Review, Phenomena Identification and Ranking Table, Objective Provision Tree, and Deterministic and Phenomenological Analysis are encompassed within the proposed LMP methodology as providing critical inputs to a PRA. Their equivalents are embodied within the early safety analyses, such as HAZOP and FMEA, along with the deterministic and probabilistic safety analyses for advanced non-LWRs. 
- A key strength of ISAM is the incorporation of DID considerations at an early stage of design.

When early stage safety analyses such as HAZOP and FMEA are introduced in the preconceptual design and the initial PRA development begun during this timeframe, the PRA model will be simplified in relation to a full scope PRA that is sufficient to meet applicable PRA standards. Typical simplifications in this early stage include:

- Limitation to internal IEs initiated during full power operation modes

- Representation of all PRA Safety Functions (PSFs) that protect each radionuclide barrier

- Representation of all known SSCs that support each PSF with no assumptions regarding safety classification

- Use of coarse high-level system fault models that reflect known design details

- Simplified treatment of common cause failures and human reliability

- Event sequence quantification using generic data engineering judgment sufficient for order of magnitude estimates and initial LBE determinations

- Plant response to events based on available plant response models

- Source terms based on best available information

- Consequences limited to site boundary dose calculations

Despite these simplifications, the PRA development would be capable of defining a reasonably complete set of event sequences and order of magnitude estimates of the frequencies and site boundary doses of those involving a release. Hence, the PRA should be sufficient to develop an initial set of LBEs to support the early stages of design. As the PRA is upgraded to conform with later stages of design development, the LBEs will be refined, however the DBAs are expected to be reasonably stable. Between major upgrades and updates of the PRA, it is expected that there would be essentially continuous use of the PRA models to inform design trade studies and to evaluate design alternatives. LBEs associated with internal plant hazards, such as fires and floods, and external events are added as sufficient design and siting information to support these analyses becomes available.

Common sense is used to select appropriate times for PRA upgrades and updates ${ }^{*}$ to correspond with key hold points in the development of the design. When the plant general arrangement drawings and cable tray layouts are available, the scope of the IEs can be expanded to include internal fires and floods and other internal hazards. The inclusion of other radionuclide sources within the scope of the PRA can begin when the design features of the supporting systems and structures have been developed. When the site characteristics or site parameter envelope is established PRA models for seismic and other external hazards can be introduced. As operational information becomes available additional modes and states may be added and the

\footnotetext{
*In the PRA standards, the term "update" refers to a revision of the PRA to reflect changes in input data, whereas "upgrade" refers to significant enhancements to the PRA models involving expansion of PRA scope and increased level of detail.
} 
treatment of human actions can be advanced. As the capabilities for simulations of plant response to events and mechanistic source terms become available the event sequence models may be refined and the consequence estimates revised. Hence the list of LBEs can be expected to be modified several times prior to the license application. However, the designer will have the benefit of risk insights to guide the design and much better predictability of the LBEs as the design is being developed. The evolution of the design, PRA, and LBE definition for the MHTGR project is illustrated in Figure 3-3.

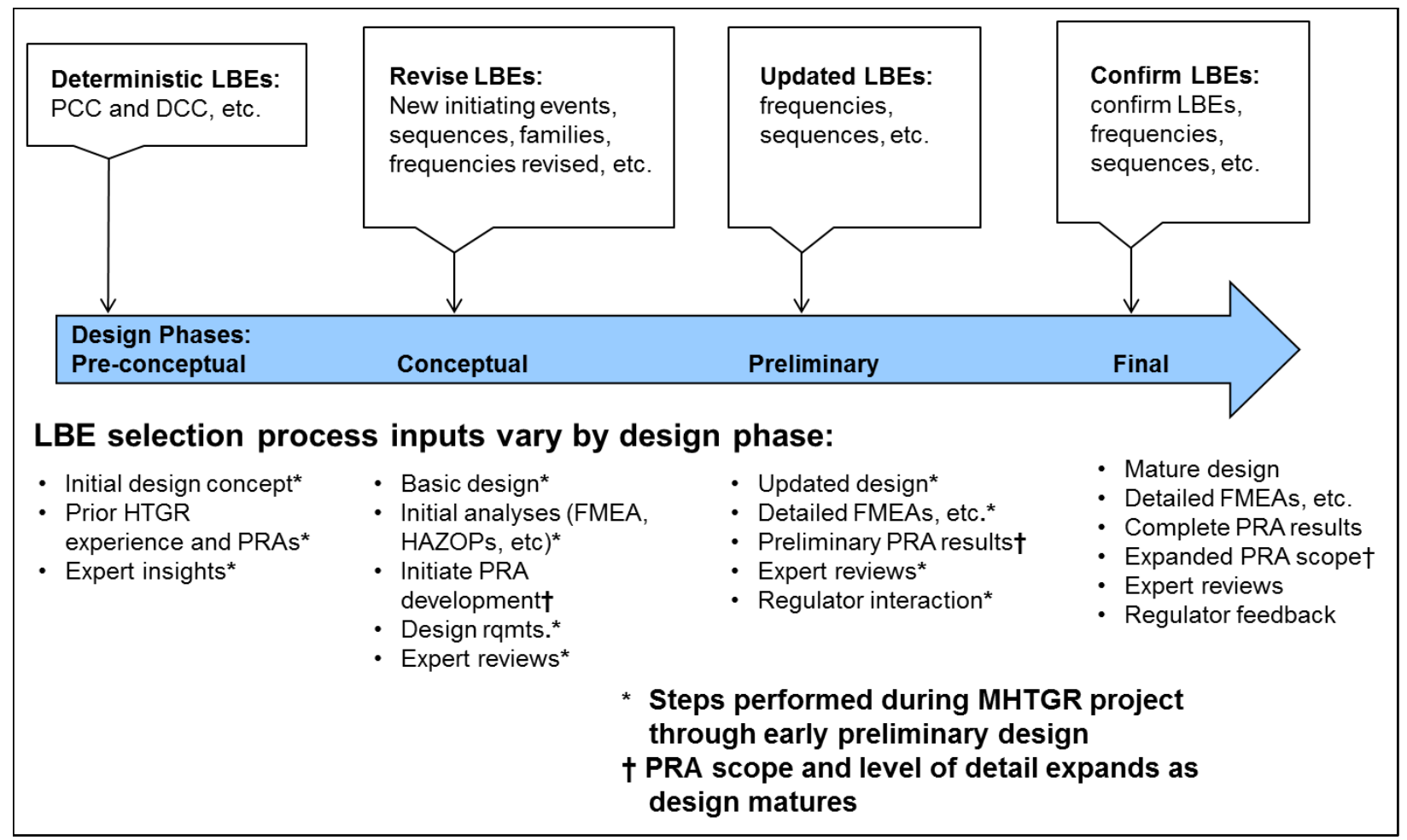

Figure 3-3. Evolution of Design, PRA, and LBE Development for the MHTGR ${ }^{[42]}$

The initial PRA model is developed in close coordination with the design development and gets input from a number of design analyses and early safety analysis methods that comprise deterministic inputs to the PRA. Several of these key PRA-Design-Analysis interfaces are illustrated in Figure 3-4. When the deterministic inputs are revised as the design evolves, the PRA models are modified as appropriate. 


\section{Systems Engineering Inputs}

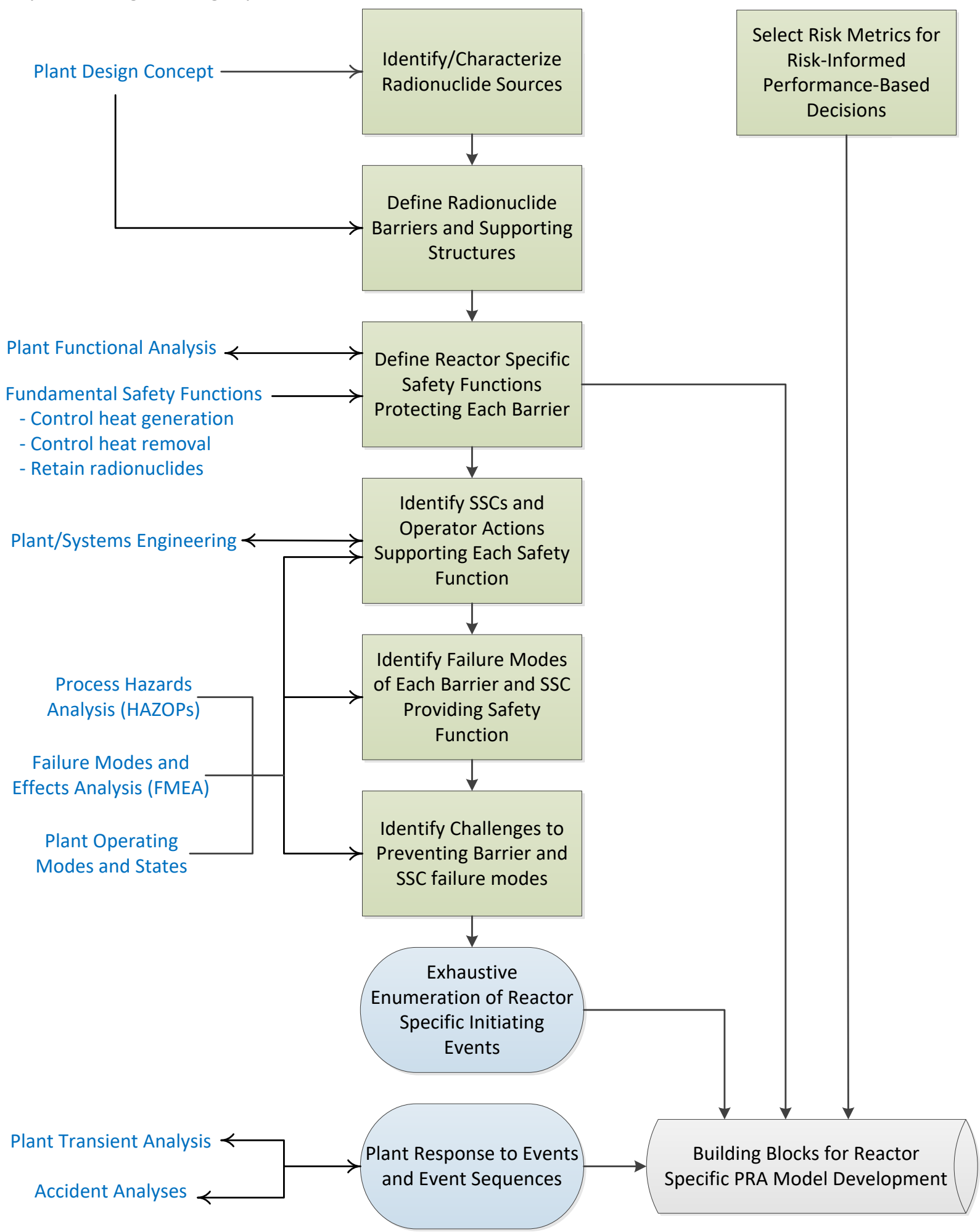

Figure 3-4. Flow Chart for Initial PRA Model Development 
As shown in Figure 3-4, the framework for the PRA development is a comprehensive set of design specific IEs and event sequences that are defined by the basic reactor design concept and a number of systems analyses that are performed as a natural part of the reactor design process. The PRA model is systematically developed by defining the sources of radioactive material that are defined by the scope of the PRA, the radionuclide barriers for each source, and the PSFs that protect each barrier. The designer selects and designs the SSCs that provide the barriers and perform the PSFs that protect them.

To develop a robust design that meets all the design requirements including those for operational reliability, availability, maintainability, investment protection and safety, the design is subject to a number of systems analyses, early safety analyses including FMEA, HAZOP, along with other analyses specified in the selected design codes and standards. When properly interfaced with the PRA development, these analyses provide an exhaustive and systematic search for IEs, which is an early step in PRA model development. The systematic identification of event sequences which are developed with PRA tools such as event sequence diagrams and event trees is accomplished with input from the selection of risk metrics for risk-informed decision making and information from plant transient analysis the designers must perform to design the plant control and protection systems.

Early safety analysis methods such as HAZOP and FMEA provide important early information regarding important internal IEs, system PSFs, and high-level system failure modes, along with insights regarding plant response and human factors. By integrating the PRA development needs with the early phases of plant design, and early safety analyses, the additional analyses that need to be performed to support the PRA development may be minimized. EPRI is conducting a project to investigate the use of PHA techniques to develop the knowledge base that is required to build a PRA model that utilizes the concepts shown in Figure 3-4. A case study was performed on the MSRE to demonstrate a useful methodology for this purpose. ${ }^{[81]}$ The Interfaces between PHA and PRA are shown in Figure 3-5. 


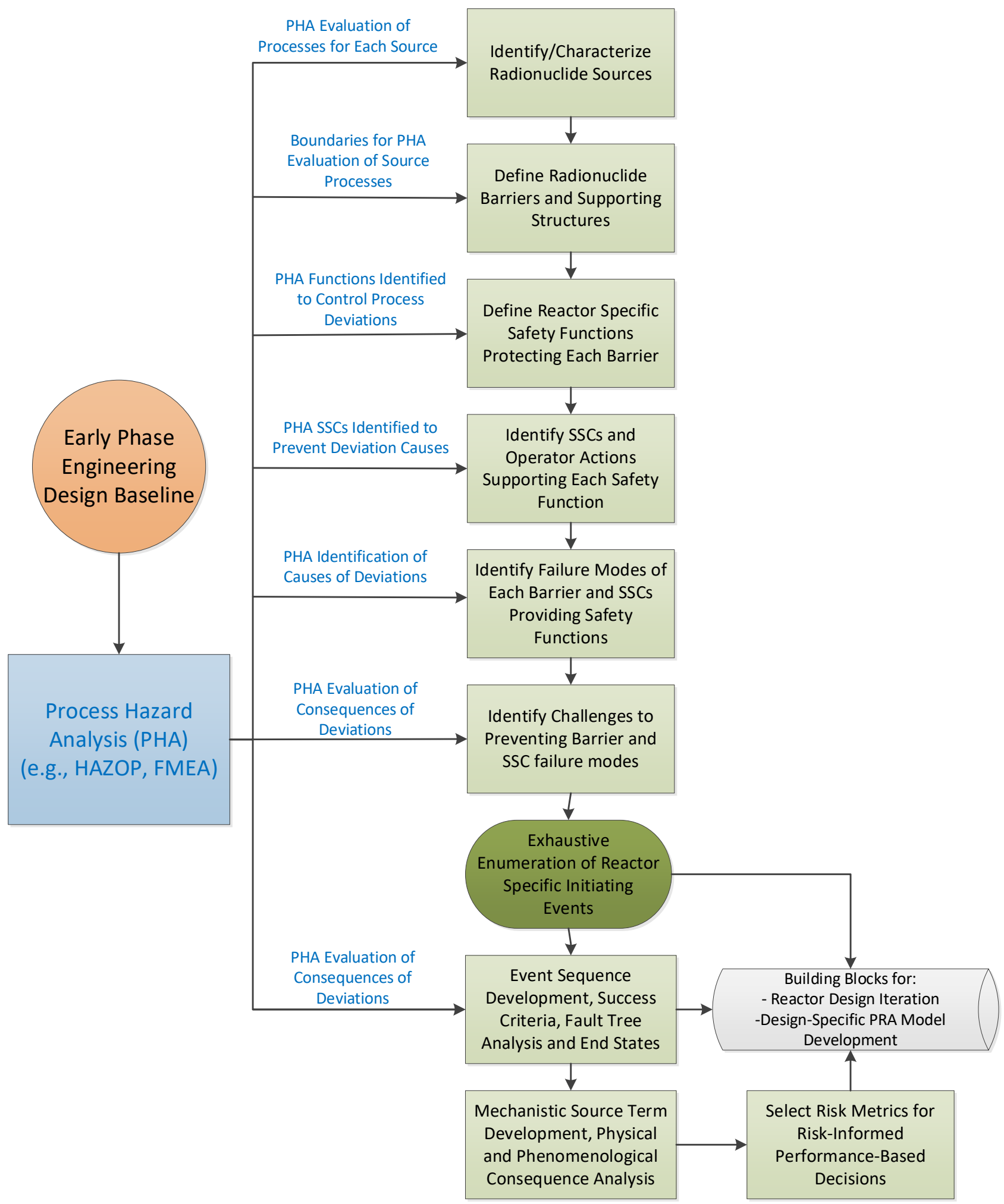

Figure 3-5. Use of Process Hazards Analysis to Inform PRA Building Blocks 
As previously noted, the term "PRA safety function," as used in this report, is any function by any SSC that is responsible for preventing or mitigating a release of radioactive material from any radioactive material source within the plant and included in the scope of the PRA. Some of these PRA safety functions may later be classified as "Required Safety Functions (RSFs)" if they are necessary or relied upon during DBEs to meet a frequency consequence (F-C) Target or "supportive safety functions" if they are not necessary to meet the F-C Target but still play a role in accident prevention and mitigation and are part of the plant capabilities for DID. Following the development of the initial PRA while selecting the LBEs that will be considered for the selection of DBAs, those SSCs that perform RSFs will be considered for selection by the designer as "safety-related," and special treatment requirements will be developed to ensure they have the necessary and sufficient capability and reliability to assure the TLRC are satisfied. Each DBE will be used to define a DBA in which only safety-related SSCs will be credited in the performance of each RSF. More details on how the PRA model is used to support the selection and evaluation of LBEs are provided in the companion LBE report.

PRA safety functions are defined starting with fundamental reactor inclusive functions of controlling heat generation, controlling heat removal, and retaining radionuclides. ${ }^{[50]}$ These are often refined into reactor technology-specific safety functions that reflect the reactor concept and unique characteristics of the reactors defining the radionuclide barriers. This then leads to the reactor technology specific SSCs that the designer has selected to perform each function as well as to perform non-safety-related functions for energy production, investment protection, and other non-safety requirements.

\subsection{Advanced Non-LWR PRA Elements}

The advanced non-LWR PRA will be organized into elements that are consistent with the way in which PRA elements have been defined in the ASME/ANS PRA standard for advanced nonLWR plants. ${ }^{[46]}$ The PRA elements, which may be considered building blocks of the PRA models are listed below. The role these elements play in the development and quantification of the advanced non-LWR event sequence model is illustrated in Figure 3-6.

- Definition of Plant Operating States

- Initiating Events Analysis

- Event Sequence Development

- Success Criteria Development

- Thermal and Fluid Flow Analysis

- Systems Analysis

- Data Analysis

- Human Reliability Analysis

- Internal Flooding Analysis
- Internal Fire Analysis

- Seismic Risk Analysis

- Other External Events Analysis

- Event Sequence Frequency Quantification

- Mechanistic Source Term Analysis

- Radiological Consequence Analysis

- Risk Integration and Interpretation of Results

- Peer Review 


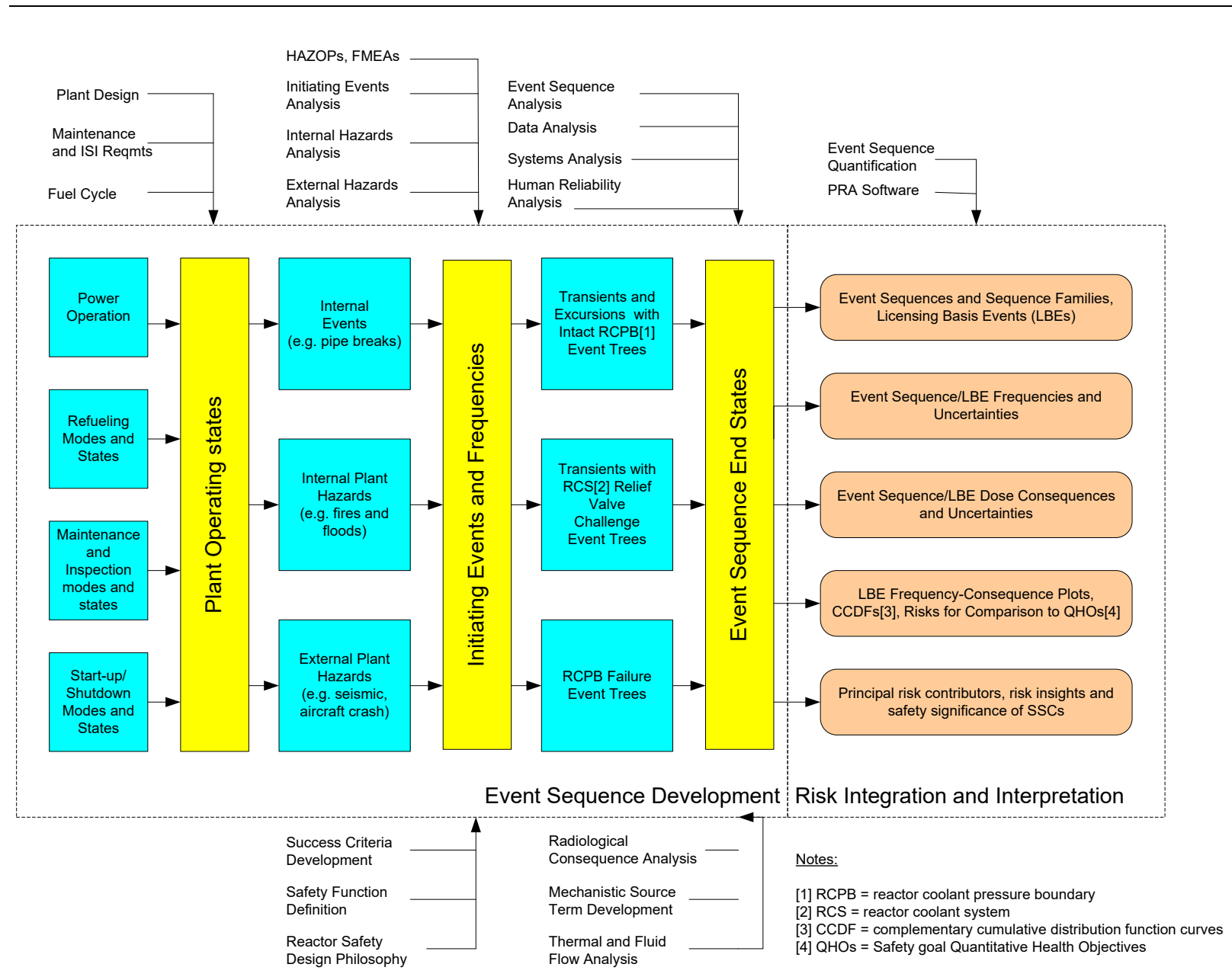

Figure 3-6. Overview of Advanced non-LWR PRA Model Elements

These elements are similar to those associated with a full-scope Level 3 PRA for an existing LWR. Some of the key differences expected for the non-LWR PRA are identified below.

- The following design-specific PRA elements are developed specifically for the advanced non-LWR, and these are expected to be fundamentally different from those for an LWR:

- Functional barriers for retention of radioactive material

○RA safety functions

- SSC available in the design to support each function

- Success criteria for each plant and SSC function modeled in the PRA

- Functional IE categories

○ Plant response to IEs

- Human actions prior to, in the initiation of, and in response to events modeled in the PRA, including the timeframes available for these actions

$\circ$ Event sequence end states 


\section{○ Mechanistic source terms \\ ○ Radiological consequences}

- The event sequences cover relatively frequent events classified as Anticipated Operational Occurrences (AOOs), infrequent events classified as Design Basis Events (DBEs), and rare events classified as Beyond Design Basis Events (BDBEs) based on frequency of occurrence.

- Rather than calculate LWR PRA intermediate risk metrics, such as CDF, the results include calculations of the frequencies and dose consequences of accident families referred to as LBEs. Each LBE is a group of event sequences with similar plant operating state, IE, plant response to performance and failure to perform PRA safety functions, and end-state with a specified mechanistic source term if there is a release. The results may also be organized into reactor-specific release category frequencies. Each release category is a grouping of LBEs with similar mechanistic source term and radiological consequence.

- For some risk metrics, such as the NRC safety goal QHOs, the risk is aggregated over all the event sequences in the PRA model. In the companion LBE report, targets for cumulative risks are defined for evaluating the integrated risks overall all modeled event sequences.

- Event sequence frequencies are calculated on a per-plant-year basis, where a plant may consist of two or more reactor modules. This facilitates an integrated treatment of risk for an entire multi-module plant. The consequences of event sequences may involve source terms from one, multiple, or all reactor modules or radionuclide sources that comprise the plant. This will facilitate the definition of LBEs for the multi-module design and provide the capability to address the integrated risk of the multi-module plant. This capability of the PRA is necessary to provide risk insights to the designers to enable the effective risk management of multi-module or multi-source accidents.

- The PRA model elements illustrated in Figure 3-6 focus on the reactor scope of the PRA. However, the PRA is also expected to include non-reactor sources of radioactive material, which may be of particular importance for some advanced reactor designs.

\subsection{Selection of Risk Metrics for PRA Model Development}

\subsubsection{Overall Plant Risk Metrics}

The advanced non-LWR PRA model may be structured differently than the traditional Level 1-2-3 model for an LWR PRA (as defined in NUREG/CR-2300 ${ }^{[44]}$ ), given the fact that modeled plant damage states may not involve an equivalent to the core damage state that separates the Level 1 and Level 2 parts of an LWR PRA model. Indeed, some advanced nonLWR designs have design features that preclude the type of core damage states that have been defined for an LWR using inherent and passive design features.

Because of the use of different materials for the fuel, moderator, and coolant, LWR risk metrics such as core damage frequency are not useful or relevant for many advanced non-LWR designs. 
Even in cases where a core damage state may be defined for a non-LWR, its meaning and risk context may be fundamentally different than that for an LWR. This issue was recognized in the development of the ASME/ANS PRA standard for advanced non-LWRs, which has adopted TI risk metrics to define PRA requirements for technical adequacy. These TI risk metrics are described below.

- Frequencies of event sequences individually and grouped into accident families having the same or similar plant response and offsite radiological consequences. Accident families may be defined in terms of release categories as the term is used in LWR Level 2 PRAs or into specific LBEs defined by similarity of IE, plant response, mechanistic source term, and offsite radionuclide consequences. Consequences are quantified in terms of offsite early and latent health effects and/or site boundary doses.

- Integrated risks of a given consequence metric, e.g., site boundary dose, number of early or latent health effects, etc. many be calculated by summing the product of the frequency and consequence of each LBE over the full set of LBEs.

- Integrated risks of individual fatalities as needed for comparison to the QHOs.

- Cumulative frequency of exceeding consequences such as large release, early or latent health effects, or a specific site boundary dose.

In addition to the above TI metrics, reactor specific risk metrics defined by the user may be used to define the parameters of the PRA model (for example, frequency of sodium boiling in liquid metal-cooled reactors, frequency of exceeding a fuel damage limit, frequency of pressurized loss of forced cooling in a gas-cooled reactor, etc.) There are requirements for the definition and use of these reactor specific metrics in the advanced non-LWR PRA standard. ${ }^{[46]}$

Another factor that needs to be considered in the selection of PRA risk metrics is the need to address accident sequences that may involve two more reactor modules or radionuclide sources. The traditional LWR PRA metrics have been used almost exclusively to support PRAs on a one reactor at-a-time basis. This is addressed in the LMP approach to PRA using the following approaches:

- The IEs and event sequences in the PRA will delineate events involving each reactor and radionuclide source separately as well as events involving two or more reactors or sources.

- Dependencies associated with shared systems and structures are explicitly modeled in an integrated fashion to support an integrated risk assessment of the entire plant where the plant may be comprised of two or more reactor modules and non-core radionuclide sources.

- Treatment of human actions will consider the unique performance shaping factors associated with multi-reactor and multi-source event sequences.

- Treatment of common cause failures will delineate those that may impact multiple reactor modules.

- The frequency basis of the event sequence quantification is events per (multi-module/multisource) plant-year. 
A summary of the technical issues that need to be addressed for PRAs involving multiple reactor modules or radionuclide sources is found in Reference [56].

\subsubsection{Risk Metrics for Selection of Licensing Basis Events}

As discussed more fully in the companion report on the LMP approach to LBE selection, there are two types of risk significance evaluations to be performed for the selection and evaluation of LBEs. The first type is an evaluation of the frequencies and consequence of each LBE, expressed in the form of mean values and uncertainty percentiles $\left(5^{\text {th }}\right.$ and $95^{\text {th }}$ percentiles), against frequency-consequence evaluation criteria such as that defined in Figure 3-7 for the LMP methodology. In this evaluation, the frequencies and consequences of individual LBEs are compared against a Frequency-Consequence (F-C) Target which was derived from top level regulatory requirements and $\mathrm{NRC}$ safety goal policy. A design objective is to keep the LBE frequencies and consequences within the F-C targets. An evaluation of the margins between the $\mathrm{LBE}$ risks and the F-C target is one aspect of the RIPB evaluation of defense-in-depth adequacy as explained more fully in the LMP report on DID. The development of the F-C Target is explained more fully in the companion LMP report on LBE selection and evaluation.

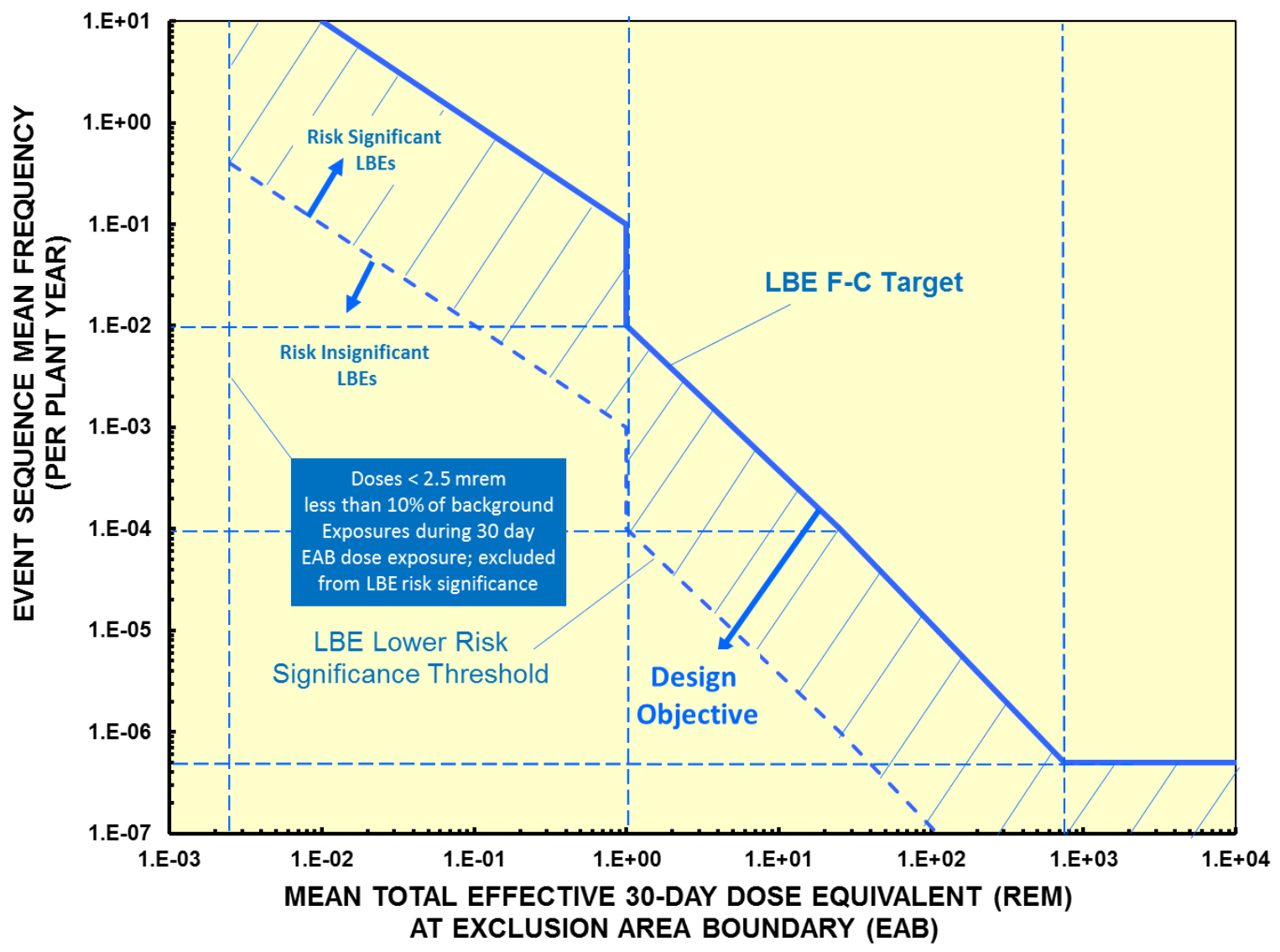

Figure 3-7. Use of the LMP F-C Target to Define Risk-Significant LBEs 
Each LBE in this evaluation is defined as a family of event sequences modeled in the PRA that groups the individual modeled PRA event sequences according to the similarity of the following elements of the event sequence:

- Plant operating state

- IE

- Plant response to the IE and any independent or consequential failures represented in the event sequence including the nature of the challenge to the barriers and SSCs supporting each PRA safety function

- Event sequence end state

- Number or combination of reactor modules and radionuclide sources affected by the sequence

- Mechanistic source term for sequences involving a release

The event sequence frequencies are expressed in terms of events/plant-year where a plant may be comprised of two or more reactor modules and sources of radioactive material.

In addition to evaluation of each individual LBE, and integrated risk evaluation of the entire plant is performed against the following criteria that have been selected for the LMP project. For this evaluation, the integrated risk of the entire plant is evaluated against three evaluation criteria:

- The total frequency of exceeding a site boundary dose of 100 mrem shall not exceed 1/plant-year to ensure that the annual exposure limits in 10 CFR 20 are not exceeded.

- The average individual risk of early fatality within 1 mile of the EAB shall not exceed $5 \times 10^{-7} /$ plant-year to ensure that the NRC Safety Goal QHO for early fatality risk is met.

- The average individual risk of latent cancer fatalities within 10 miles of the EAB shall not exceed $2 \times 10^{-6} /$ plant-year to ensure that the NRC Safety Goal QHO for latent cancer fatality risk is met.

Risk-significant LBEs, as defined within the LMP methodology, are those with frequencies and consequences within $1 \%$ of the F-C target with site boundary doses exceeding $2.5 \mathrm{mrem}$. To consider the effects of uncertainties, the upper $95^{\text {th }}$ percentile estimates of both frequency and dose are used for this purpose. The use of the 1\% significance criterion is consistent with the approach to defining risk-significant accident sequences in the PRA standards. The $2.5 \mathrm{mrem}$ cut-off is selected as this is approximately $10 \%$ of the dose that an average U.S. person at the site boundary would receive in 30 days due to background radiation.

\subsubsection{Contributors to Risk and Risk Importance Measures}

To derive useful risk insights from the results of a PRA, it is necessary to understand the principal contributors to each evaluated risk metric. This is normally achieved by rank ordering 
the PRA event sequences and sequence minimal cut-sets to identify their relative and absolute contribution to each risk metric and to calculate the risk importance measures that evaluate contributions to basic events that may be common to two or more sequences or cut-sets. For any of the integrated risk metrics, such as the QHOs, the relative risk significance of any LBE may be calculated as a percentage of the LBE risk (product of the LBE frequency and LBE consequence) to the aggregated risk of all the modeled LBEs.

In order to evaluate the risk contributions from basic events that may appear in two or more event sequences or cut-sets, risk importance measures are often used. The most commonly used risk importance measures in PRA are listed in Table 3-1, which is developed from

Reference [58]. In this table, the term $R$ represents the total risk, $R$ (base), is the risk with each basic event probability set to its base value, and the term $x_{i}$ represents the probability of a basic event $i$, which may be, for example, the event that a specific valve fails to perform its function.

Table 3-1. Risk Importance Measures ${ }^{[58]}$

\begin{tabular}{|c|c|c|}
\hline Measure & Abbreviation & Principle \\
\hline Risk reduction & $\mathrm{RR}$ & $R$ (base) $-R\left(x_{\mathrm{i}}=0\right)$ \\
\hline Fussell-Vesely & FV & $\frac{R(\text { base })-R\left(x_{\mathrm{i}}=0\right)}{R(\text { base })}$ \\
\hline Risk reduction worth & RRW & $\frac{R(\text { base })}{R\left(x_{\mathrm{i}}=0\right)}$ \\
\hline Criticality importance & $\mathrm{CR}$ & $\frac{R\left(x_{\mathrm{i}}=1\right)-R\left(x_{\mathrm{i}}=0\right)}{R(\text { base })} \times x_{\mathrm{i}}$ (base) \\
\hline Risk achievement & RA & $R\left(x_{\mathrm{i}}=1\right)-R$ (base) \\
\hline Risk achievement worth & RAW & $\frac{R\left(x_{\mathrm{i}}=1\right)}{R(\text { base })}$ \\
\hline Partial derivative & PD & $\frac{R\left(x_{\mathrm{i}}+\partial x_{\mathrm{i}}\right)-R\left(x_{\mathrm{i}}\right)}{\partial x_{\mathrm{i}}}$ \\
\hline Birnbaum importance & BI & $R\left(x_{\mathrm{i}}=1\right)-R\left(x_{\mathrm{i}}=0\right)$ \\
\hline
\end{tabular}

In LWR PRAs, the risk metrics used for $R$ are typically limited to CDF and large early release frequency (LERF). However, the associated Table 3-1 risk importance measures definitions can also be used with any of the technology-inclusive risk metrics selected for the advanced nonLWR PRA under the LMP methodology. These include:

- Frequency of a specific LBE

- Total risk (sum of the product of frequency and site boundary dose) of all the PRA modeled sequences, or individual risk of fatality in the plant vicinity

- Frequency of exceeding a specified site boundary dose

- Individual risk of prompt or latent fatality for comparison to NRC Safety Goal QHOs 
The above metrics are considered relative metrics because they measure importance relative to the baseline risk calculated in the PRA. Relative risk metrics are necessary for the purpose of screening out non-risk significant events and contributors and for analyzing the event sequences and basic events in the PRA model that are most important to determining the overall risk. However, as explained below, there are also absolute risk metrics that are used to support RIPB decisions that need to be anchored to a fixed level of acceptable risk.

\subsubsection{Absolute Risk Metrics}

The traditional approach to evaluating risk importance produces only the relative importance of each basic event because the formulas are normalized against the total calculated risk for the plant, $R$ (base). However, this total risk may be very small, especially for advanced non-LWR designs. Indeed, PRAs for evolutionary LWRs have produced estimates of CDF and LERF that are as much as several orders of magnitude lower than those estimated for operating plants. For advanced non-LWR plants, the frequencies of accidents involving a release of radioactive material may be very small and even those accidents with releases may involve very small source terms compared with releases from an LWR core damage accident. In order to take into account the importance of risk contributors in the context of a fixed level of acceptable risk, absolute risk metrics are used in the LMP methodology. Hence, it is appropriate to evaluate risk significance not only on a relative but also on an absolute basis.

For this purpose, the risks can be compared against the risk goals rather than the baseline risks. One example of the use of absolute risk metrics is the approach to defining risk significance LBEs as illustrated in Figure 3-7. Another example is that identified in the LMP SSC report for establishing the risk significance of SSCs. For this metric, SSCs are risk significant if any of the following criteria are met:

- A prevention or mitigation function of the SSC is necessary to meet the design objective of keeping all LBEs within the F-C target. This is determined by assuming failure of the $\mathrm{SSC}$ in performing and prevention or mitigation function and checking on how the resulting LBE risks compare with the F-C target. The LBE is considered within the F-C target when a point defined by the upper $95 \%$-tile uncertainty of the LBE frequency and dose estimates are within the F-C target.

- The SSC makes a significant contribution to one of the cumulative risk metrics used for evaluating the risk significance of LBEs. A significant contribution to each cumulative risk metric limit is satisfied when total frequency of all LBEs with failure of the SSC exceeds $1 \%$ of the cumulative risk metric limit. ${ }^{*}$ The cumulative risk metrics and limits include:

\footnotetext{
* This evaluation of SSC risk significance requires the aggregation of all the LBEs in which any basic event in the PRA model associated with the SSC is failed. There are normally different basic events for different SSC failure modes (e.g. failure to start, failure to run), unavailability for test or maintenance, or a common cause basic event involving that SSC. When the total frequency of LBEs with all the basic events associated with the SSC exceeds the $1 \%$ criterion, the SSC is regarded as risk significant according to these criteria.
} 
0 The total frequency of exceeding of a site boundary dose of $100 \mathrm{mrem}<1$ /plantyear (10 CFR 20)

- The average individual risk of early fatality within 1 mile of the Exclusion Area Boundary $(\mathrm{EAB})<5 \times 10^{-7} /$ plant-year $(\mathrm{QHO})$

- The average individual risk of latent cancer fatalities within 10 miles of the EAB shall not exceed $2 \times 10^{-6} /$ plant-year $(\mathrm{QHO})$

This topic is under discussion for the next edition of the Advanced Non-LWR PRA Standard.

\subsection{Example PRA Development for Modular HTGRs}

This section summarizes how the technology-inclusive approach to developing a PRA model for advanced non-LWRs is implemented for mHTGR designs of the type supported by the ANS Standard 53.1. ${ }^{[49]}$ The objective is not to present an actual PRA but to show examples of PRA model elements for HTGR designs, such as the MHTGR, whose design is described in Reference [42] and whose supporting PRA is documented in Reference [8]. The PRA model elements presented in this section are representative of other modular HTGRs such as the Exelon PBMR and the NGNP HTGR. This example develops PRA model elements for a plant comprised of four reactor modules and includes both single module and multi-module accidents. Accident sequences involving non-core sources of radioactive material are not included in this example.

The key characteristics of these modular HTGR designs include:

- Graphite moderated and helium cooled

- Ceramic coated particle fuel with robust radionuclide retention capabilities over the full range of operating and accident conditions

- Fuel elements arranged into compacts inserted into graphite blocks or graphite fuel spheres

- Strong negative temperature coefficient of reactivity

- Passive decay heat removal capability in pressurized and depressurized conditions

- Concentric barriers to radionuclide release including the fuel, helium pressure boundary (HPB), and vented reactor building

\subsubsection{Systematic Search for HTGR Initiating Events}

As noted in Figure 3-4, the PRA model development begins with a systematic search for IEs for which event sequences need to be defined. A logic model for guiding this search is often referred to as a Master Logic Diagram (MLD). The form of the MLD used to guide IE development for the MHTGR is shown in Figure 3-8. The MLD process starts with the identification of the sources of radioactive material, barriers to fission product release, safety functions that protect each barrier, and initial plant operating states. 


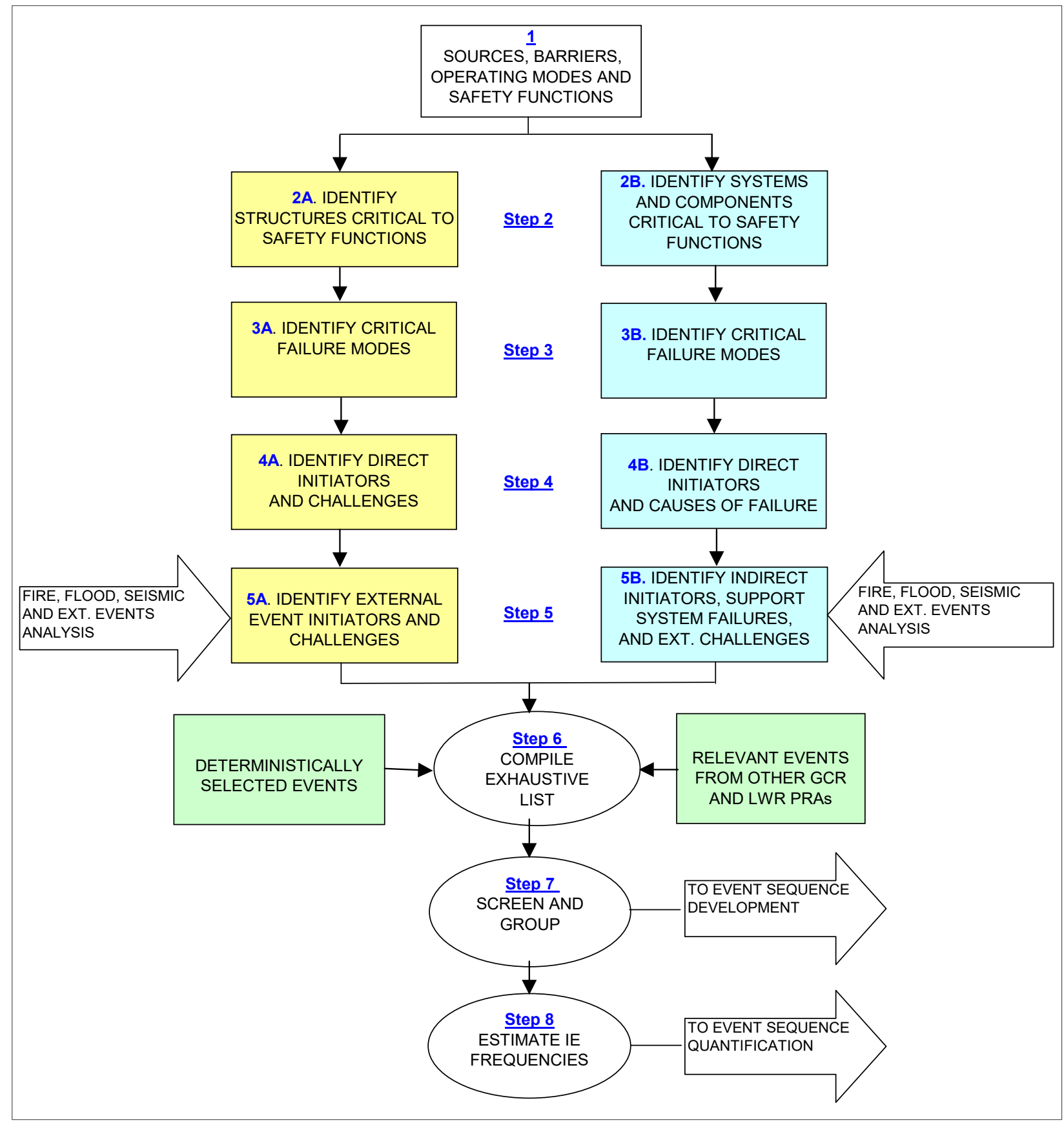

Figure 3-8. Master Logic Diagram Guiding the Steps to Selection of MHTGR Initiating Events

The following sources of radioactive material are considered for the MHTGR:

- Sources within the primary system HPB:

- Fuel elements in core

- Intact coated particles

- Failed or defective coated particles 

- Uranium contamination outside coated particles
○ Sources imbedded/attached to graphite components
- Dust and plateout on HPB surfaces
○ Circulating primary coolant activity

- Sources outside the HPB:
○ Fuel elements in storage systems
○ Helium Purification System (HPS) gas-borne activity
○ Solid and liquid radwaste systems

Table 3-2 summarizes the principal barriers to each of these sources. Once the sources, barriers, and safety functions are defined, the Master Logic Diagram follows a step-by-step process of defining the failure modes of each SSC, the impacts of these modes in challenging the barriers and safety functions, and of identifying direct IEs, as well as challenges posed by internal and external hazards. Two separate paths are followed through these steps in Figure 3-8: one from the viewpoint of each barrier and its set of challenges, and the other from the viewpoint of the SSCs providing safety functions in support of these barriers. The former may be viewed as direct challenges to the integrity of the barriers and the latter as indirect challenges to the barriers.

Table 3-2. MHTGR Radionuclide Sources and Barriers

\begin{tabular}{|c|c|}
\hline $\begin{array}{l}\text { Radioactive } \\
\text { Material Source }\end{array}$ & Barriers to Radionuclide Transport \\
\hline $\begin{array}{l}\text { Fuel elements in } \\
\text { the core }\end{array}$ & $\begin{array}{l}\text { Fuel particle kernel, silicon carbide and pyrocarbon coatings of the fuel } \\
\text { particle, fuel matrix and fuel element graphite, HPB (primary circuit), reactor } \\
\text { building }\end{array}$ \\
\hline $\begin{array}{l}\text { Fuel elements } \\
\text { outside the core }\end{array}$ & $\begin{array}{l}\text { Fuel particle kernel, silicon carbide and pyrocarbon coatings of the fuel } \\
\text { particle, fuel matrix and fuel element graphite, fuel handling and storage } \\
\text { systems, reactor building }\end{array}$ \\
\hline $\begin{array}{l}\text { Non-core sources } \\
\text { within the HPB }\end{array}$ & HPB, reactor building \\
\hline $\begin{array}{l}\text { Other sources } \\
\text { within the plant }\end{array}$ & $\begin{array}{l}\text { Various tanks, piping systems and containers, reactor building or ancillary } \\
\text { buildings housing waste management equipment }\end{array}$ \\
\hline
\end{tabular}

An initial screening is performed for all SSCs in the plant, including the radionuclide transport barriers for SSCs that play no direct or indirect role in supporting a PRA safety function and whose failure does not impact the PRA safety functions of other SSCs or cause an IE are screened out. Failure modes and effects analyses are performed for all unscreened SSCs and radionuclide transport barriers to identify potential internal IEs. An analysis of internal and external plant hazards (including those from co-located facilities) is performed to encompass the remaining challenges to the plant PRA safety functions. These processes ensure that events 
specific to the MHTGR design are considered. Insights from reviews of nuclear plant operating experience and previous safety and risk analyses are used to ensure completeness of the exhaustive list of events. In the design and licensing of the MHTGR facility, the systematic selection of IEs is viewed as common to both the probabilistic and deterministic elements of the safety analysis approach. This fact is important to understand the way in which deterministic and probabilistic elements have been integrated into the MHTGR design, which is the key advantage of applying PRA technology in the beginning.

\subsubsection{MHTGR PRA Safety Functions}

The MHTGR PRA includes a set of reactor-specific PRA safety functions and define the SSCs available or potentially available to perform these PRA safety functions. This section describes the basis for defining the PRA safety functions modeled in the MHTGR PRA and selecting the SSCs to be modeled in the performance of these PRA safety functions.

As noted previously, the scope of SSCs to be included in the PRA includes all SSCs that perform either a required or supportive safety function for the radionuclide sources and barriers in the scope of the PRA. Since the PRA is performed initially, prior to the safety classification of SSCs, it is not initially known which modeled SSCs will perform a required safety function and of those which will be relied on in the Chapter 15 safety analyses.

The exhaustive set of IEs determined in Step 6 (Figure 3-8) is grouped according to the nature of the challenges to PRA safety functions. PRA safety functions have been defined in the context of a top-down logical structure starting with the high-level function of controlling the transport of radionuclides. Such transport is fundamentally controlled in the safety design approach by preserving the integrity of the radionuclide transport barriers identified in Table 3-2.

\subsubsection{MHTGR PRA safety functions and Supporting SSCs}

Both inherent and engineered (other than inherent) safety features and SSCs are included in the design to perform the PRA safety functions. The inherent features are the characteristics that are the direct consequence of the selection of materials and design features of the reactor fuel and core, moderator (for thermal reactor designs), and coolant. Engineered safety features are those introduced specifically to perform a PRA safety function, and they may include both passive and active SSCs.

Consistent with good PRA practice, the safety functions modeled in the PRA include those required to meet the required safety functions, as well as SSCs included to meet availability and investment protection needs and serve DID roles by preventing and mitigating challenges to barriers and SSCs performing the required safety functions. The MHTGR safety design philosophy uses inherent safety features and passive SSCs to perform the required safety functions. Active SSCs are also provided for supportive safety functions as well as to meet plant investment protection and availability performance requirements. SSCs that serve both required and supportive safety functions are included in the PRA in order to capture a sufficiently complete set of safety function challenges and associated event sequences and to apply the principle of realistic PRA success criteria. 
The process of using PRA safety functions to develop the event sequences is fundamentally the same process as used in LWR PRAs. The need to model both safety and non-safety classified SSCs is also no different; only the functions and SSCs differ. Once the differences in PRA safety functions and the SSCs that provide these functions are understood, the capability to review the PRA event sequence model is achieved.

The PRA safety functions for the MHTGR, which are representative of all known modular HTGR designs include:

- Maintain control of radionuclides

- Maintain control within fuel barriers

○ Maintain control within HPB

○ Maintain control within reactor building

- Control heat generation (reactivity)

- Control heat removal

- Control chemical attack

- Maintain core and reactor vessel geometry

A summary of the inherent features and passive SSCs along with the active SSCs that support or provide DID for the PRA safety functions for an HTGR is provided in Table 3-3. The table shows design features representative of those under consideration for the NGNP. This indicates the types and scope of SSCs that would be modeled in the NGNP PRA. Each HTGR module includes one primary loop with a steam generator and a conventional steam turbine generator. It has a steam generator isolation and dump system to minimize water ingress to the primary following a steam generator tube failure and resides in a vented leak-controlled reactor building with a recirculation filter heating, ventilation, and air-conditioning (HVAC) system. 
Table 3-3. Major SSCs Modeled in the Example NGNP HTGR PRA

\begin{tabular}{|c|c|c|}
\hline $\begin{array}{l}\text { Safety } \\
\text { Function }\end{array}$ & Inherent Features and Passive SSCs & Active SSCs* \\
\hline $\begin{array}{l}\text { Control } \\
\text { Radio- } \\
\text { nuclides }\end{array}$ & $\begin{array}{l}\text { - Fuel barrier } \\
\text { - Fuel particle kernel } \\
\text { - Silicon carbide and pyrocarbon coatings of } \\
\text { fuel particle } \\
\text { - Fuel matrix and fuel element graphite } \\
\text { - HPB barrier } \\
\text { - Reactor building barrier } \\
\text { - Retention capabilities of reactor building } \\
\text { - Reactor building pressure relief vents }\end{array}$ & $\begin{array}{l}\text { - Primary system safety relief valves } \\
\text { - Reactor building dampers (reclosure) } \\
\text { - Reactor building HVAC filtration system } \\
\text { - Steam generator isolation and dump } \\
\text { system isolation valves }\end{array}$ \\
\hline $\begin{array}{l}\text { Control } \\
\text { Heat } \\
\text { Generation }\end{array}$ & $\begin{array}{l}\text { - Strong negative temperature coefficient of } \\
\text { reactivity } \\
\text { - Gravity fall of control rods and reserve } \\
\text { shutdown system absorber material }\end{array}$ & $\begin{array}{l}\text { - Control and protection systems } \\
\text { - Operational control systems } \\
\text { - Investment protection system } \\
\text { - Reactor Protection System } \\
\text { - Reactivity control systems } \\
\text { - Trip release of control rod drives } \\
\text { - Reserve shutdown system release of } \\
\text { absorber material }\end{array}$ \\
\hline $\begin{array}{l}\text { Control } \\
\text { Heat } \\
\text { Removal }\end{array}$ & $\begin{array}{l}\text { - Large thermal heat capacity } \\
\text { - Passive core heat removal } \\
\text { - Core size, power density, geometry } \\
\text { - Core, uninsulated reactor vessel, and reactor } \\
\text { cavity configuration } \\
\text { - Passive Reactor Cavity Cooling System (RCCS) } \\
\text { - Reactor building pressure relief vents }\end{array}$ & $\begin{array}{l}\text { - Main Loop cooling systems via: } \\
\text { - Electric power conversion system } \\
\text { - Process steam system } \\
\text { - Shutdown cooling system }\end{array}$ \\
\hline $\begin{array}{l}\text { Control } \\
\text { Chemical } \\
\text { Attack }\end{array}$ & $\begin{array}{l}\text { - HPB high reliability piping and pressure vessels } \\
\text { - HPB design minimize penetrations in top of } \\
\text { reactor vessel } \\
\text { - High purity specifications for inert helium } \\
\text { coolant } \\
\text { - Primary system safety valves } \\
\text { - Reactor building pressure relief vents }\end{array}$ & $\begin{array}{l}\text { - Reactor building vent dampers limit air } \\
\text { ingress } \\
\text { - Isolation valves in primary interfacing } \\
\text { systems } \\
\text { - HPS maintains high purity levels of } \\
\text { helium coolant } \\
\text { - Steam generator isolation and dump } \\
\text { system }\end{array}$ \\
\hline $\begin{array}{l}\text { Maintain } \\
\text { Core and } \\
\text { Reactor } \\
\text { Vessel } \\
\text { Geometry }\end{array}$ & $\begin{array}{l}\text { - Reactor core and structures } \\
\text { - Reactor pressure vessel and structures } \\
\text { - Passive RCCS maintains integrity of structures } \\
\text { - Reactor building structure }\end{array}$ & - None \\
\hline
\end{tabular}

* Not shown in this table are support systems such as electric power systems, instrument and service air systems, and some of the man-machine interface systems. 
Functional IE categories are defined by the nature of the challenge to safety functions. These categories are used to decide which different event sequence models need to be developed. The following list presents representative examples (not considered exhaustive) of functional IE categories being considered for the advanced non-LWR PRA for the sources of radioactive material inside the reactor vessel and the primary system pressure boundary:

- Plant transients with intact primary system HPB:

○ Main Loop and Shutdown Cooling System (SCS), still capable of forced cooling operation

- Main Loop system failed, SCS still capable of operation

- SCS failed, Main Loop system still capable of operation

○ Main Loop and SCS not capable of operation

- Energy conversion system transients with intact HPB and reactivity addition:

- Control rod or group withdrawal

- Overcooling transients

- Primary system HPB leaks and breaks:

○ HPB failures resulting in slow depressurization

- HPB failures resulting in rapid depressurization

- HPB heat exchanger failures:

○ Steam generator tube leak

- Steam generator tube rupture

- SCS heat exchanger failure

Each of the above categories represents a unique challenge to the MHTGR required and supportive safety functions. These categories are used as a starting point for the development of event sequence models as described below.

Specific IEs or causes of IEs for each of the above categories can be defined having the same functional challenge to the PRA safety functions. For example, one cause of a transient with the Main Loop system failed and the SCS still capable of operation (if the onsite diesel generator successfully starts) is a loss of offsite power. An example of a transient with the Main Loop and SCS still capable of operation is a Power Turbine Generator trip. Seismic events that do not cause a breach of the HPB are classified as power conversion system transients, while those that do are included in the HPB leaks and breaks category. To meet the requirements in the Advanced non-LWR PRA Standard, the comprehensive treatment of IEs and how they are dispositioned by screening and grouping will be documented according to applicable PRA guides and standards. 


\subsubsection{Development of Event Sequence Models}

Once functional categories of the IEs are established, event sequence diagrams and event trees are developed to define event sequences resulting from each IE and initial condition to be modeled. The event trees will be quantified for each specific IE in each functional IE category in order to account for significant dependencies between the causes of the IE and the modeled SSC failure probabilities. The event tree top events will be derived in consideration of the SSCs provided to support each of the PRA safety functions. The event sequences define the possible successes and failures of each SSC to implement each PRA safety function to a sufficient extent to determine the event sequence end-states.

The treatment of operator actions in the modeling and quantification of event sequences follows the same process as for LWR PRAs. The following are the major differences in human reliability analysis (HRA) treatment in the modular HTGR PRA:

- Because of the safety design approach of the modular HTGR, there are few operator actions that must be fulfilled to achieve a safe, stable end-state to an event sequence.

- In general, the time windows available to implement the operator actions in the PRA model are very long. The application of existing HRA techniques that recognize the dependence of the human error rate on the time window may result in human error rates that are too small to be verifiable or appear credible. This is expected to result in a conservative treatment of human error rates in relation to that which would be considered realistic. It should not be viewed as a problem for the HTGR PRA because the PRA results are not that sensitive to the assumed human error rates and most of the important PRA safety functions are fulfilled without need for time critical operator actions. Hence, the use of conservative human error rates is not expected to mask risk insights.

- Since there is less experience in performing HRA in PRAs for reactors such as the HTGR, it is expected that the uncertainties in the human error rates will be larger than found in typical LWR PRAs. For the same reasons cited above regarding the use of conservative human error rates, the assignment of large uncertainties should not be viewed to adversely impact the PRA results or their use in selecting LBEs.

- Because the PRA provides input in the selection of LBEs and the greater reliance on inherent and passive means to fulfill PRA safety functions in the HTGR, there will be increased emphasis on the treatment of human errors of commission in the HTGR PRA.

- At the early design stage versions of the PRA, many of the details of the emergency operating procedures, man-machine interface, and human factors engineering model will be unknown. This will be taken into account in the human error rate uncertainty analysis and will tend to increase the uncertainties. As noted above, this is not expected to cause a problem in terms of masking risk insights or adversely impacting the capability of the PRA to support LBE selection.

Figure 3-9 depicts the event sequence modeling framework for the advanced non-LWR. This framework includes the following elements: 
- IE in the context of a plant operating state

- Plant response to IE

- Response of the reactor building and associated SSCs

- Factors influencing the end-state, including achievement of success criteria and mechanistic source terms

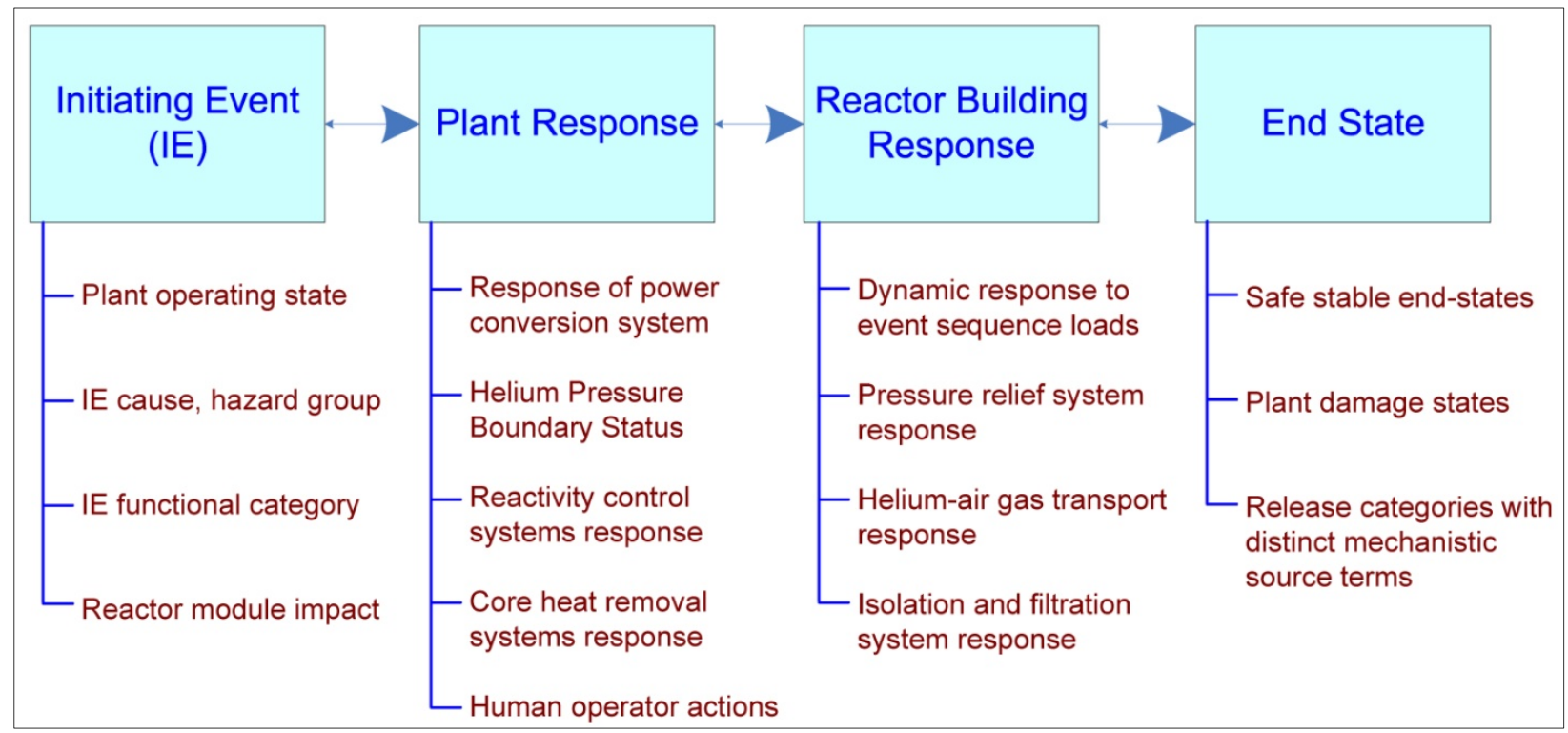

Figure 3-9. Event Sequence Modeling Framework for a Modular HTGR PRA

The causes of the IEs depicted in Figure 3-9 include internal plant hardware failures, human errors, internal plant hazards such as fires and floods, and external hazards such as seismic events and transportation accidents. The responses of the plant and reactor building functions include the responses of SSCs and the human operators that are involved in the performance of or failure to perform each function. Human responses include favorable or unfavorable acts and errors of omission and commission.

Using the high-level logic of Figure 3-9, the framework for developing the event sequences for an HTGR includes the following elements:

- Definition of initial plant conditions

- IE

- Cause of the IE

- IE functional category

- Reactor module impact (single versus multiple modules)

- Response of the systems for reactivity control 
- Response of primary circulators to IE

- Status of the Helium Pressure Boundary including any mitigating actions

- Response of the core heat removal systems

- Core oxidation status

- Status of fuel in each affected module

- Response of the reactor building(s)

- Early response to IE

- Long term response including mitigating actions

- Source term characteristics for each affected module

\subsubsection{Event Sequence End States for Modular HTGR PRA}

The thought process used to apply this framework in the development of the event sequence diagrams (ESDs) and event trees for each IE is to ask sufficient questions to resolve the end states of each sequence. These end states start with the states that define the safe termination of the event with no damage or release beyond that which is consequential to the IE and include all the possible plant damage states and states of radioactive release. In previous HTGR PRAs, an end state coding scheme was developed to capture all the factors that characterize a unique modular HTGR end state.

The coding scheme in Figure 3-10 was developed for previous modular HTGR PRAs including the PBMR PRA in South Africa and serves as a starting point for future HTGR PRA end states. Each end state code is defined by three capital letters and one or more small letters. The first letter defines the status of the primary HPB at the end of the accident sequence, the second defines the response of the reactor building (RB) and associated SSCs, and the third letter defines the components of the radioactive release source term from the plant site, if the sequence has a release. Small letters at the end are source term modifiers. These source term end states codes facilitate grouping of event sequences having the same or similar consequences which is important because the event trees will eventually capture hundreds to thousands of event sequences. 


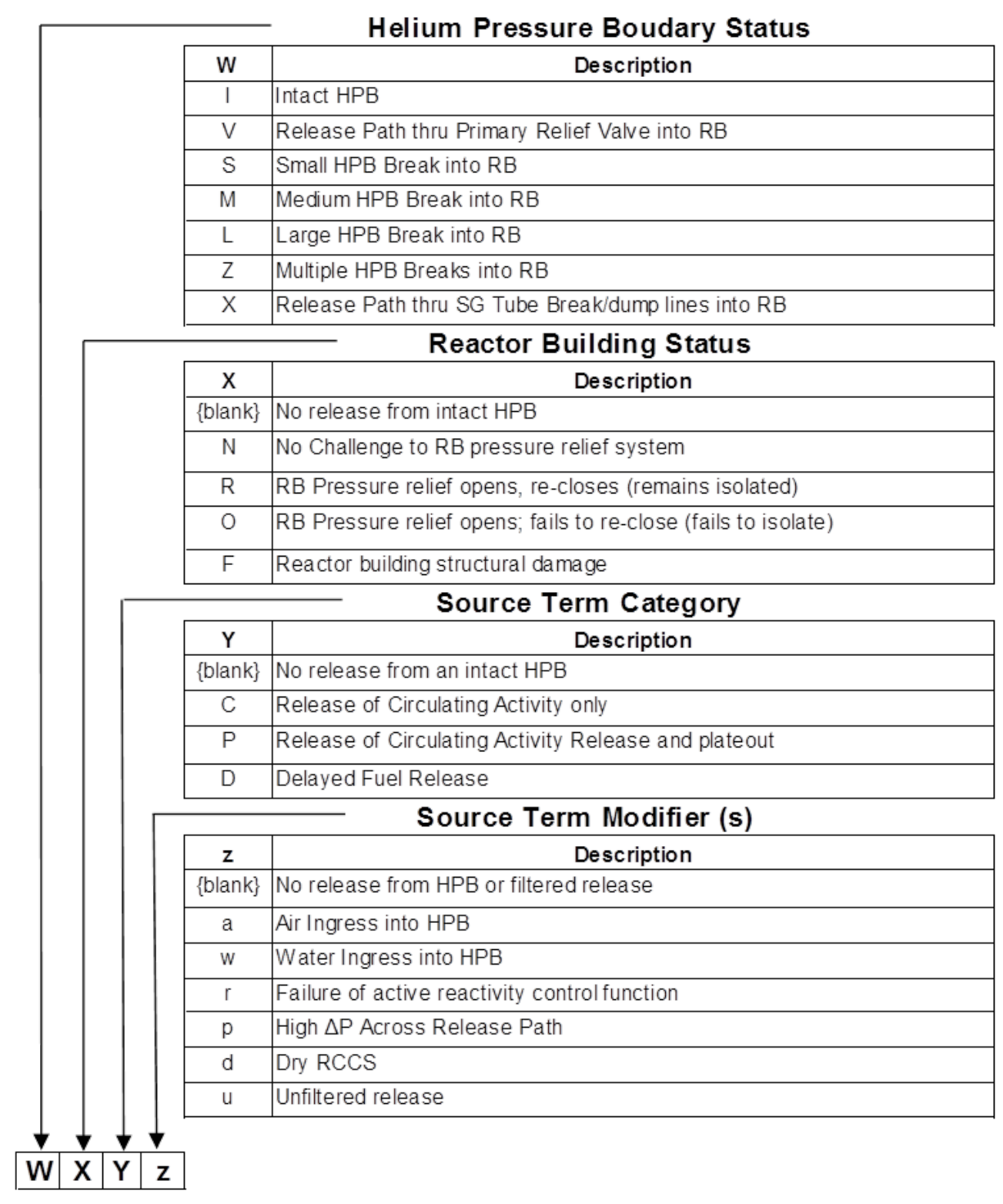

Figure 3-10. End State Codes for HTGR Event Sequences

\subsubsection{LBEs as Event Sequence Families}

In selecting LBEs, event sequence families are used to group together two or more event sequences when the sequences have a common IE, safety function response, and end-state. The process of defining event sequence families applies the following considerations:

- The guiding principle is to aggregate event sequences to the maximum extent possible while preserving the functional impacts of the IE, safety function responses, and end-state. The end-state for a multi-module plant includes the number of reactor modules involved in any releases for the event sequence. 
- The PRA safety function responses are delineated to a necessary and sufficient degree to identify unique challenges to each SSC that performs a given PRA safety function along the event sequence. Event sequences with similar but not identical PRA safety function responses are not combined when such combination would mask the definition of unique challenges to the SSCs that perform PRA safety functions.

- In many cases for a single module plant, there may be only one event sequence in the family.

- For a multi-module plant, event sequence families are used to combine event sequences that involve individual reactor modules independently into a single family of single reactor module event sequences. In this case, the individual event sequences are associated with a specific reactor module and the family groups them together for the entire multi-module plant.

- Each event tree IE and PRA safety function response has a corresponding fault tree that delineates the event causes and SSC failure modes that contribute to the frequencies and probabilities of these events. Hence each event sequence is already a family of event sequences when the information in the fault trees is taken into account.

- The frequency of the LBE defined by the accident family is the linear sum of the individual event sequence frequencies. The frequency units are events per plant-year. This provides a common frequency basis to compare and combine different types of sequences involving different numbers of reactor modules, and different plant operating states.

Without the use of event sequence families, the level of detail in the definition of the IE categories and decisions to balance the level of detail between the event trees and fault trees may inadvertently impact the classification of an individual event sequence as an AOO, DBE, or BDBE. By aggregating the sequences into the event sequence families, the decisions made in structuring the event sequence model do not impact the LBE classification. A discussion of how event sequence families are used to define LBEs is provided in the LBE selection report.

\subsubsection{Example Modular HTGR Event Sequence Model for Slow Depressurization Event}

The purpose of this section is to present an example of the event sequence development for one IE that is common to all modular HTGR designs. The event sequence development example includes a definition of the IE, the development of an event sequence diagram, and an event tree which quantifies the event sequence frequencies, assignment of end states, and a classification into LBE categories. This is an example of a PRA model that was developed in an early stage of the conceptual design of a modular HTGR and is provided to show the level of detail of an early stage PRA that is sufficient to develop an initial set of LBEs.

\subsubsection{Definition of Initiating Event}

The IE for this example is defined as a small depressurization event on one and only one HTGR module. This event is a leak or breach in the primary system HPB with an equivalent break size up to $10 \mathrm{~mm}$ diameter. Such an event, if not isolated, would result in a slow depressurization of the primary system so that if forced circulation cooling is lost there would still be a positive 
pressure in the primary system when peak core temperatures are reached during a depressurized condition cooldown. This event has a relatively high frequency of occurrence. Possible causes include leaks or breaks in HPB piping or welds connecting pipes and vessels in the primary system pressure boundary. It would be expected that the module could be restarted and return to power once the breach is corrected, however a relatively long outage may be needed to repair the affected component.

\subsubsection{Safety Design Mitigation Strategy}

It is assumed in the development of the event sequences for this event that the HTGR will be designed to implement the following event mitigation strategy. This strategy is developed through collaboration between the design team and the PRA team.

- Some parts of the active HPB, such as Helium Purification System piping, have isolation valves that can be closed to terminate the leak, depending on the location of the leak relative to the isolation valves. It is assumed in the initial PRA development that there will be means to detect the leak and isolate it via automatic or manual action. Risk insights from the initial PRA development for this event will assist the design team to incorporate capabilities in the design to detect and isolate leaks.

- For very slow leaks and rates of depressurization, there should be a means of pumping down the system to reduce the system pressure in the event there is a loss of forced cooling. Risk insights from this initial PRA development will help the designers evaluate and decide on the helium pump down capabilities.

- The reactor will be shutdown to reduce heat generation either by operator action or reactor trip via Investment Protection System (IPS) or Reactor Protection System (RPS).

- Forced cooling of the affected reactor can be maintained by the Main Heat Transport System or Startup/Shutdown (SU/SD) System until the system is fully cooled down and depressurized.

- If forced cooling cannot be established, passive cooling via the RCCS will be provided until forced cooling and module restart is affected.

- An RB HVAC system can be used to reduce the environmental release source term. While such a system may not be necessary, it is included in the sequence development to support future RB design options studies.

\subsubsection{Key Assumptions Regarding Plant Response and SSC Capabilities}

The following assumptions are made to support event sequence development during the conceptual design and will be replaced by appropriate analyses as the design matures.

- The plant control systems will be designed so that expected plant transients such as slow depressurization on one module do not disturb or adversely affect operation of the remaining modules. 
- The rate of depressurization for this category of small leaks is insufficient to challenge the reactor building pressure relief system; however, an RB HVAC system can be used to filter any releases to the environment.

- Although the response of the reactivity control systems is identified in the sequence development, due to the negative temperature coefficient, the reactor power will always match the core heat removal; hence, failure to trip the reactor has little if any impact on the resulting end state.

\subsubsection{Event Sequence Diagram Development}

The first step in the development of the event sequence model for slow or small depressurization is to develop an ESD, which is often used in a PRA as a precursor to an event tree development. The ESD symbols used in this example are shown in Figure 3-11, and the acronyms used in the ESD and event tree are defined in Table 3-4.

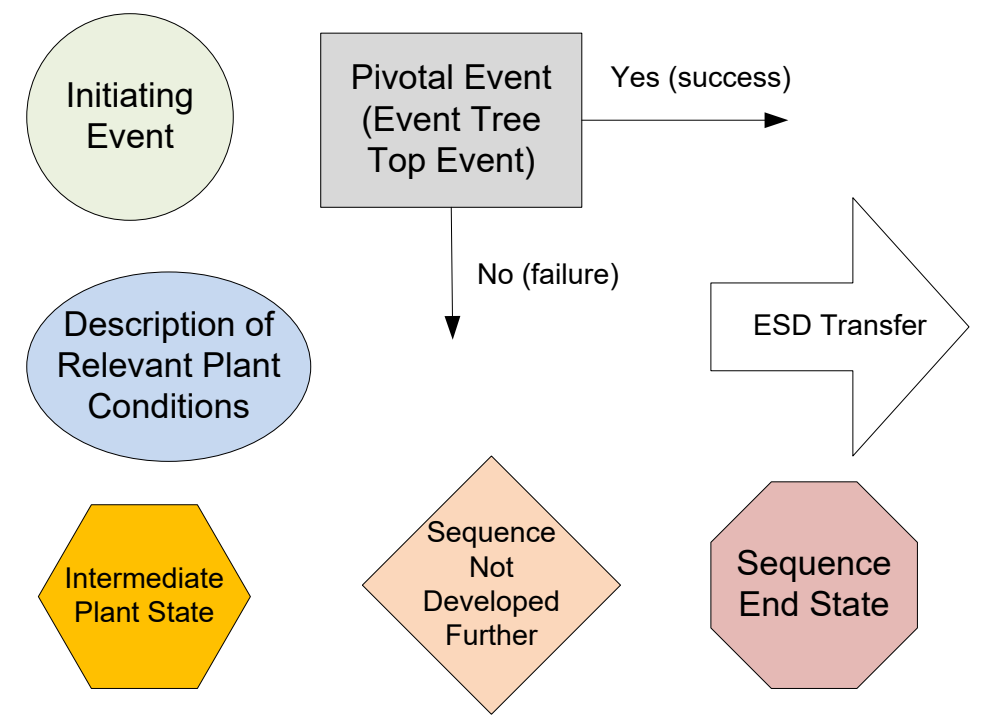

Figure 3-11. Event Sequence Diagram Symbols

Table 3-4. Acronyms Used in ESD

CA-Circulating primary coolant activity

CC-Conduction cool down (RCCS works)

CG-Conduction to ground (RCCS fails)

DCC-Depressurized conduction cool down (RCCS works)

DCG-Depressurized conduction to ground (RCCS fails)

D(LO)FC-Depressurized (Loss of) forced circulation

cooling

FC-Forced circulation cooling

HPB-PHTS Helium Pressure Boundary

MLTP-heat transport path via ML

ML-Main Loop Heat Transport System

IPS-Investment Protection System

OCS-Operational Plant Control System
PCC-Pressurized conduction cooling (RCCS works)

PCG-Pressurized conduction to ground (RCCS fails)

PFC-Pressurized forced cooling

RCCS-Reactor Cavity Cooling System

RCTP-Heat transport path via RCCS

RPS-Reactor Protection System

RSS-Reserve Shutdown System

RTF-Reactor Trip Failure Transient

SCP-Heat transport path via SU/SD System

SDG-Standby Diesel Generator

SCS-Shutdown Cooling System

SG-Steam Generator

SV-Primary Heat Transport System Safety Valve 
Figure 3-12 and Figure 3-13 provide the ESD for the small or slow depressurization event for the HTGR. If the leak is successfully isolated in Event 2, the Operational Plant Control System (OCS) is designed to maintain power operation with a minor increase in normal leakage, and the sequence successfully terminates. With failure to isolate in Event 2, there is a slow depressurization of the reactor and signals to trip the reactor from the IPS and RPS at different setpoints for high radiation in the reactor building or low system pressure. The automatic trip functions modeled in Events $4 \mathrm{a}$ and $4 \mathrm{~b}$ are backed up by manual actions to trip the reactor in Event $4 \mathrm{c}$. If the control rods are not inserted, the reactor power will follow the core heat removal rate. In Events 5 and 6, consideration is given as to whether forced circulation cooling is maintained using either the Main Loops (MLs) or SCS. For modular HTGRs, when forced cooling is maintained the only source term available for release to the reactor building is the circulating activity that exists in normal operation. In the event that forced cooling is not maintained, there will be small delayed fuel release source term which will occur when peak core temperatures are reached more than 24 hours after the IE. The release of this delayed fuel release to the reactor building can be mitigated by pumping down the HPB which reduces the pressure driving force to expel radionuclides out the break into the RB. On Page 2 (Figure 3-13) of the ESD, the responses of the RCCS and the reactor building HVAC systems are considered which response will modify the magnitude of the source term from the reactor building. 
Modernization of Technical Requirements for Licensing of Advanced Non-Light Water Reactors: Probabilistic Risk Assessment Approach

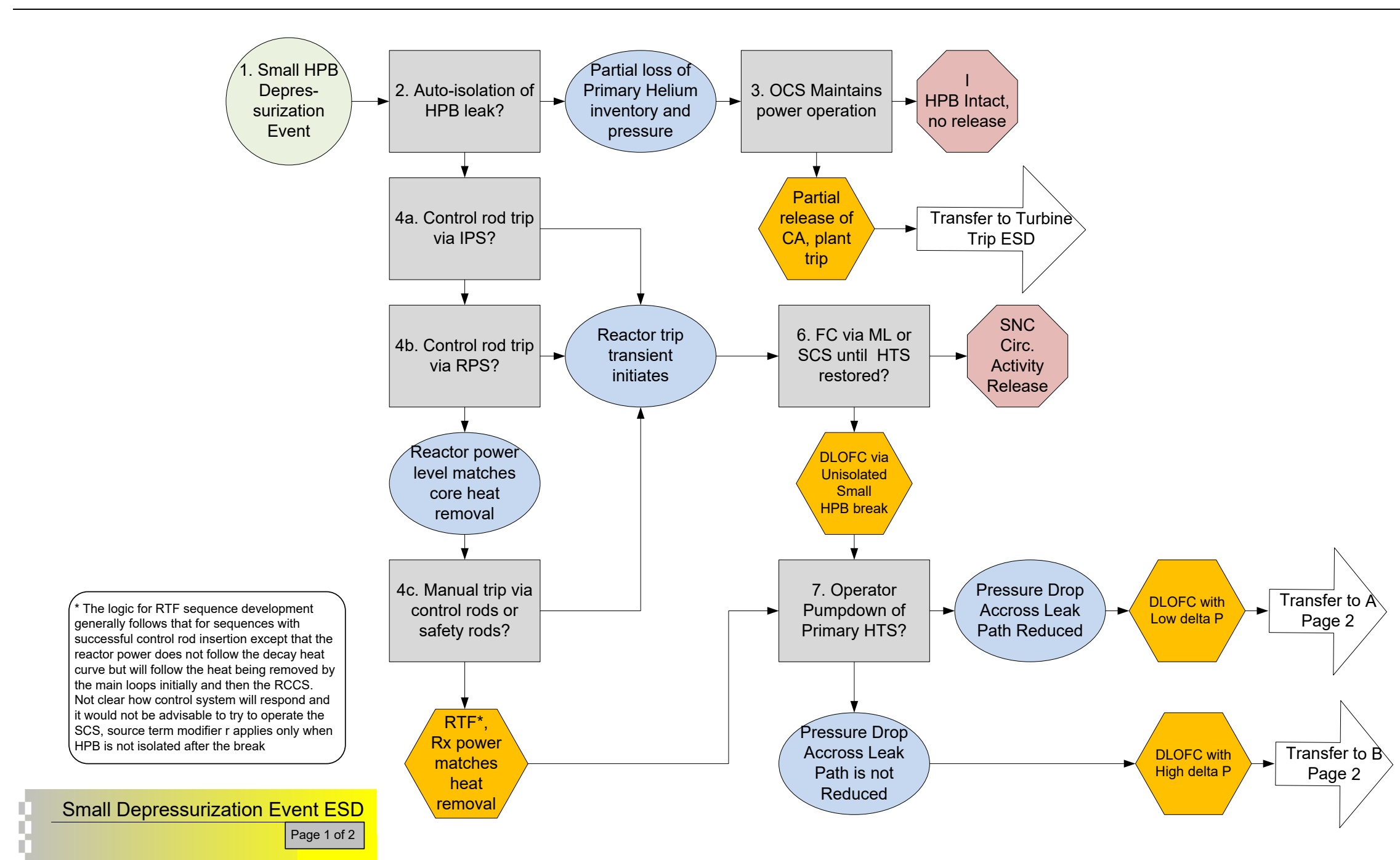

Figure 3-12. Event Sequence Diagram for HTGR Small (Slow) Depressurization Event (Page 1 of 2) 
Modernization of Technical Requirements for Licensing of Advanced Non-Light Water Reactors: Probabilistic Risk Assessment Approach

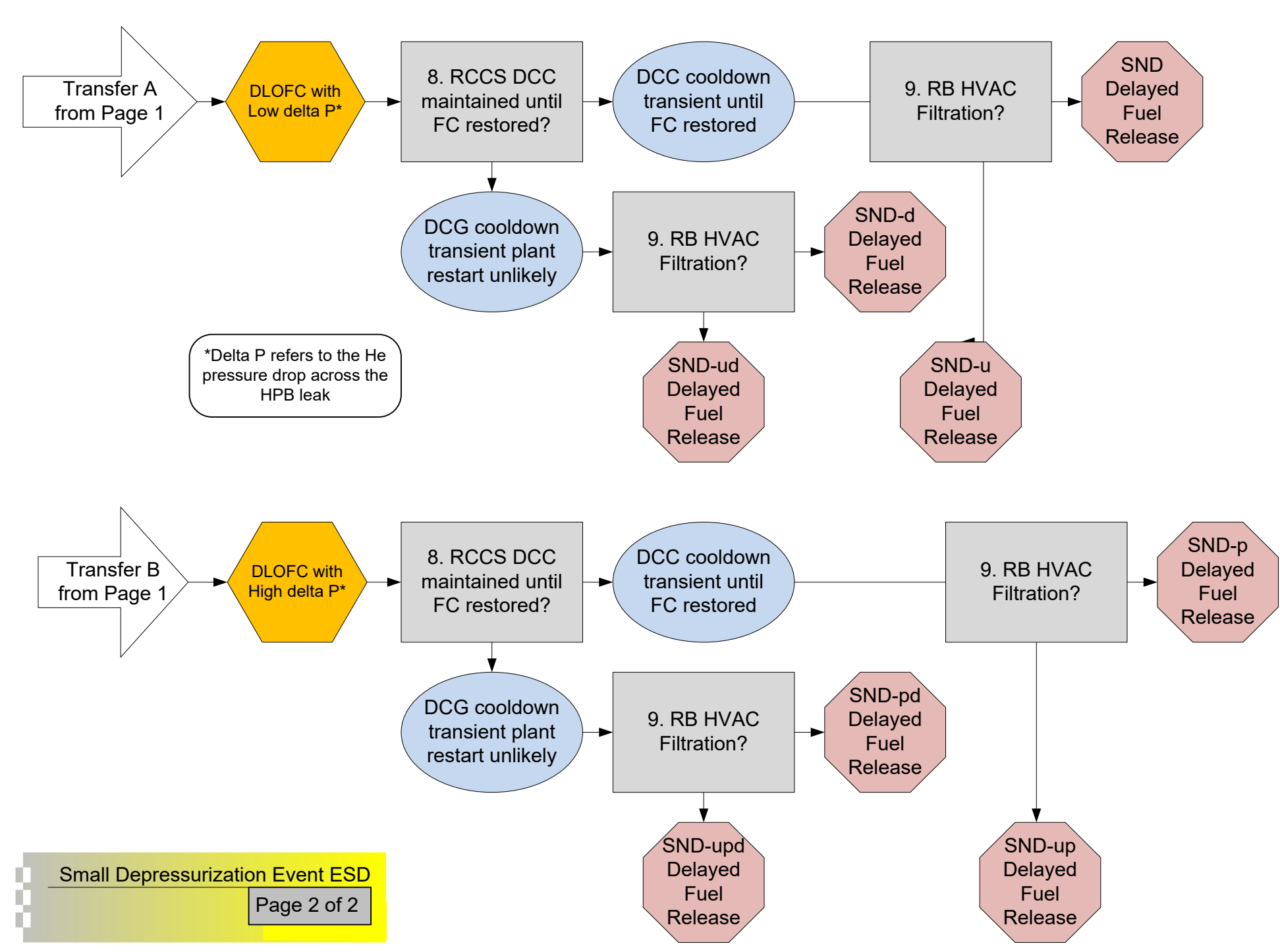

Figure 3-13. Event Sequence Diagram for HTGR Small (Slow) Depressurization Event (Page 2 of 2) 
The event tree for this small depressurization IE is shown in Figure 3-14. This event tree example was developed at an early stage in the conceptual design. The quantification of the event tree sequences was made using engineering judgments that were sufficient to obtain order of magnitude estimates. As the design matures, these estimates will be replaced with appropriately detailed system fault tree models and human reliability analyses, and data analyses sufficient to meet PRA standard requirements. However, these estimates provide insights to the design in the form of a preliminary list of LBEs. Table 3-5 lists the preliminary LBEs developed using this example.

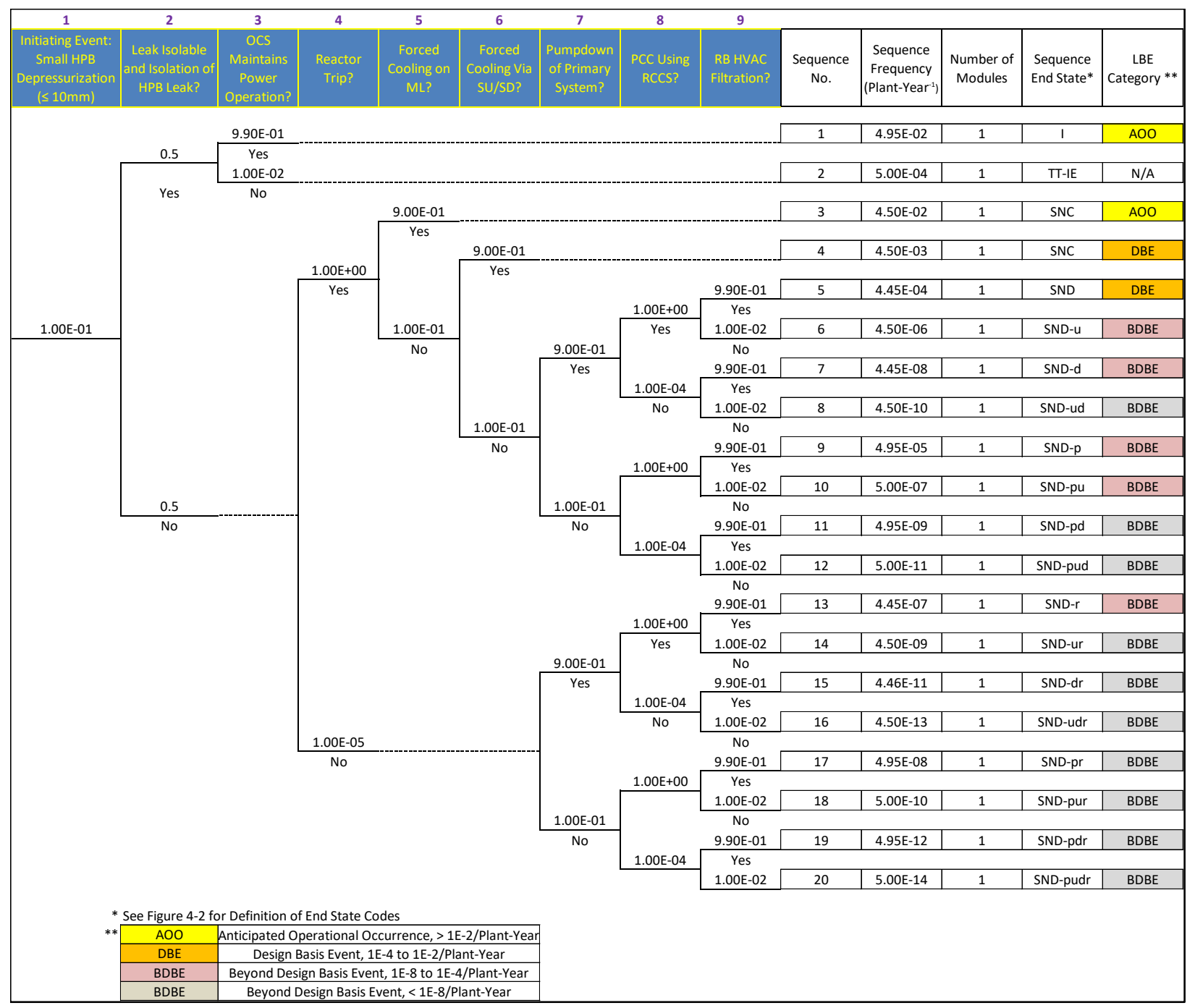

Figure 3-14. Event Tree for HTGR Small (Slow) Depressurization Event

An example of a more detailed PRA based on the conceptual design of the MHTGR is found in Reference [8]. The results of that PRA are used to illustrate the LMP approach of selecting and evaluating LBEs in Reference [3]. 
Table 3-5. LBEs for Small Depressurization Initiating Event in a Modular HTGR

\begin{tabular}{|c|c|c|c|c|}
\hline LBE No. & LBE Type & Plant Response & $\begin{array}{l}\text { Frequency, } \\
\text { Plant-Year }\end{array}$ & End State \\
\hline SD-1 & AOO & Leak isolated, OCS maintains power operation & 4.95E-02 & 1 \\
\hline SD-3 & $\mathrm{AOO}$ & $\begin{array}{l}\text { Fail to isolate leak, reactor trip, forced } \\
\text { cooldown on } \mathrm{ML}\end{array}$ & $4.50 \mathrm{E}-02$ & SNC \\
\hline SD-4 & DBE & $\begin{array}{l}\text { Fail to isolate leak, reactor trip, ML failure, } \\
\text { forced cooldown on SCS }\end{array}$ & $4.50 \mathrm{E}-03$ & SNC \\
\hline SD-5 & DBE & $\begin{array}{l}\text { Fail to isolate leak, reactor trip, ML failure, } \\
\text { SU/SD System failure, primary pumpdown, } \\
\text { conduction cooldown via RCCS, RB filtration }\end{array}$ & 4.45E-04 & SND \\
\hline SD-6 & BDBE & $\begin{array}{l}\text { Fail to isolate leak, reactor trip, ML failure, } \\
\text { SU/SD System failure, primary pumpdown, } \\
\text { conduction cooldown via RCCS, RB filtration } \\
\text { failure }\end{array}$ & $4.50 \mathrm{E}-06$ & SND-u \\
\hline SD-9 & BDBE & $\begin{array}{l}\text { Fail to isolate leak, reactor trip, ML failure, } \\
\text { SU/SD System failure, primary pumpdown } \\
\text { failure, conduction cooldown via RCCS, RB } \\
\text { filtration }\end{array}$ & 4.95E-05 & SND-p \\
\hline SD-10 & BDBE & $\begin{array}{l}\text { Fail to isolate leak, reactor trip, ML failure, } \\
\text { SU/SD System failure, primary pumpdown } \\
\text { failure, conduction cooldown via RCCS, RB } \\
\text { filtration failure }\end{array}$ & $5.00 \mathrm{E}-07$ & SND-p \\
\hline SD-13 & BDBE & $\begin{array}{l}\text { Fail to isolate leak, reactor trip failure, primary } \\
\text { pumpdown, conduction cooldown via RCCS, RB } \\
\text { filtration }\end{array}$ & $4.45 \mathrm{E}-07$ & SND-r \\
\hline
\end{tabular}

\subsubsection{Example HTGR PRA Results}

Example HTGR results evaluated for the PBMR in South Africa are shown in Figure 3-15 in comparison with the frequency-dose criteria that were defined for the NGNP project. ${ }^{[6]}$ The results reflect quantified uncertainties in both the frequencies and site boundary doses (using the unit of Total Effective Dose Equivalent, or TEDE) in comparison with the Top Level Regulatory criteria for acceptable frequencies and consequences that were proposed in the NGNP LBE selection report. ${ }^{[10]}$ The site boundary dose consequence uncertainties are based on mechanistic source terms that were evaluated for PBMR event sequences grouped into LBE categories which are called for in the ASME/ANS PRA standard. ${ }^{[45]}$ 


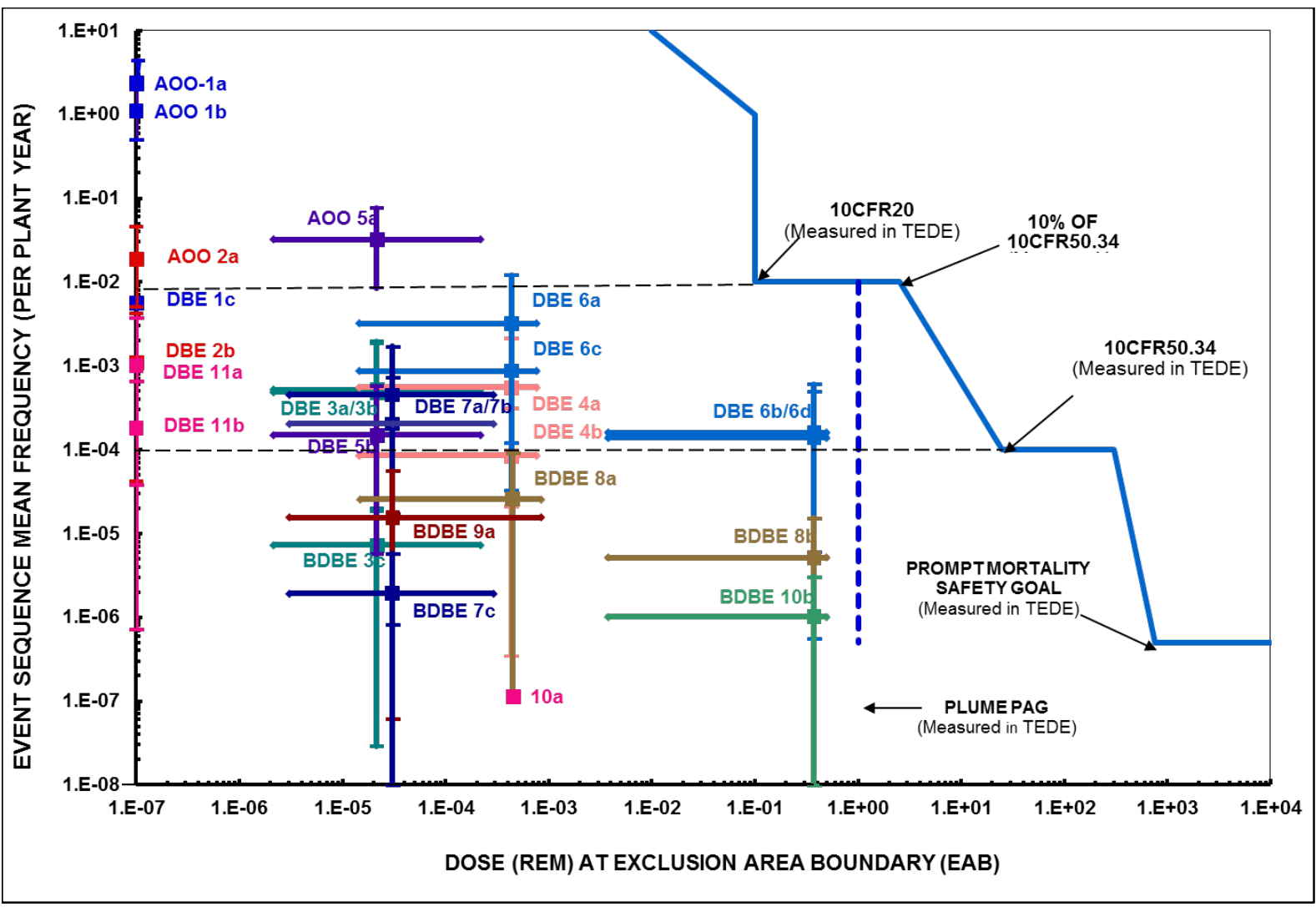

Figure 3-15. PBMR LBE Results Compared with NGNP Frequency-Dose Criteria

In the LMP LBE report on the selection and evaluation of LBEs, PRA results from Reference [8] are used to illustrate how LBEs are developed from a completed conceptual design of the MHTGR. The reader is referred to that PRA for details on how the event sequences are defined and quantified, how the plant response and mechanistic source terms were evaluated, and radiological consequences determined.

\subsection{Example PRA Development for PRISM Sodium-Cooled Fast Reactor}

The purpose of this section is to summarize how the technology-inclusive approach to developing a PRA model for an advanced non-LWR is implemented for an SFR design. The example is based on results of a PRA performed on the PRISM sodium-cooled fast reactor, whose design is documented in Reference [9]. This example develops PRA model elements for a plant comprised of two reactor modules and includes both single module and multi-module accidents. Accident sequences involving non-core sources of radioactive material are not included in this example.

Please note that, unlike the MHTGR example presented in the previous section, which was developed to support the identification of LBEs and safety classification of SSCs, the PRISM PRA was developed to pilot the ASME/ANS PRA standard for advanced non-LWRs, ${ }^{[46]}$ and was focused on the risk assessment of severe accidents. However, the applicability of the TI PRA approach for the LMP is aptly demonstrated. 
The key characteristics of the SFR design include:

- The PRISM core resides in a pool reactor with sodium coolant and a cover gas space at the top of the vessel at essentially atmospheric pressure; therefore, high energy releases of primary coolant from the vessel are not physically possible. Because there are no reactor vessel penetrations below the top of the sodium level, line breaks that would lead to loss of coolant accidents (LOCAs) are not possible either.

- The intermediate heat transfer loop separates the primary sodium core coolant from the secondary sodium coolant whose heat is transferred to the Steam Generator.

- The intermediate heat transfer loop is elevated above the primary loop to provide enough pressure head to prevent migration of radioactive or contaminated primary sodium to the intermediate loop or the environment following an unexpected leak of an intermediate loop heat exchanger tube.

- Metal fuel with a sodium bond inside the cladding improves heat transfer and allows for axial expansion to significantly reduce fuel-clad stress.

- Sodium is chemically compatible with the fuel, cladding, vessel and piping surfaces, thus eliminating corrosive decay mechanisms.

- Passive negative reactivity feedback mechanisms that reduce reactor power or limit its increase to safe levels even under anticipated transients with failure of the active scram system. These mechanisms respond to increases in the system temperature (Doppler broadening of the non-fission absorption neutron cross section, and thermal expansion of the fuel, control rods, and core support structure).

- Given a failure of the normal heat removal path through the condenser, passive shutdown heat removal is available by the continuously operating and monitored Reactor Vessel Auxiliary Cooling System (RVACS) that relies only on the natural circulation of the primary sodium coolant and atmospheric air to remove decay heat.

\subsubsection{Systematic Search for SFR Initiating Events}

The IE analysis is performed to identify perturbations that could occur during any plant operating state (POS), that challenge plant control and safety systems, whose failures could potentially lead to undesirable plant conditions, including radioactive material release. IEs include transients, losses of offsite power and special initiator groups. IE identification is based on review of industry PRAs, guidance documents, and design experience.

The IEs are initially limited to at-power internal events, that is, those IEs occurring during power operation either as a direct result of equipment failure, or as the result of errors while performing maintenance, testing, or operator action. Then, IEs occurring as a result of external hazards such as seismic events and those occurring during shutdown POSs are identified and included for consideration. 
A systematic approach is used to identify events that challenge normal plant operation and require successful mitigation to prevent radionuclide release. This includes an evaluation of previously identified LWR and non-LWR IEs that are also applicable to PRISM, and an assessment of the failure modes and effects of systems that are unique to the PRISM design.

Individual IEs that require similar response from front line and auxiliary systems and operators are combined into IE groups. Combining IEs into groups reduces the number of event trees that need to be developed. In grouping IEs, the events must be similar in terms of plant response, success criteria, accident progression timing (including time available for mitigating systems and operator actions to be performed), and the effect of the event on the operability and performance of mitigating systems and plant operators. The following IE groups are thus identified:

- Transient overpower

- Loss of primary forced flow (LOF)

- Intermediate Heat Exchanger (IHX) bypass leak

- Intermediate Heat Transport System (IHTS) leak

- Steam Generator Tube Rupture

- Nuclear Steam Supply System (NSSS) and General Transient faults, which have the subgroups:
○ NSSS transients
○ Turbine / balance-of-plant (BOP) transient faults
○ BOP / Loss of Heat Sink faults
○ Loss of Offsite Power
○ Core Faults
○ Reactor Vessel Leak

\subsubsection{PRISM PRA safety functions}

The PRISM reactor design has five concentric barriers that separate core radionuclide material from the environment.

- The metal fuel retains many radionuclides (i.e. plutonium, neptunium) within its matrix as long as the fuel has not melted.

- The fuel cladding around the fuel provides a barrier for gaseous fission products (i.e. xenon, krypton) as long as the cladding is intact.

- The sodium coolant acts as a third radionuclide barrier by retaining fission products either by chemical solubility or adsorption mechanisms.

- The reactor vessel is the radionuclide barrier for fission gases that are released by the sodium to the cover gas space which is at or near atmospheric pressure. 
- The containment is the final radionuclide barrier. A filtered reactor building ventilation system could also possibly mitigate radioactive release to the atmosphere, but it is not credited in this analysis. A full application of the LMP approach to PRA for input to selection of LBEs would require that all systems capable of preventing or mitigating a release be included.

A set of four key safety functions for the PRISM design prevent or mitigate damage to the radionuclide release barriers (i.e., reactivity control, core flow, heat removal, and radionuclide confinement). As IEs present challenges to one or more release barriers, various systems are relied upon to provide safety functions that protect against those barrier challenges. The plant's response systems are characterized by the functions listed below and illustrated in Figure 3-16.

- The reactivity control function influences the amount of heat being generated within the reactor core, which dictates the rate at which energy must be removed from the core. The success criterion of the reactivity control function is to reduce core power quickly enough to match core flow or heat removal faults in the short-term, preventing damage to the fuel matrix and fuel cladding barriers. Plant features that satisfy this function are the control rod drive system, inherent reactivity feedbacks (Doppler broadening, changes in sodium density and metallic fuel expansion and contraction), gas expansion modules, and the backup ultimate shutdown system control rods.

- The core flow function transports heat from the core to the primary sodium coolant. The success criterion of the core flow function is to provide enough cooling to match power, thus preventing damage to the fuel matrix and fuel cladding barriers due to overheating. The electromagnetic (EM) pump coastdown machines for unprotected loss of flow scenarios, and natural circulation for the remaining scenarios fulfill this safety function.

- The primary sodium heat removal function rejects the heat transported to the primary sodium coolant away from the reactor vessel. The success criterion of the primary sodium heat removal function is to remove enough heat to prevent damage in the long-term to the fuel cladding and reactor vessel barriers. The shutdown heat can be removed by three systems: (1) the main condenser, (2) the auxiliary (steam generator to air) cooling system, and (3) the passive RVACS. Supporting features/systems include the intermediate heat transfer loop through the Steam Generator and tripping the breakers to the primary and intermediate EM pumps to eliminate heat from pumping power.

- The confinement function provides the integrity of the final radionuclide release barriers, namely the reactor vessel and the containment. Any failures of the fuel matrix or cladding that result in fission products released to the cover gas space are mitigated by the vessel head and the containment. The success criterion of the confinement function is a release of no more than the design basis leakage rate of radionuclides from the vessel head and containment. Metal-water detection, steam generator (SG) isolation and blowdown, vessel head isolation, and containment isolation are key systems that work together to fulfill this function. 


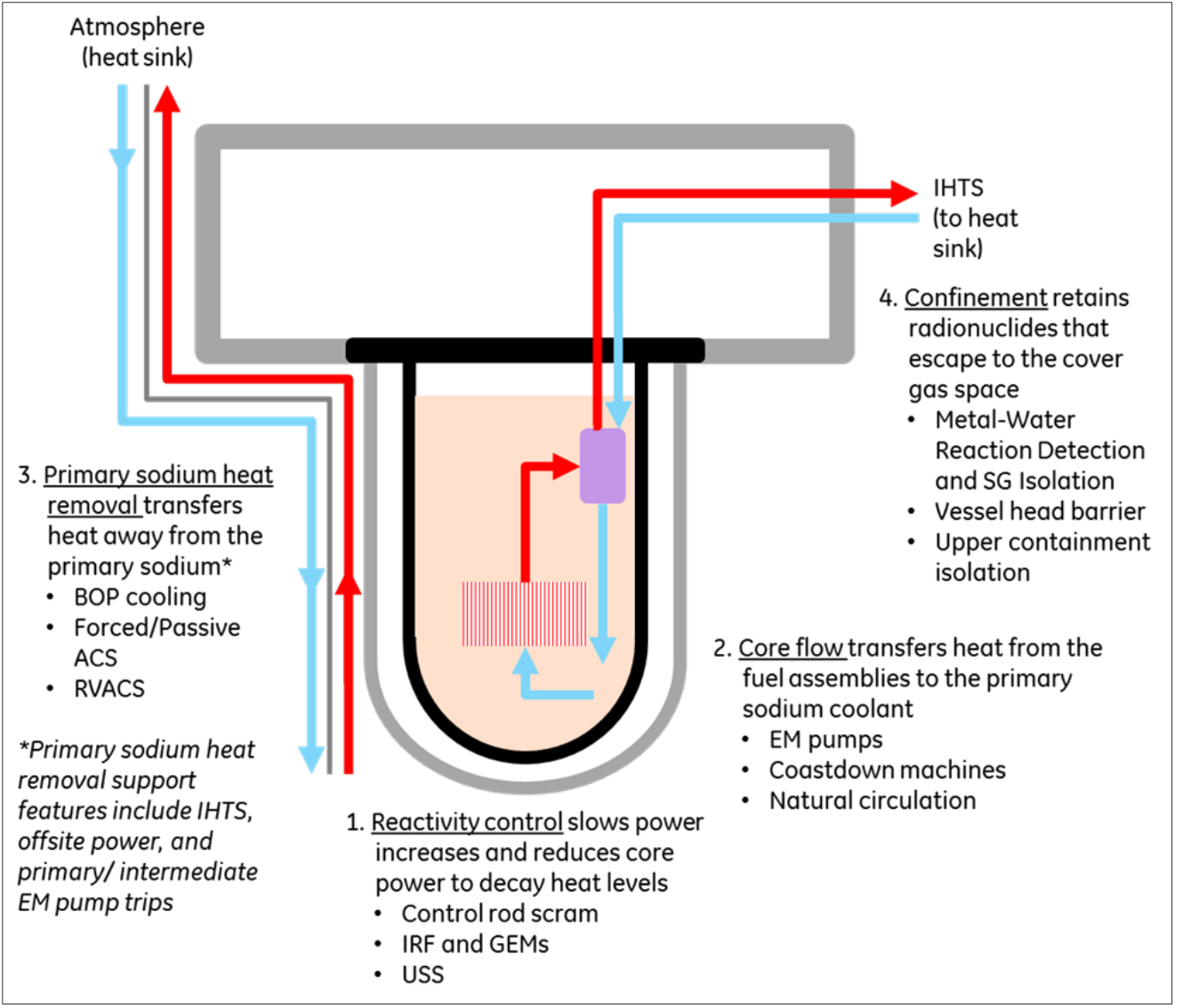

Figure 3-16. PRISM PRA Safety Functions

\subsubsection{PRISM PRA safety functions and Supporting System Development}

Event trees developed for the PRISM PRA follow the standard practices, as described below. Event tree node success or failure is informed by the Success Criteria analysis. Success criteria are developed for active and passive systems performing safety functions modeled in the PRISM PRA. Unlike the success criteria for LWR PRAs, which are rooted in the known CDF risk surrogate, the PRISM PRA bases the success or failure of mitigating plant features on the potential for release of radionuclide material from the core with transport to the environment.

Active systems, such as Auxiliary Cooling Systems (ACSs), BOP cooling and electrical power are treated by traditional reliability analysis with failures and design basis performance characteristics identified for each analyzed system. In addition, passive systems that perform or support key safety functions are given special reliability treatment within the success criteria analysis because they often have no components that must move or change state to provide the safety function. They experience degrees of failure or degradation that range from no plant damage to higher, less probable levels of plant damage.

The success criteria for the PRISM design include the barriers and mitigating systems needed to prevent radiological releases based on the identification of possible release categories. Each release category consists of a quantified level of fuel barrier damage and a combination of intact 
and failed confinement release barriers. For each event sequence modeled, plant parameters are defined with various thresholds that represent the different release categories that are possible for that sequence. For those categories with a release, radiological consequences are evaluated.

The robust PRISM design accommodates failures of active reactivity control and active primary sodium heat removal systems. When these active systems are successful, sub-criticality is quickly reached and decay heat is accommodated without a challenging heat-up of the core or primary sodium coolant, meaning that stable plant conditions have been achieved. The success criteria analysis confirms that a mission time of 24 hours is appropriate for sequences where scram is successful and primary sodium heat removal is provided by BOP Cooling or Forced Air ACS (i.e., a backup heat removal system that operates by natural circulation air cooling of the Steam Generator outer shell while sodium is available in the Steam Generator).

Sequences where primary sodium heat removal must be provided by passive systems (RVACS, Passive ACS) are accommodated by the PRISM design, but stable plant conditions may not be reached within 24 hours for these scenarios since they develop slowly. When decay heat removal is accomplished by RVACS, a 72-hour extended mission time is appropriate to ensure that a safe and stable plant condition has been reached. This mission time has been confirmed by the success criteria analysis.

Sequences where reactivity control must be provided by passive inherent reactivity feedback (IRF) are accommodated by the PRISM design, but the reactor will not be subcritical unless control rods or Ultimate Shutdown System (USS) assemblies are inserted into the core. Previous calculations indicate that this must happen within days of the event. For the purpose of this analysis, a 24-hour mission time is assumed. The plant will be placed in a stable condition once either control rods or USS assemblies are inserted.

One of the features of the PRISM PRA model was the approach to determining success criteria for passive features, namely the air cooling by RVACS and the IRF features of the core that intrinsically suppresses reactivity when reactor power increases. The PRISM reactor core is designed to provide strong inherent negative reactivity feedbacks with rising temperature. With this characteristic and RVACS heat removal capability, the PRISM reactor is capable of safely withstanding severe undercooling and overpower transient events even with a failure to scram. As the temperature increases during an event, the negative feedbacks from the radial core expansion, grid plate expansion, axial core assembly expansion, Doppler, and control rod drive line expansion are activated, creating a net negative reactivity for the core. To evaluate the reliability of IRF, the key question is: how fast do the IRF mechanisms respond to an initiating event to reduce power? If the IRF mechanisms reduce power too slowly, fuel damage may not be prevented. Monte Carlo sampling calculations were performed to give probabilities of various levels of fuel damage being reached.

Innovative reliability models are employed to model the passive features of RVACS. The key question is: what levels of degradation would result in damage to fuel? To answer this question, the states of six major boundary conditions were evaluated for three cases: a normal condition, an off-normal condition, and an extreme condition. Calculations were run for each of the 729 combinations to determine the level of damage to the fuel within the vessel, if any. The 
PRISM systems and functional failure modes that could adversely affect key PRA safety function performance are listed in Table 3-6. Table 3-7 defines the passive function categories.

Table 3-6. PRISM Systems and Functions Modeling

\begin{tabular}{|c|c|c|c|}
\hline System Name & Postulated Failures Modeled & $\begin{array}{l}\text { PRA safety } \\
\text { function }\end{array}$ & Passive / Active \\
\hline $\begin{array}{l}\text { Primary Heat Transport } \\
\text { System }\end{array}$ & $\begin{array}{l}\text { Loss of flow initiating event } \\
\text { EM pumps fail to coastdown } \\
\text { EM pump(s) fails to trip }\end{array}$ & $\begin{array}{l}\text { Core Flow } \\
\text { Core Flow } \\
\text { Heat Removal }\end{array}$ & $\begin{array}{l}\text { Active } \\
\text { Passive Cat D } \\
\text { Passive Cat D }\end{array}$ \\
\hline $\begin{array}{l}\text { Intermediate Heat } \\
\text { Transport System }\end{array}$ & $\begin{array}{l}\text { Failure of IHTS to move heat to ACS and BOP systems } \\
\text { Intermediate EM pump(s) fail to trip }\end{array}$ & $\begin{array}{l}\text { Heat Removal } \\
\text { Heat Removal }\end{array}$ & $\begin{array}{l}\text { Passive Cat B } \\
\text { Passive Cat D }\end{array}$ \\
\hline $\begin{array}{l}\text { Steam Generator System / } \\
\text { BOP }\end{array}$ & $\begin{array}{l}\text { BOP SG heat removal unavailable for single module IEs } \\
\text { BOP SG heat removal unavailable for power block IEs } \\
\text { Failure to isolate module from main steam header } \\
\text { Non-arrested SG/IHTS pressurization from a sodium- } \\
\text { water reaction }\end{array}$ & $\begin{array}{l}\text { Heat Removal } \\
\text { Heat Removal } \\
\text { Heat Removal } \\
\text { Confinement \& } \\
\text { Heat Removal }\end{array}$ & $\begin{array}{l}\text { Active } \\
\text { Active } \\
\text { Active } \\
\text { Active }\end{array}$ \\
\hline $\begin{array}{l}\text { Active Reactivity Control } \\
\text { Systems: } \\
\text { - Control Rod System } \\
\text { - RPS (Scram) } \\
\text { - USS }\end{array}$ & Failure of Control Rod Drive system scram function & Reactivity Control & Active \\
\hline $\begin{array}{l}\text { Inherent Reactivity } \\
\text { Feedback Mechanisms }\end{array}$ & $\begin{array}{l}\text { Reactivity feedback insufficient to prevent fuel damage } \\
\text { from overheating }\end{array}$ & Reactivity Control & Passive Cat A \\
\hline RVACS & Passive decay heat removal degradation & Heat Removal & Passive Cat B \\
\hline Auxiliary Cooling System & $\begin{array}{l}\text { Passive heat removal through natural circulation } \\
\text { around steam generator shell } \\
\text { Active heat removal through forced flow around steam } \\
\text { generator shell }\end{array}$ & $\begin{array}{l}\text { Heat Removal } \\
\text { Heat Removal }\end{array}$ & $\begin{array}{l}\text { Passive Cat B } \\
\text { Active }\end{array}$ \\
\hline $\begin{array}{l}\text { Electrical AC } \\
\text { Electrical DC }\end{array}$ & Numerous loss of power supports to other systems & $\begin{array}{l}\text { Supporting } \\
\text { Supporting }\end{array}$ & $\begin{array}{l}\text { Active } \\
\text { Active }\end{array}$ \\
\hline $\begin{array}{l}\text { Confinement (Reactor } \\
\text { Vessel \& Containment) }\end{array}$ & $\begin{array}{l}\text { Primary system radionuclide barrier faults } \\
\text { Containment radionuclide barrier faults } \\
\text { Bypass the containment boundary }\end{array}$ & $\begin{array}{l}\text { Confinement } \\
\text { Confinement } \\
\text { Confinement }\end{array}$ & $\begin{array}{l}\text { Active } \\
\text { Active } \\
\text { Active }\end{array}$ \\
\hline $\begin{array}{l}\text { Reactor Component } \\
\text { Cooling Water System }\end{array}$ & $\begin{array}{l}\text { Provide cooling to active supporting equipment (e.g., } \\
\text { AC generator) }\end{array}$ & Supporting & Active \\
\hline Chilled Water System & $\begin{array}{l}\text { Provide room cooling to active supporting equipment } \\
\text { (e.g., AC generator) }\end{array}$ & Supporting & Active \\
\hline $\begin{array}{l}\text { Condensate Storage and } \\
\text { Transfer System }\end{array}$ & Provide makeup to condenser hotwell & Heat Removal & Active \\
\hline Instrument Air & Provide air supply to valves & Supporting & Active \\
\hline $\begin{array}{l}\text { Condensate and Feedwater } \\
\text { System }\end{array}$ & Provide Feedwater to SG & Heat Removal & Active \\
\hline $\begin{array}{l}\text { Main Condenser and } \\
\text { Circulating Water System }\end{array}$ & Provide cooling to main condenser & Heat Removal & Active \\
\hline $\begin{array}{l}\text { Digital Instrumentation } \\
\text { and Controls }\end{array}$ & $\begin{array}{l}\text { Provide automatic actuation signals } \\
\text { Provide interface and software conduit for manual } \\
\text { actuation signals }\end{array}$ & $\begin{array}{l}\text { Supporting } \\
\text { Supporting }\end{array}$ & $\begin{array}{l}\text { Active } \\
\text { Active }\end{array}$ \\
\hline
\end{tabular}


Table 3-7. IAEA Passive Function Categories ${ }^{[69]}$

\begin{tabular}{|c|c|c|}
\hline Category & Characteristics & Examples \\
\hline$A$ & $\begin{array}{l}\text { No signal inputs of "intelligence" } \\
\text { No external power sources or forces } \\
\text { No moving mechanical parts } \\
\text { No moving working fluid }\end{array}$ & $\begin{array}{l}\text { Nuclear Fuel Cladding } \\
\text { Primary Coolant Boundary } \\
\text { Inherent Reactivity Feedback }\end{array}$ \\
\hline B & $\begin{array}{l}\text { No signal inputs of "intelligence" } \\
\text { No external power sources or forces } \\
\text { No moving mechanical parts } \\
\text { Moving working fluids }\end{array}$ & $\begin{array}{l}\text { Containment Cooling Systems based } \\
\text { on natural circulation of air flowing } \\
\text { around the containment walls }\end{array}$ \\
\hline C & $\begin{array}{l}\text { No signal inputs of "intelligence" } \\
\text { No external power sources or forces } \\
\text { Moving mechanical parts } \\
\text { Whether or not moving working fluids are also present }\end{array}$ & $\begin{array}{l}\text { Overpressure Protection and/or } \\
\text { Emergency Cooling Devices of } \\
\text { Pressure Boundary Systems based } \\
\text { on fluid release through relief valves }\end{array}$ \\
\hline D & $\begin{array}{l}\text { Contain inputs, mechanical parts and working fluid, but meet } \\
\text { the following criteria: } \\
\text { (1) energy must only be obtained from stored sources such as } \\
\text { batteries or compressed or elevated fluids; (2) active } \\
\text { components are limited to controls instrumentation and valves } \\
\text { (single-action relying on stored energy); (3) manual initiation is } \\
\text { excluded }\end{array}$ & $\begin{array}{l}\text { Emergency Core Cooling Systems, } \\
\text { based on gravity driven flow of } \\
\text { coolant, activated by valves which } \\
\text { break open on demand }\end{array}$ \\
\hline
\end{tabular}

One of the objectives of the PRISM PRA described herein was to benchmark the ASME/ANS PRA Standard for Advanced non-LWRs. The entire development of the PRA models was guided by the requirements of the standard. Feedback from this benchmark is currently being considered by the Writing Group responsible for the standard in preparation of a revised ANSI PRA standard for non-LWR PRAs.

\subsubsection{Development of Event Sequences}

To model the PRISM SFR event sequences, three general groups of event trees are required:

- Protected

- Unprotected

- Confinement

The protected trees provide the logic for sequences in which active reactivity insertion is successful via the control rods. The unprotected trees accommodate those scenarios where control rod insertion fails so that inherent reactivity feedback and the ultimate shutdown system must satisfy the reactivity control safety function. Finally, the confinement trees analyze the various radionuclide barrier success and failure combinations that ultimately result in the event sequence end states. A simplified representation of this approach is shown in Figure 3-17 for the Loss of Primary Forced Flow IE. 


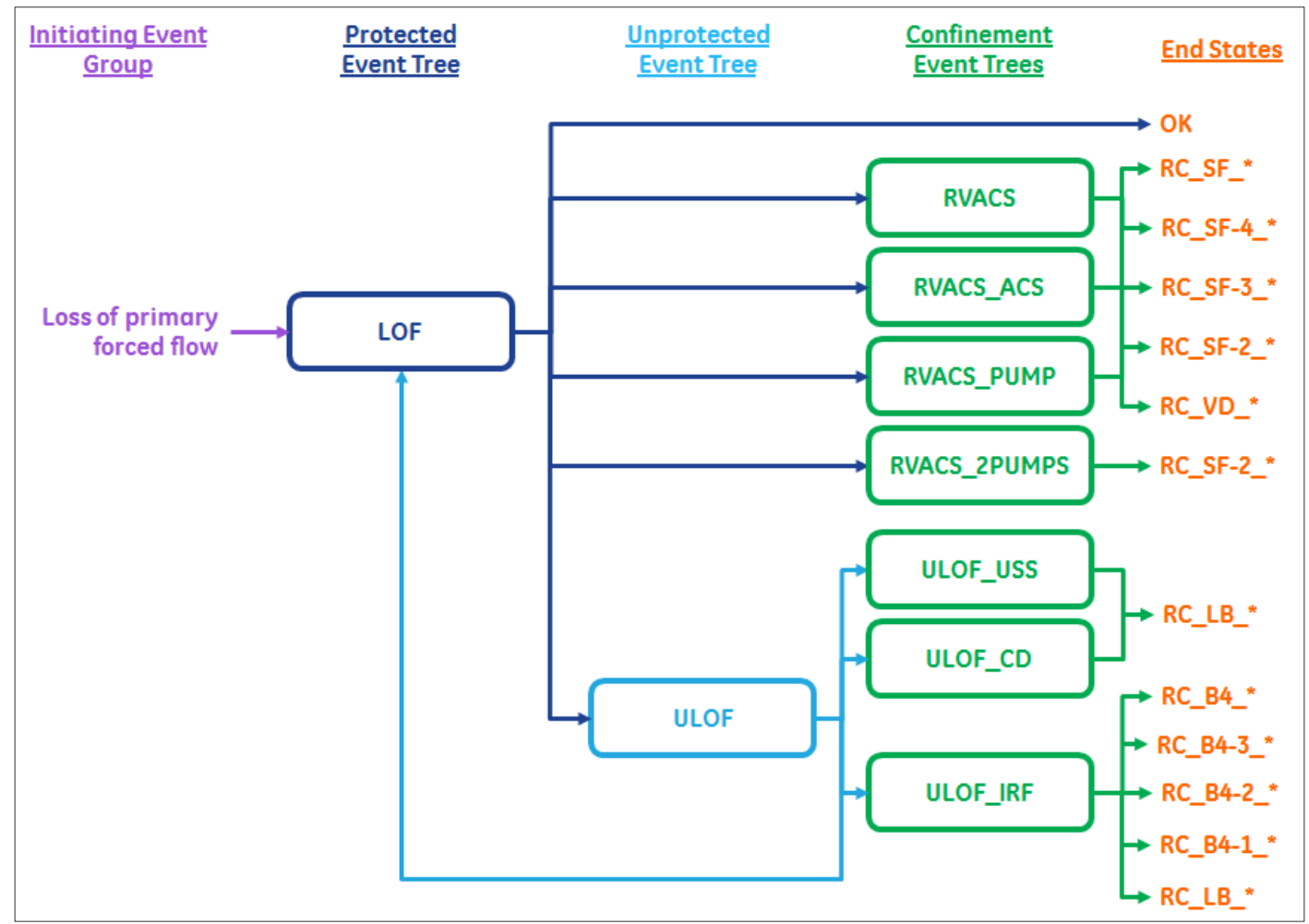

Figure 3-17. Example Event Sequence Overview Diagram

The protected and unprotected event trees identify the potential sequences that can lead to radionuclide release outside containment. Many of the sequences have common characteristics with respect to the challenge to the radionuclide barriers. These sequences are grouped using end states that are defined and analyzed within the Mechanistic Source Term analysis.

End states were selected to cover the range of possible plant conditions for the PRISM design, given the spectrum of IEs. End states take the form of either a safe, stable state (OK) or result in a radionuclide release outside of containment. The latter category of end states is referred to as release categories. All radionuclide releases are identified regardless of their magnitude.

The protected event trees provide the starting point for the event sequence analysis and are developed based on the IE groups identified in the IE chapter. The protected event trees developed for the PRISM PRA are as follows:

- $\mathrm{BOP}-\mathrm{BOP} /$ loss of heat sink (LOHS) faults

- IHTS-IHTS large leak

- IHX-IHX bypass leak

- LOF-Loss of primary forced flow

- LOOP_Loss of offsite power

- NSSS-NSSS faults/general transients 
- SGTR - Steam generator tube rupture

- TOP-Transient overpower

Each IE group is assigned to a protected event tree. Credit is taken for the systems and functions that are capable of responding to the event, as well as key operator actions that are available to mitigate the event. Event sequences in the protected event trees that do not lead to safe, stable conditions or release categories transfer to another protected, unprotected, or confinement event tree.

The unprotected event trees were developed to evaluate event sequences that involve a failure of the reactor to scram via the Control Rod Drive system. In this event, the inherent reactivity feedback mechanisms of Doppler broadening, changes in sodium density and metallic fuel expansion and contraction respond to the core temperature increases by bringing the core to a safe, and stable, near zero fission power state. As a backup, the USS can also shut down the reactor. Owing to the negative reactivity feedbacks, potentially severe, but extremely unlikely accidents can be accommodated with benign consequences. Three postulated, beyond design basis scenarios can illustrate this: inadvertent withdrawal of all control rods without scram (unprotected transient overpower), loss of primary pump power and loss of all cooling by the IHTS without scram (unprotected loss of flow/loss of cooling), and loss of all cooling by the IHTS without scram (unprotected loss of cooling).

Based on the three beyond design basis scenarios listed above, the following unprotected event trees are developed for the PRISM PRA:

- ULOF-Unprotected loss of primary forced flow

- ULOHS-Unprotected loss of heat sink

- UTOP-Unprotected transient overpower

The confinement event trees were developed to evaluate the release categories for protected and unprotected event sequences. The confinement event trees developed for the PRISM PRA include:

- RVACS-RVACS degradation with passive ACS success

- RVACS_PUMPS—RVACS degradation with pump heat from EM pumps

- RVACS_ACS - RVACS degradation with passive ACS failure

- ULOF_CD_ULOF with EM pump coastdown failures

- ULOF_IRF-ULOF and IRF/ gas expansion modules failure

- ULOF_USS - ULOF with failure to manually insert USS rods

- ULOHS_IRF-ULOHS and IRF failure

- LOHS_US_-ULOHS with failure to manually insert USS rods 
- UTOP-UTOP and IRF failure

- UTOP_USS_UTOP with failure to manually insert USS rods

The outcome of each event tree mitigating function (i.e., success or failure) is determined by success criteria analysis described earlier. Success criteria analysis defines the mitigating system and functions that are included in the PRA model, including combinations of systems and functions that prevent radioactive release. Each event tree node and its respective mitigating function are designated as event tree top events. The SSC supporting mitigation functions are:

- Forced air ACS

- Passive ACS

- BOP cooling

- Confinement integrity

- Containment isolation

- Reactivity control of control rods

- Steam generator sodium water reaction arrest (relief-isolation-blowdown)

- Fuel barrier damage state

- IHTS available/natural circulation

- Tripping of intermediate EM pumps

- Pump coastdown

- Tripping of primary EM pumps

- IRF

- Gas expansion modules

- RVACS cooling

- USS reactivity control

- Vessel head integrity

\subsubsection{Event Sequence End States}

Release categories are defined for the event sequence end states based on similar release characteristics. Initially, all event sequences resulting in radionuclide release are identified. The different characteristics of these releases are summarized. Finally, the end states are grouped into formal release categories.

For the PRISM plant design, the characteristics of radionuclide release are studied for all instances where a sequence results in damage to the cladding or fuel within the reactor vessel. For completeness, this accounting includes sequences where the reactor vessel head and 
containment are successfully performing their confinement functions as radionuclide barriers. In this way, the very small release that results from clad damage and the assumed level of leakage from the vessel and containment are quantified for PRISM for any level of clad damage.

The radionuclide release categories that group the release event sequences have several common features and differentiating attributes. Postulated radionuclide releases from the PRISM design take the following release path. Fuel cladding fails primarily by hoop stress rupture and releases fission products to the sodium coolant. Many isotopes remain trapped within the fuel matrix and sodium and do not contribute to the source term. The radionuclides that escape the sodium by vaporization or boiling are released to the cover gas space between the sodium hot pool surface and the vessel head. From the cover gas space, the radionuclides either leak out through failed seals in the vessel head, or if seals are not failed, gases leak at an assumed rated design leakage rate. Gases that escape the cover space by failure or by leakage end up in the upper containment. Any radionuclide release to the environment from the gases that reach upper containment is by either a failure of the containment isolation function or by rated design leakage if containment isolation is successful. All source terms that take this path are ground level releases, with no credit for retention in the reactor building because the upper containment resides near ground level.

The exception to the release path described above is in sequences where bypass of the vessel head and containment barriers is postulated following a postulated rupture of IHX tubes. Realistically, this is not believed to be a direct release path to the environment, given that the static head of the IHTS would keep sodium flowing from the intermediate loop to the primary loop. However, no mechanistic modeling of radionuclide release from a damaged IHX through the IHTS has been performed. Therefore, any damage to IHX tubes is assumed to result in a release that bypasses containment.

The time of barrier failure is driven by the thermal-hydraulic calculations of fuel cladding performance in various sequences. After clad failure, no additional delay time is considered for transport of radionuclides through the hot pool to the cover gas space. The transport of radionuclides from the cover gas space to the containment is either controlled by the design leak rate through the vessel head, or the transport is assumed to be instantaneous if there is a failure of the vessel head seals. Similarly, transport from the containment to the environment is either controlled by the leak rate or is considered simultaneous given a failure of containment isolation.

Table 3-8 is an excerpt from the Mechanistic Source Term Analysis (mentioned in Table 4-2 in Reference [46]) which shows some release categories. Each category identified contains a listing in the table of all intact and not intact radionuclide release barriers and each release is described. Release barriers include the combinations of the following faulted or intact states: metal fuel matrix, fuel cladding, hot pool sodium, vessel head, and containment. 
Table 3-8. Release Category Definitions ${ }^{[46]}$

\begin{tabular}{|c|c|c|}
\hline $\begin{array}{l}\text { Release } \\
\text { Category }\end{array}$ & $\begin{array}{c}\text { Release Barriers } \\
\text { Intact }(\boldsymbol{V}) \text { or Not Intact }(\boldsymbol{X})\end{array}$ & $\begin{array}{c}\text { Radionuclide Release } \\
\text { Description }\end{array}$ \\
\hline RC_B4_1 & $\begin{array}{l}\boldsymbol{V} \text { All metal fuel matrices } \\
\boldsymbol{V} \text { Clad in spent fuel \& batches 1-3 } \\
\boldsymbol{x} \text { Clad in batch } 4 \\
\boldsymbol{V} \text { Hot pool sodium } \\
\boldsymbol{\sim} \text { Vessel head } \\
\boldsymbol{V} \text { Containment }\end{array}$ & $\begin{array}{l}\text { Radionuclides within cladding } \\
\text { of every pin in core batch } 4 \text { are } \\
\text { released to sodium coolant }\end{array}$ \\
\hline RC_B4_2 & $\begin{array}{l}\checkmark \text { All metal fuel matrices } \\
\checkmark \text { Clad in spent fuel \& batches 1-3 } \\
x \text { Clad in batch } 4 \\
\checkmark \text { Hot pool sodium } \\
\checkmark \text { Vessel head } \\
\boldsymbol{x} \text { Containment }\end{array}$ & $\begin{array}{l}\text { Release is dominated by } \\
\text { inventory from these pins that } \\
\text { is not retained by the sodium } \\
\text { coolant and escapes the hot } \\
\text { pool to the cover gas space (i.e. } \\
\text { noble gases) }\end{array}$ \\
\hline
\end{tabular}

\subsubsection{LBEs as Event Sequence Families}

Selecting LBEs for the PRISM PRA followed the same process that is described in the previous example. Event sequence families are used to group together two or more event sequences when the sequences have a common IE, PRA safety function response and end-state. The PRA safety function responses are delineated to a necessary and sufficient degree to identify unique challenges to each SSC that performs a given PRA safety function along the event sequence. Event sequences with similar but not identical PRA safety function responses are not combined when such combinations would mask the definition of unique challenges to the SSCs that perform PRA safety functions.

\subsubsection{Example PRISM Event Sequence for Loss of Flow Event}

The purpose of this section is to present an example of the event sequence development for an IE that is common to SFR designs. This example includes a definition of the IE, the development of an event sequence, and an event tree which quantifies the event sequence frequencies, assignment of end states, and a classification into LBE categories.

\subsubsection{Definition of Initiating Event}

The IE for this example is Loss of Primary Flow, which considers total or partial loss of forced flow in the primary sodium loop. It centers around the possible faults of the primary EM pumps to function. 


\subsubsection{Safety Design Mitigation Strategy}

EM pumps have no inertia, so to prevent flow stagnation in the core region following EM pump stoppage, synchronous machines provide an artificial coastdown. These coastdown machines are typically flywheels coupled with motor-generator units. They are operated continuously so that there will be a coastdown if there is a power loss or other faults causing the primary EM pumps to trip. As the synchronous machines coast down, the rotational energy is converted to electrical power for the primary EM pumps. They experience a gradual reduction in pumping power, and thus provide better removal of the relatively high decay heat immediately following a scram or a passive shutdown.

\subsubsection{Key Assumptions}

The following assumptions are made to support the loss of flow event sequence development for the advanced conceptual design and will be replaced by appropriate analyses in the final design phase:

- The primary and intermediate loop EM pumps are assumed to release their entire rated gross thermal power to the sodium if their breakers fail to open.

- It is assumed that local boiling always leads to fuel damage. This assumption is made in lieu of detailed analyses of fuel, neutronics and thermal-hydraulic relationships for stagnated flows.

- For long-term decay heat transients, the Intermediate Heat Transfer System is assumed to provide the necessary heat transfer via natural circulation in the Steam Generator. Any failure probabilities associated with this natural circulation are assumed to be negligible when compared to other heat transfer failure mechanisms that are modeled.

\subsubsection{Event Sequence Development}

The event tree for Loss of Flow events is shown in Figure 3-18. With a loss of primary forced flow, a scram signal is generated on power-to-flow mismatch. Failure to insert control rods transfers to the Unprotected Loss of Flow event tree which considers coastdown of the EM pumps and power reduction due to negative reactivity feedbacks. Successful control rod insertion takes the sequence to decay heat removal functions. If the preferred heat sink (Main Condenser/Balance of Plant) is available, the reactor is brought to a safe stable shutdown. If it is unable to provide heat removal, then Forced Air Auxiliary Cooling can be actuated. This system removes heat from the exterior of the shrouded Steam Generator by an induction fan and relies on a natural circulation flow path in the intermediate loop. 


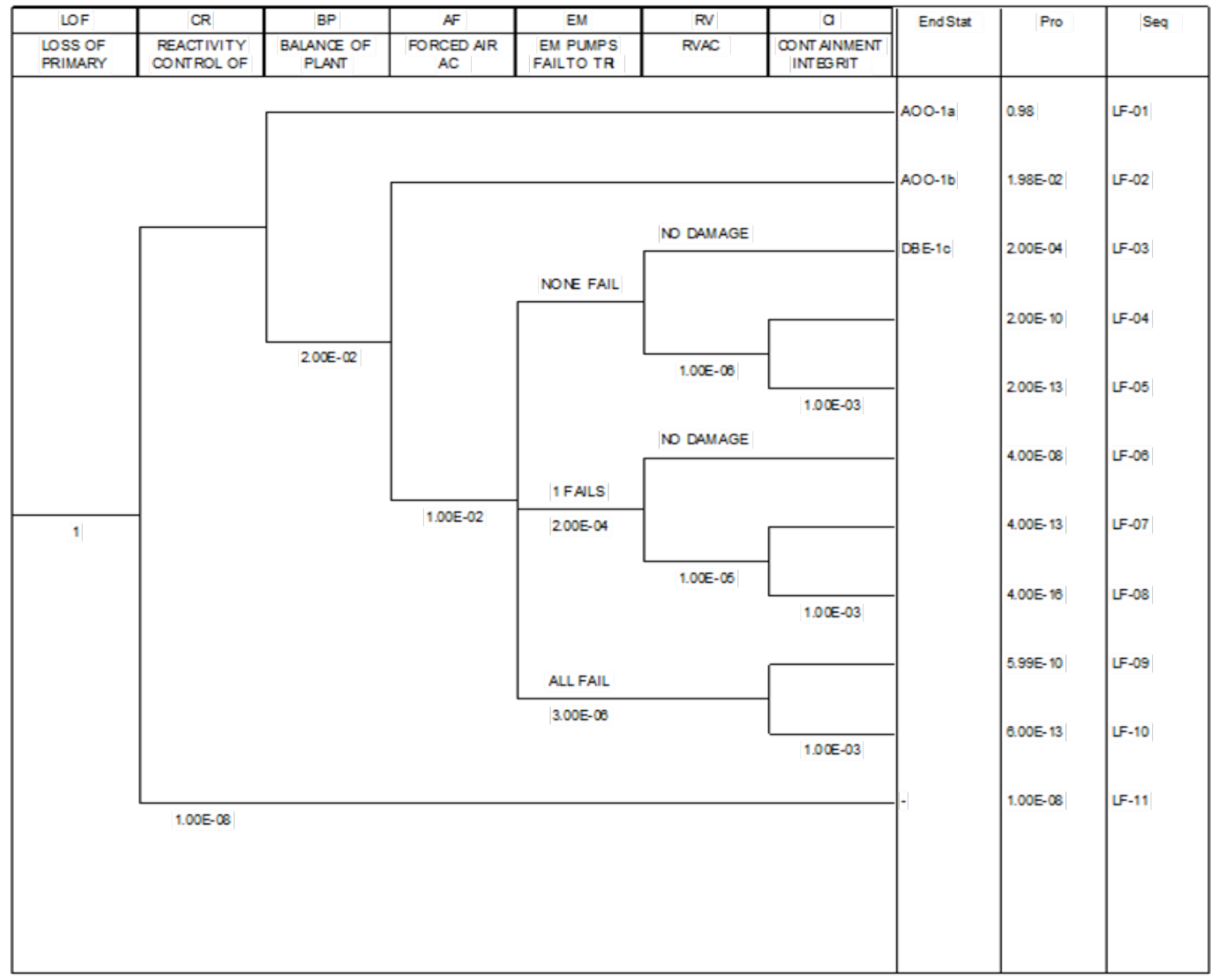

Figure 3-18. Simplified Event Tree for PRISM Loss of Flow Event

The residual heat from EM pumps can be a significant load if the EM pump trip breakers fail to open. Thus, three outcomes are modeled. RVACS passively removes heat from the vessel to the atmosphere by establishing a natural convection flow path for air to circulate in and around the vessel/lower containment and to exit back to the atmosphere. RVACS is sized to remove sufficient heat to prevent primary sodium temperature from causing cladding failure and fuel damage to the spent fuel in the in-vessel racks and core. Because RVACS is a passive system, its performance is subject to degradation. Thus, to account for uncertainties an RVACS failure (degradation) branch is applied to the tree. It is actually there to account for the possibility of degraded heat removal capability due to external factors in which RVACS cannot remove sufficient heat to prevent further heating of the core and sodium. Thus far, all end states are safe stable shutdowns. However, with a postulated BOP/ACS/RVACS fault chain, spent fuel damage is assumed to eventually occur, albeit in a few days. Therefore, the Reactor Vessel and Containment barrier effects on the source term from the core/sodium are challenged and the final end states are thus identified as either AOOs, DBEs, or BDBEs.

Quantification of this event tree was made using engineering judgments and assumptions that will be replaced with appropriate design detail and analysis when the design is finalized. 
However, these preliminary estimates are used to yield a preliminary set of LBEs, whose results are listed in Table 3-9.

Table 3-9. LBEs for a Simplified Loss of Flow Event

\begin{tabular}{|c|c|c|c|}
\hline LBE No. & $\begin{array}{l}\text { LBE } \\
\text { Type }\end{array}$ & Plant Response & $\begin{array}{l}\text { Frequency per } \\
\text { Plant-Year }\end{array}$ \\
\hline LF-01 & AOO & $\begin{array}{l}\text { Reactor Scram, Balance of Plant cooling removes decay heat; Safe } \\
\text { Shutdown }\end{array}$ & 0.98 \\
\hline LF-02 & $\mathrm{AOO}$ & $\begin{array}{l}\text { Reactor Scram, Forced Air Aux Cooling removes decay heat; Safe } \\
\text { Shutdown }\end{array}$ & $1.98 \mathrm{E}-2$ \\
\hline LF-03 & DBE & Reactor Scram, RVACS removes decay heat; Safe Shutdown & $2.0 \mathrm{E}-4$ \\
\hline LF-04 & NR & $\begin{array}{l}\text { Reactor Scram, Degraded decay heat removal from RVACS, core } \\
\text { damage with nominal leakage past reactor vessel head and } \\
\text { nominal leakage past containment }\end{array}$ & $<\mathrm{E}-8$ \\
\hline LF-05 & NR & $\begin{array}{l}\text { Reactor Scram, Degraded decay heat removal from RVACS, core } \\
\text { damage with nominal leakage past reactor vessel head and } \\
\text { penetration leakage or bypass past containment }\end{array}$ & $<\mathrm{E}-8$ \\
\hline LF-06 & NR & $\begin{array}{l}\text { Reactor Scram, residual heat from one untripped EM pump, RVACS } \\
\text { removes pump and decay heat; Safe Shutdown }\end{array}$ & $4 \mathrm{E}-8$ \\
\hline LF-07 & NR & $\begin{array}{l}\text { Reactor Scram, Degraded decay heat removal from RVACS, residual } \\
\text { heat from one untripped EM pump, core damage with penetration } \\
\text { leakage past reactor vessel head and nominal leakage past } \\
\text { containment }\end{array}$ & $<\mathrm{E}-8$ \\
\hline LF-08 & NR & $\begin{array}{l}\text { Reactor Scram, Degraded decay heat removal from RVACS, residual } \\
\text { heat from one untripped EM pump, core damage with penetration } \\
\text { leakage past reactor vessel head and penetration leakage or } \\
\text { bypass past containment. }\end{array}$ & $<\mathrm{E}-8$ \\
\hline LF-09 & NR & $\begin{array}{l}\text { Reactor Scram, all EM pump breakers fail to trip, core damage with } \\
\text { penetration leakage past reactor vessel head and nominal leakage } \\
\text { past containment }\end{array}$ & $<\mathrm{E}-8$ \\
\hline LF-10 & NR & $\begin{array}{l}\text { Reactor Scram, all EM pump breakers fail to trip, core damage with } \\
\text { penetration leakage past reactor vessel head and penetration } \\
\text { leakage or bypass past containment }\end{array}$ & $<\mathrm{E}-8$ \\
\hline LF-11 & NR & $\begin{array}{l}\text { Unprotected Loss of Flow (failure to scram); Transfer to ULOF } \\
\text { event tree }\end{array}$ & $1 \mathrm{E}-8$ \\
\hline
\end{tabular}

Note: $\mathrm{NR}=$ No rating as the BDBE category is defined as between $1 \mathrm{E}-4$ and $5 \mathrm{E}-7 /$ plant-year

\subsubsection{Example PRISM PRA Results}

Example results evaluated for the PRISM reactor are shown in Figure 3-19. Sequences with RVACS success are AOOs and reside at the y-axis (zero consequence). With RVACS degradation, DBEs and BDBEs are possible; however, these very preliminary results only appear in the lower uncertainty range with a frequency greater than E-8 per year. Site exclusion area boundary doses are compared to the TLRC proposed limits for acceptable frequencies and consequences as proposed in the LBE selection report. The site boundary dose consequences are 
based on mechanistic source terms that were evaluated for PRISM event sequences grouped into LBE categories. The development of LBEs from the PRISM PRA results is described in Reference [3].

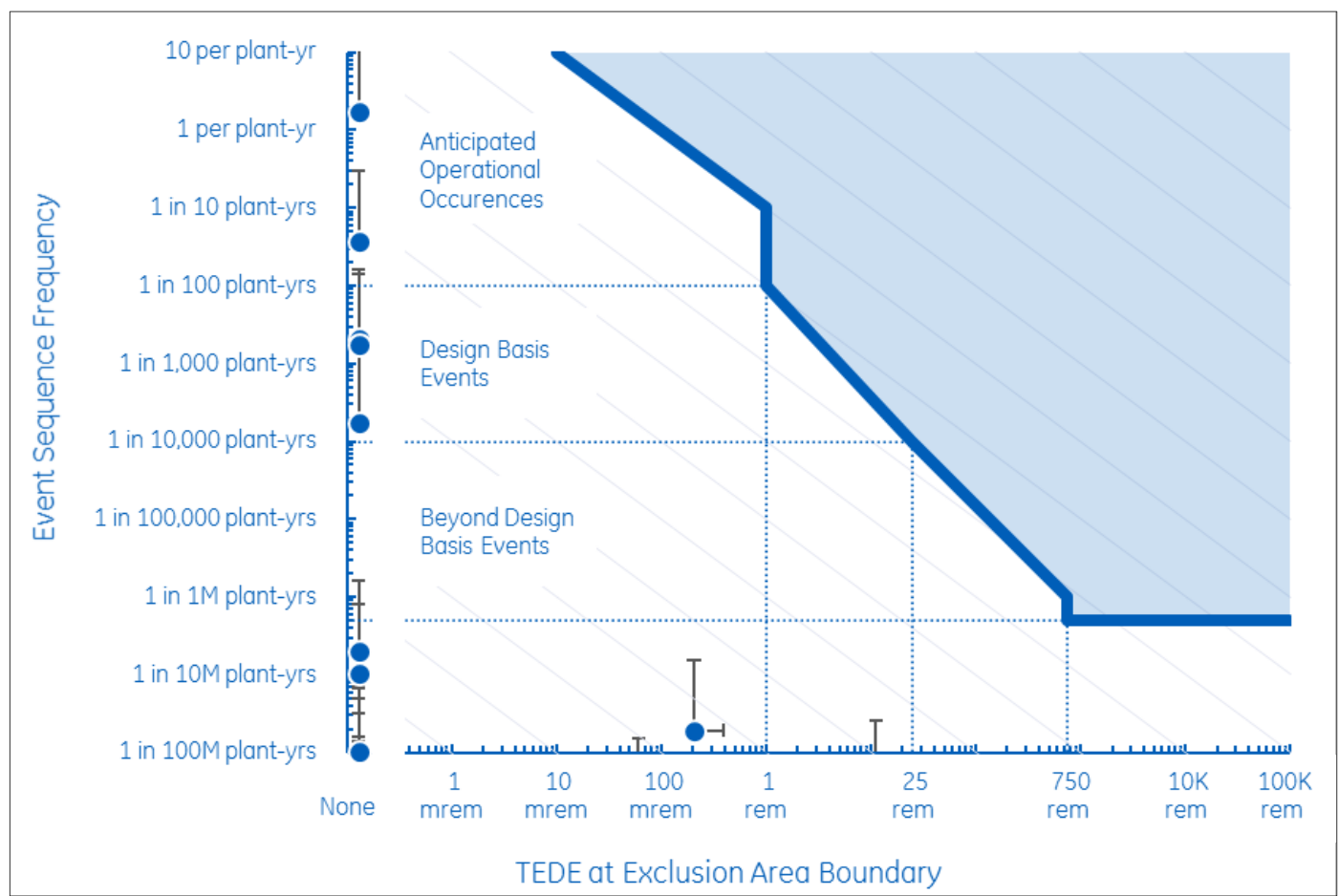

Figure 3-19. Example PRISM LBEs Compared with TLRC Frequency-Dose Evaluation Criteria

\subsection{PRA Development for Molten Salt Reactors}

The University of California, Berkeley, Massachusetts Institute of Technology, and University of Wisconsin-Madison hosted a series of four workshops during 2012 under a DOE project to review technical and licensing issues for FHRs. The focus of the first workshop was to identify key development goals for FHRs, including the major technical characteristics that differentiate FHRs from other power reactor technologies, the major systems and subsystems expected to be used in FHRs, high-level functional requirements for these systems and subsystems, and LBEs that should be considered in FHR design and licensing. ${ }^{[80]}$

In the course of identifying LBEs, the experts followed a thought process that is outlined in the NGNP white paper on selection of LBEs. While an actual PRA was not fully developed, the workshop produced an identification of safety functions, technical requirements, and a preliminary list of initiating events that would be useful as a first step in producing an FHR PRA. The preliminary list of initiating events is reproduced in Table 3-10. An example event tree for the loss of the power conversion unit produced in the workshop is shown in Figure 3-20. 
Table 3-10. Preliminary List of Initiating Events Selected for the FHR From Reference [80]

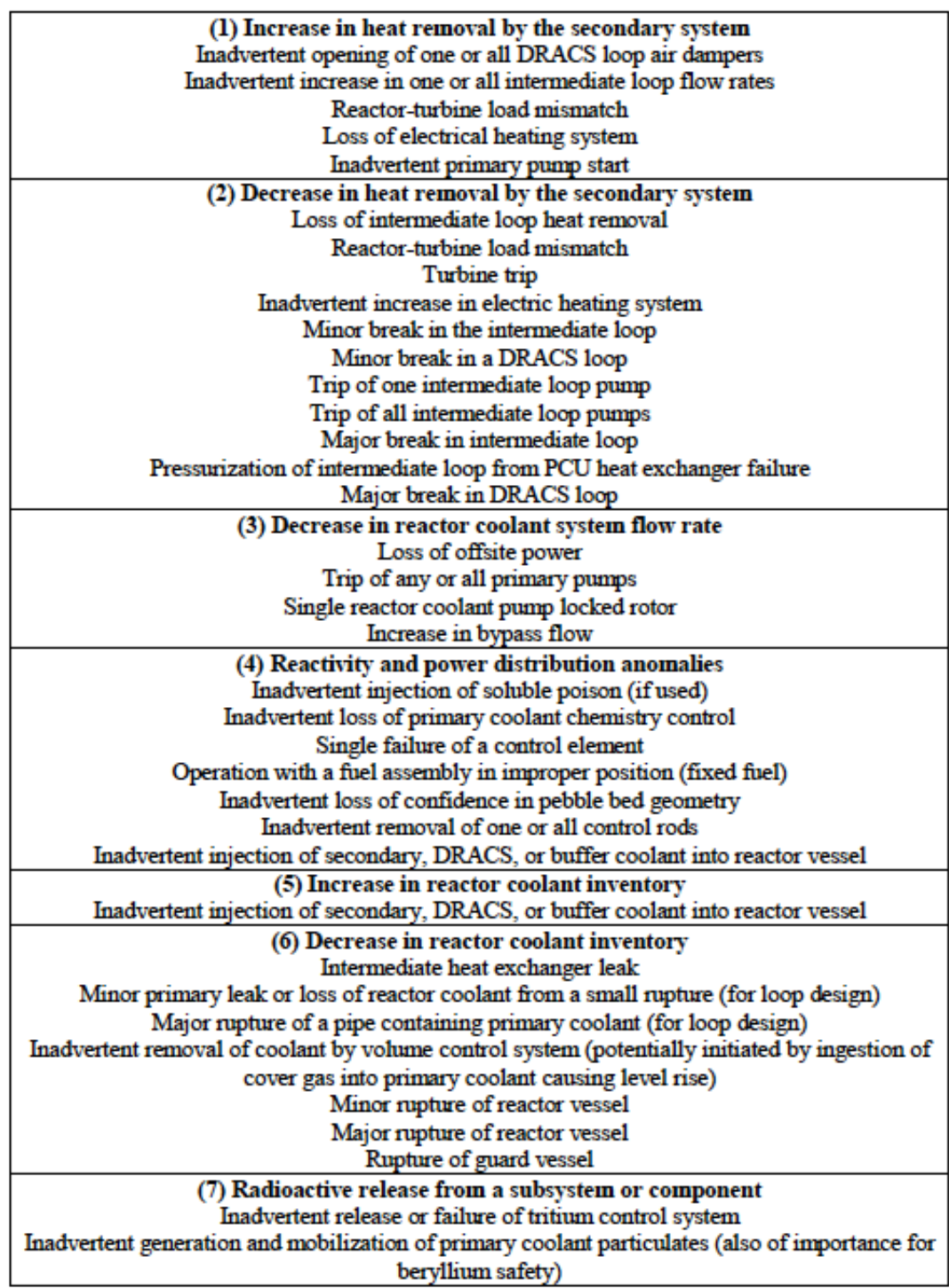

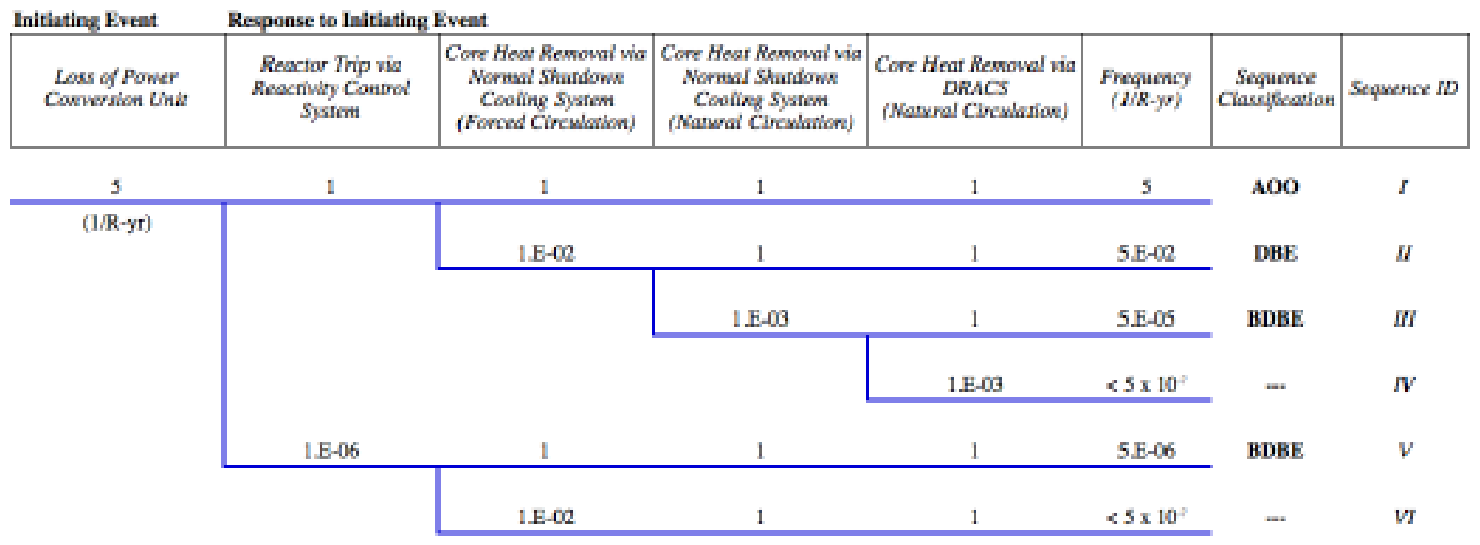

Figure 3-20. Sample Event Tree for the Loss of Power Conversion Unit in an FHR From Reference [80] 
Vanderbilt University has performed and is performing several projects to advance the state of practice for PRAs for molten salt reactors. These include an EPRI-sponsored project to demonstrate the use of PHA methods to inform the development of a knowledge base for a PRA model using the MSRE as an example. ${ }^{[1]}$ The other is a tabletop demonstration of the LMP methodology for the MSRE. Some early work toward the tabletop is documented in Reference [82] which included the definition of PRA safety functions for the MSRE as shown in Figure 3-21. A preliminary list of initiating event groups with specific initiating event examples is shown in Table 3-11.

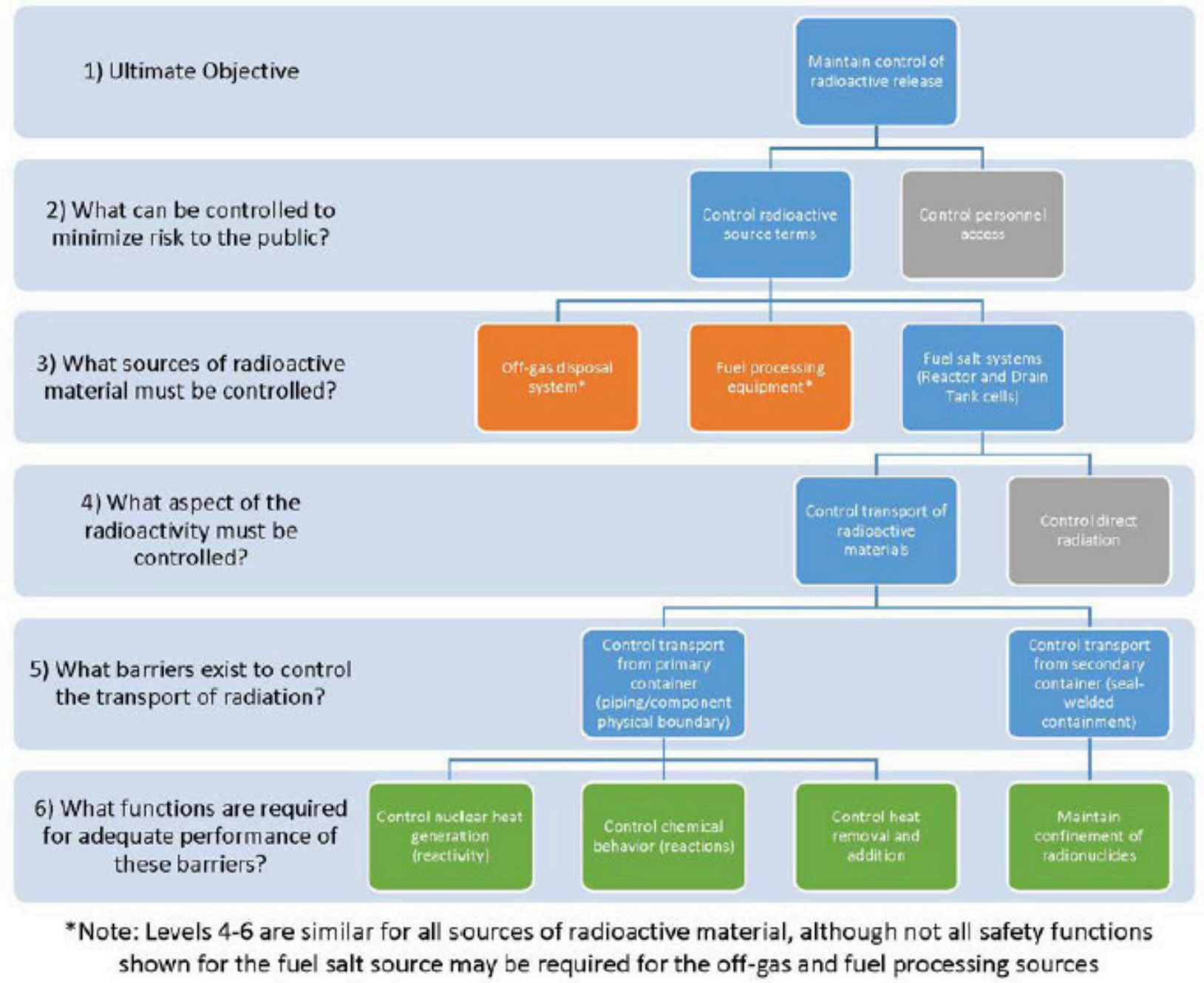

Figure 3-21. PRA Safety Functions for the MSRE ${ }^{[82]}$ 
Table 3-11. Initiating Events for the MSRE ${ }^{[82]}$

1. Increase in heat removal by coolant system

a. Inadvertent raising of radiator door

b. Radiator blower overspeed

2. Decrease in heat removal from fuel salt (or increased electrical heat addition)

a. Coolant salt pump failure

b. Plugging in coolant salt loop

c. Plugged drain line

d. Failure of drain tank afterheat removal system

e. External heaters over-temperature

f. Inadvertent load scram

3. Decrease in fuel salt flow rate

a. Fuel pump failure

b. Plugging in fuel salt loop

4. Reactivity and power distribution anomalies

a. Unexpected criticality during startup

b. Fuel separation

c. Collection of separated fuel material in reactor core

d. Cold slug upon pump start

e. Uncontrolled rod withdrawal

5. Leakage of substance through the first barrier

a. Heat exchanger leak

b. Heat exchanger tube rupture

c. Leak of drain tank heat removal system

6. Decrease in fuel salt inventory for a given volume

a. Inadvertent melting of FV

7. Radioactive release from a subsystem or component

a. Leaking of FV

b. Leaking/failure of freeze flange

c. Ignition of charcoal beds in off-gas system 


\subsection{ADVANCED NON-LWR PRA TECHNICAL ADEQUACY FOR RISK-INFORMED AND PERFORMANCE-BASED APPLICATIONS}

The purpose of this section is to discuss technical issues and challenges for advanced non-LWR PRA and the proposed approach for achieving technical adequacy that is fit-for-purpose for the intended PRA applications during design development and licensing.

\subsection{Technical Issues and Challenges for Advanced non-LWR PRA}

There are several technical issues and challenges in developing the advanced non-LWR PRAs within the LMP methodology. Providing a context for the approach to PRA technical adequacy requires resolution of these issues, which are listed below and are discussed in the following sections.

- PRA treatment of multi-reactor module plants

- Sufficiency of relevant PRA data

- Identification of initiating events for new designs

- Development of mechanistic source terms for new designs

- Treatment of inherent and passive safety features

- New risk-informed applications for non-LWR PRAs

- Use of dynamic PRA methods

\subsubsection{PRA Treatment of Multi-Reactor Module Plants}

As discussed more fully in the companion report on the LMP approach to selection of LBEs, the scope of the PRA is intended to cover all the reactor modules and radionuclide sources that may be within the scope of an advanced non-LWR plant design. This is to ensure that there is sufficient feedback to the plant design team on multi-module and multi-source risk insights so that design strategies to manage the risks of multi-module and multi-source accidents can be implemented. An important safety design strategy is to ensure that there are no risk significant accident sequences that involve releases from two or more reactor modules or radionuclide sources. This strategy is also required to justify the definition of design basis accidents in a manner that single reactor source terms are involved as explained more fully in the LMP report on selection and evaluation of LBEs.

Although the vast amount of experience with the performance of nuclear reactor PRAs has been limited to single reactor PRAs, there have been multi-unit and multi-module PRAs on LWRs as well as non-LWRs. In addition, there are number of references available to provide useful guidance in the performance of both multi-unit PRAs for operating LWR plants as well as future non-LWR plants that are based on a modular plant design.

A summary of some key available references is provided in Table 4-1. The example PRAs summarized in the previous section for the MHTGR and PRISM both included multi-module 
treatment. Examples of LBEs developed from these PRAs that involve both single reactor units, and multiple reactor units are provided in the LMP report on LBE selection and evaluation. However, neither of these PRAs included non-core sources of radioactive material due to lack of sufficient design details on the systems and structures associated with these sources.

Table 4-1. References for Multi-Module PRA Development

\begin{tabular}{|c|c|}
\hline Category & Reference \\
\hline $\begin{array}{l}\text { Non-LWR Case } \\
\text { Studies }\end{array}$ & $\begin{array}{l}\text { MHTGR PRA (4 Reactor Modules) } \\
\text { PRISM PRA ( } 2 \text { Reactor Modules) }{ }^{[9]} \\
\text { HTR-PM PRA (2 Reactor Modules) }\end{array}$ \\
\hline $\begin{array}{l}\text { Non-LWR Guidance } \\
\text { and Standards }\end{array}$ & $\begin{array}{l}\text { ASME/ANS Non-LWR PRA Standard }{ }^{[45]} \\
\text { NGNP PRA White Paper }{ }^{[6]}\end{array}$ \\
\hline LWR Case Studies & $\begin{array}{l}\text { Seabrook PRA ( } 2 \text { Reactor Units) } \\
\text { NRC Level } 3 \text { PRA ( } 2 \text { Reactor Units) } \\
\text { NuScale Multi-module PRA } \\
\text { [73] }\end{array}$ \\
\hline $\begin{array}{l}\text { LWR Guidance and } \\
\text { Standards }\end{array}$ & $\begin{array}{l}\text { IAEA Technical Approach to Multi-Unit PSA } \\
\text { IA2][50] } \\
\text { CanA TECDOC } 1804^{[51]} \\
\text { Internation Nuclear Safety Commission } \\
\text { Inorkshop on Multi-Unit PSA }\end{array}$ \\
\hline
\end{tabular}

Frameworks for performing a multi-unit or multi-module PRA have been developed in several of these references. The framework developed by the IAEA as part of "Technical Approach for Multi-Unit Probabilistic Safety Assessment" ${ }^{\text {[52] }}$ is shown in Figure 4-1. The approach followed in the NRC Level 3 PRA project ${ }^{[56]}$ is shown in Figure 4-2. The approach followed in both of these cases is to first perform a single reactor unit PRA, and then to use the data and models from the single reactor PRA to build a model that addresses accidents involving two or more reactor units or modules. 


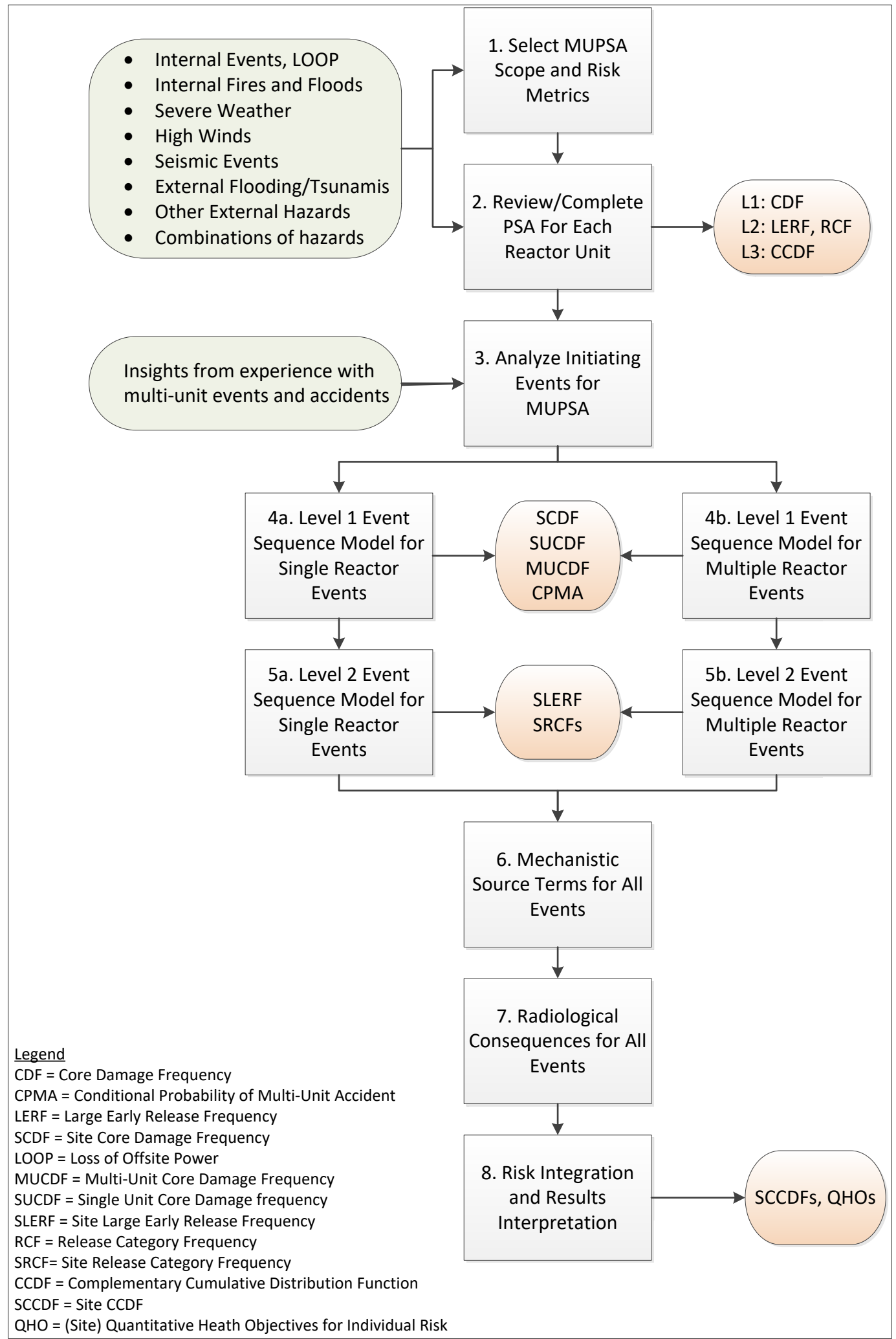

Figure 4-1. IAEA Framework for Multi-Unit Site PRAs ${ }^{[52]}$ 


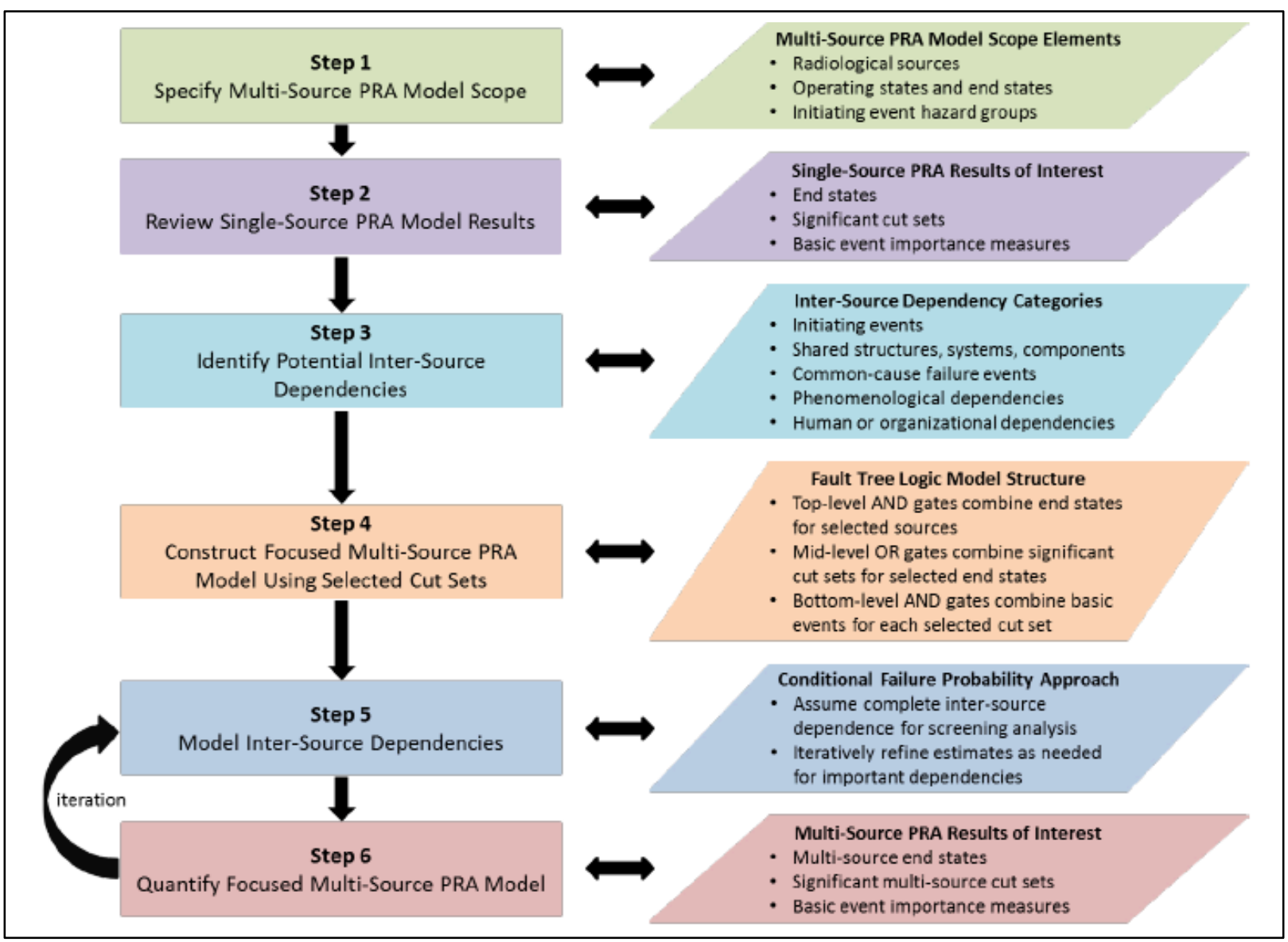

Figure 4-2. Multi-Unit Risk Approach in NRC Level 3 Project ${ }^{[56]}$

In this part of the model, the IEs from the single reactor model need to be analyzed to break down which events affect a single module and those that impact two or more modules. Multimodule IEs would typically include loss of offsite power, loss of any shared systems, Internal hazard events such as fires and floods that may occur in any shared structures, and most of the IEs caused by an external hazard such as seismic events and external flooding. Some of the technical issues that must be addressed in the modeling of multi-module accidents include:

- Increased stress and workload on plant operators in implementing emergency operating procedures, accident management, and emergency planning

- Analysis of common cause failures to distinguish between those confined to a single module and those that may occur in different modules

- Correlation of seismic fragilities for SSCs appearing in single and multiple modules characterized by the same fragility curve

- Treatment of time dependent releases that may occur from more than one location in the plant

- PRA modeling complexity when the plant to be analyzed includes more than two reactor modules 
- Need to select risk metrics that sufficiently capture the dimensions of multi-unit risk including the increase in the frequency of a single module accident due to more modules being at risk and the introduction of new types of accidents that involve two or more reactors or radionuclide sources

These and other issues have been addressed in the available case studies and guidance documents to varying degrees. It is emphasized that that inclusion of multiple modules and sources serves to capture sufficient risk insights to implement effective risk management strategies.

\subsubsection{Sufficiency of Relevant PRA Data}

Questions have been raised as to whether there are sufficient PRA data to perform advanced nonLWR PRAs and whether uncertainties associated with availability of relevant data can be sufficiently addressed.

To address this question, it is helpful to clarify the distinction between probabilistic risk assessment (PRA) and statistical analysis of data. PRA is an investigation of rare events for which direct statistical data is insufficient to characterize risks using statistical methods. There is some role for statistical analyses to support a PRA, but this is performed at the level of events and components and not for estimating the overall plant risk.

There are four major categories of advanced non-LWRs being considered today including high temperature gas cooled reactors, sodium cooled fast reactors, molten salt reactors, and microreactors using heat pipes. There has been progress made to varying degrees to develop PRA models and supporting databases for each one of these reactor types.

In contrast with the challenges faced by Rasmussen, these advanced reactor PRAs benefit from using many components and systems that are common to LWRs and therefore benefit from the LWR service experience that has been responsible for reducing uncertainties in estimating most of the PRA component level data. For components unique to each advanced reactor, there is evidence to support the estimation of failure data from research and test reactors, non-reactor facilities that have service conditions similar to those in the reactors, and engineering judgements to compare the new components to those for which service data is available.

The PRA data parameters for the non-LWR PRA database will include the following data categories:

1. Failure rates and unavailability parameters for active components unique to the non-LWR (e.g. gas blowers and compressors for HTGRs and electromagnetic pumps for liquid metal reactors)

2. Failure rates and unavailability parameters for active components common to LWRs (e.g., pumps and valves in water systems, water-to-water heat exchangers, diesel generators, breakers, and instrumentation and control components) 
3. Common cause failure parameters for a limited set of redundant components (Based on experience with the MHTGR and PRISM PRAs, these parameters are mostly in common cause groups of components typical for LWRs.)

4. IE frequencies and failure probabilities for passive component failure modes (e.g., pipes, pressure vessels, weldments, and pressure relief valves)

5. IE frequencies for power conversion system and other equipment failure modes common to LWRs (e.g. loss of feedwater, turbine trip, loss of offsite power, electrical system faults)

6. IE frequencies for internal and external plant hazards found in full-scope LWR PRAs (fires, floods, seismic events, transportation accidents)

Of the six categories of data parameters listed above, the ones that are subjected to the most uncertainty due to lack of relevant operating experience for non-LWRs in general are Categories 1 and 4 and to a lesser extent Category 3. For the remaining categories, as well as most of the parameters expected in Category 3, the advanced non-LWR may benefit from PRA data that have been developed for LWRs. The extent of non-LWR PRA data development, of course, will vary among the various reactor types.

There is a rich history of PRA development for SFRs and HTGRs. The database that was developed to support the recent PRA on PRISM, which benefits from operating experience with sodium reactors is summarized in Reference [63]. The PRA data developed for the MHTGR PRA, which benefited from service experience with gas-cooled reactors in the U.K, is documented in Reference [8]. For the PBMR project in South Africa, service experience with LWRs and evaluations of HTGR degradation mechanism were used to develop HPB IE frequencies as illustrated in Figure 4-3. This assessment benefitted from the use of LWR materials and design codes for the HPB piping.

In Reference [84], a PRA model and supporting data is developed to apply the predecessor methodology to LMP from the NGNP program to a molten salt reactor. This work is one of the data sources used to support the development of the PRA for the MSRE LMP demonstration in Reference [85]. Reference [86] describes the LMP demonstration for the Westinghouse MicroReactor which used engineering judgement to apply data from LWRs and industrial sources. 


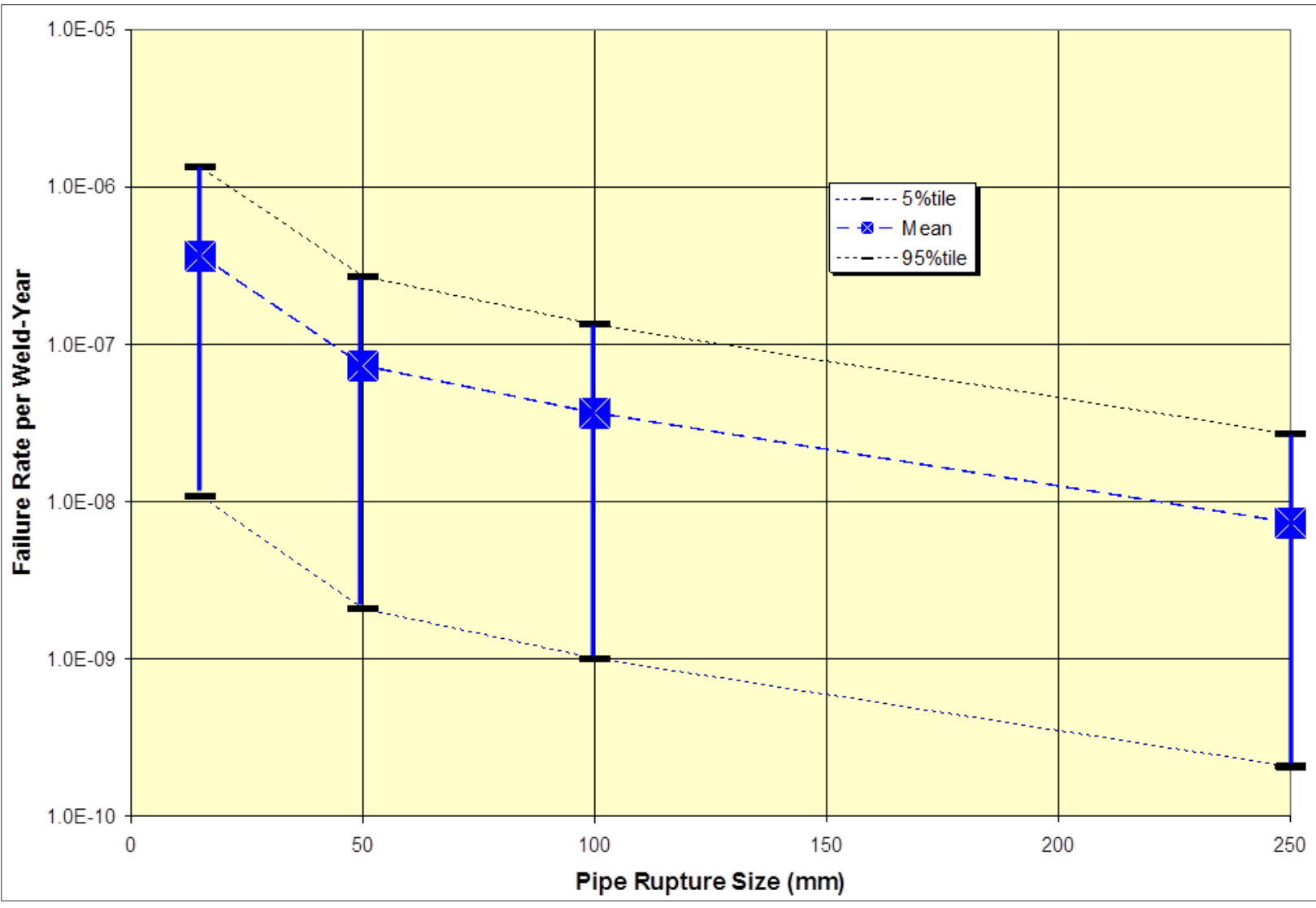

Figure 4-3. Failure Rate vs. Rupture Size for 250 mm Carbon Steel Pipe Weld on PBMR HPB ${ }^{[61]}$

To provide a perspective on the technical issues that need to be addressed in non-LWR PRA database development, the fact that many of the PRA data parameters can be addressed using PRA data from LWR PRAs means that the challenge is not nearly as significant as it was for the first LWR PRA published in WASH-1400. ${ }^{[6]}$ The Reactor Safety Study was performed before any of the then limited amount of service experience * was analyzed to develop failure rates and IE frequencies for the early LWR PRAs. Generic non-nuclear sources were used to develop component failure rate estimates. Loss of coolant accident frequencies were estimated using gas pipeline data and service experience from fossil fuel power plants and engineering judgements to account for the expected reliability improvements from ASME nuclear piping and pressure vessel codes. Today, with the benefit of extensive service experience, uncertainties in the values of data parameters for relatively frequent events have been greatly reduced. However, uncertainties in the values of data parameters for rare events continue to be large as even thousands of reactor years of service data is insufficient alone to provide a statistical basis for failure rate estimates. It is noted that today, LOCA frequencies are not estimated directly from data but rather from an expert elicitation. ${ }^{[67]}$ Such expert elicitation approaches may be needed to establish estimates for non-LWR PRA parameters for components with little or no available

\footnotetext{
${ }^{*}$ When the Reactor Safety Study was performed, there were only about 400 reactor-years of service experience with LWRs, and no studies had been performed to convert this experience into PRA data parameters.
} 
service experience. Hence, the perspective on current PRA data available to support LWRs has the same general character, the only difference being a matter of degree.

The PRA database developed in WASH-1400 was the primary basis for the first decade of PRA development until LWR service experience could be factored in. In retrospect, that data was sufficient to support the early applications of PRA which included the resolution of generic and unresolved safety issues associated with severe accidents. Advanced non-LWR PRAs need to deal with a smaller scope of data parameters that are not supported by available reactor service data. Notwithstanding, it will be important that uncertainties in the data parameter estimates be well characterized and managed in a fashion that reflects the state of knowledge regarding the parameters.

A very important aspect of developing data for any PRA, including those on advanced nonLWRs, is the treatment of uncertainty in the estimation of the data parameters on initiating event frequencies, component failure rates and maintenance unavailabilities, common cause failure parameters, and human error rates. The PRA standard for advanced non-LWR requires that uncertainties be addressed in all the technical elements of the PRA including the treatment of data. ${ }^{[46]}$ Guidance on the PRA treatment of uncertainties is available in Reference [68].

\subsubsection{Identification of Initiating Events for New Reactor Designs}

In general, the methods for the systematic search for initiating events in PRA include:

- Plant level Failure Modes and Effects Analysis (FMEA) where the faults are postulated at the system and system train level and the effects are evaluated on the overall plant response, including an initiating event with potential adverse impacts on mitigating systems

- Master Logic Diagram in which a logic tree is developed in a top-down fashion to identify the causes of an adverse plant state in terms of the sources of radionuclides affected, the safety functions impacted, and the initiating events that could trigger an adverse end state

- Heat Balance Fault Tree (HBFT) in which a logic tree is developed to identify disturbances in the plant heat balance that could initiate a plant transient and resulting initiating event

- Process Hazards Analysis such as HAZOPs in which deviations in plant process parameters are postulated and their causes, effects and corrective actions are evaluated.

- Reviews of initiating events from reactor operating experience, NRC reports, and results of published PRAs

The systematic search for initiating events for the MHTGR PRA using a form of the MLD method is described in Section 3.8.1. In Section 3.9.1, the selection of initiating events for PRISM is described. Additional examples of applications of these approaches may be found in many published PRAs on LWRs. The original South Texas Project PSA documents the analysis of initiating events using many of the above-listed methods, including MLD, HBFT, FMEA, and comparison with experience. ${ }^{[87]}$ The EPRI project on PHA to PRA transition, which was responsible for the LMP MSRE demonstration, ${ }^{[85}$ is an excellent example of a PRA where PHA techniques such as HAZOPs were used to inform the selection of initiating events and build the 
knowledge base for developing a PRA model. Additional guidance for this approach is found in References [88] and [89]. More recent work to advance the development of MLDs for the systematic search of initiating events and building the PRA logic models for event sequence development may be found in References [90] and [91].

\subsubsection{Mechanistic Source Term Development}

PRAs developed to support the LMP methodology as well as deterministic safety analyses will require the development of mechanistic source terms for event sequences involving a release of radioactive material. The term mechanistic source terms is used to identify the need to estimate the reactor design-specific source terms based on the radionuclide transport mechanisms associated with that reactor, rather than a conservatively estimated source term such as was used to license existing operating reactors. Technical requirements to develop mechanistic source terms for the PRA are included in the PRA standard for advanced non-LWRs. ${ }^{[4]}$ The resulting source terms from meeting these requirement for any advanced non-LWR will be highly technology- and design-specific. The level of technology development to support mechanistic source terms is different for different reactor technologies and is relatively more mature for HTGRs and SFRs.

A good process for developing mechanistic source terms and the associated technology is the development of a white paper, such as was done for HTGRs in the NGNP project. ${ }^{[2]}$ As part of the NGNP project, an evaluation of uncertainties in the development of mechanistic source terms for an HTGR design based on the South African pebble bed reactor was used to develop design specifications for the radionuclide retention capabilities of barriers, including the TRISO fuel barrier, the helium pressure boundary barrier, and the reactor building barrier in Reference [93]. There has also been a lot of technology development to support the estimation of mechanistic source terms for SFRs. Reference [94] addresses how the PRA standard requirements for source terms were developed for PRISM. While these references for HTGRs and SFRs are associated with specific reactor technologies, they offer useful guidance to the work that needs to be done for other advanced reactor concepts to develop mechanistic source terms.

\subsubsection{Treatment of Inherent and Passive Safety Features}

Evolutionary LWRs and advanced non-LWRs rely more on inherent and passive safety features and less on active SSCs in the performance of safety functions, consistent with the NRC advanced reactor policy. ${ }^{[28]}$ Consistent with the approach that is used for the treatment of passive and inherent safety features, the approach used in non-LWR PRAs is to use phenomenological models supported by a robust uncertainty analysis to analyze the plant transient response to events, success criteria, and mechanistic source terms. This can be contrasted with traditional PRA modeling of active systems based on fault trees, failure rates, maintenance unavailability parameters, common cause models and parameters, and human reliability models. Useful guidance on this aspect of the PRA is provided in the Standard Review Plan Chapter 19. ${ }^{[30]}$ In the recent upgrade to the PRISM PRA, a comprehensive uncertainty analysis was performed to support the PRA success criteria and meet associated requirements for passive systems in the ASME/ANS PRA standard for advanced non-LWRs, as 
discussed more fully in Reference [65]. This work benefited from a European Commission project that developed methods for passive component reliability. ${ }^{[95]}$

An important insight for the evaluation of defense-in-depth adequacy is that passive SSCs may be subject to service life degradation, and hence programmatic measures such as in-service inspection may be considered.

\subsubsection{Need to Address New Risk-Informed Applications}

The PRAs performed under the LMP methodology are intended for a broader range of riskinformed and performance-based decisions including input to selection of LBEs, SSC safety classification, and evaluation of DID adequacy. In addition, any risk-informed licensing decisions that are supported by the PRA would be subject to full licensing review by including the justification for the decision as part of the license application or supporting topical report.

\subsubsection{Role of Dynamic PRA Methods}

The LMP methodology was developed with the assumption that the PRAs would be based on the conventional event tree/fault tree methods that are reflected in the current PRA standard for both LWRs and non-LWRs. In principle, the PRA standard are supposed to define "what to do" rather than "how to do it." However, both the LWR and non-LWR standards and the supporting industry guidance on PRA peer reviews were written under the assumption that the PRA model would be based on event sequences defined in event trees and fault trees and that quantification of event sequence frequencies would be based on initiating event frequencies and basic event probabilities.

Since the inception of the PRA event tree/fault tree methodology, more advanced methods have been introduced that provide enhanced capabilities for modeling the time-dependent interactions of SSC failures and event sequence progression. These are often referred to as "dynamic PRA" methods. Such methods do not use event trees/fault trees and do not represent event sequences in the form assumed in the PRA standards, but rather they use simulation techniques to represent event sequences in a manner more like they occur in an actual plant. It is noted that the available methods of dynamic PRA have not been standardized in terms of scope and capability.

A significant degree of interpretation would be needed to apply the current PRA standards for both non-LWRs and LWRs to dynamic PRAs in establishing PRA technical adequacy. As explained more fully in the LMP report on DID evaluation, a focus of the LMP DID evaluation is the examination of limitations and uncertainties identified from the PRA. The process for identifying these limitations and uncertainties is framed in the context of the technical requirements in ASME/ANS RA-S-1.4-2013 and the results of the peer reviews performed against this standard. Hence, when dynamic PRA methods are used, how the PRA standards and supporting peer review processes have been interpreted and applied needs to be addressed in order to establish the PRA technical adequacy and DID evaluation aspects of the LMP methodology. 


\subsection{ASME/ANS PRA Standard for Advanced Non-LWR PRA RA-S-1.4-2013 ${ }^{[46]}$}

\subsubsection{Non-LWR PRA Standard Development}

For non-LWRs, the guidance in the ASME/ANS RA-S-1.4 provides an acceptable means to establish the scope and technical adequacy of the PRA. The scope and level of detail of the PRA models align with the state of definition of the design, the safety design approach, and systems design concepts. As the design matures and more design information becomes available for different types of risk evaluations, the scope of the PRA can be broadened to address other plant conditions and progressively confirm the plant capability to meet safety objectives.

When the NGNP PRA white paper was developed in 2011, the only published PRA standards were for currently operating LWR nuclear power plants. In December 2013, the ASME/ANS Joint Committee on Nuclear Risk Management (JCNRM) issued a trial use PRA standard for advanced non-LWR nuclear power plants. This standard was developed to support PRA development and risk-informed applications on advanced non-LWR nuclear power plants. The stakeholders who participated in the development of this standard included the Exelon PBMR project, the DOE NGNP project, the China HTR-PM project, several SFR projects including GEPRISM, the Argonne National Laboratory/Korea Atomic Energy Research Institute fast reactor project, and the TerraPower Traveling Wave Reactor project. Since the trial use standard was issued, representation on the JCNRM non-LWR project team responsible for the standard was expanded to include representation by the molten salt reactor community and the X-energy project to develop a small modular HTGR based on the pebble bed fuel concept.

Several representatives of the NRC participated on the JCNRM non-LWR project team responsible for developing the trial use standard, but the NRC has not endorsed it because there were no active licensing interactions with a prospective non-LWR licensee when the standard was issued for trial use. During the trial use period, which ended in December 2016, there were several pilot PRA projects that utilized the vast majority of the technical requirements in the standard and provided feedback to the project team which will provide the technical basis for a revised ANSI standard which is currently being developed. The following pilot PRAs were performed that provided feedback to the project team:

- GE-Hitachi performed a project for DOE which included a major PRA upgrade for the GEPRISM reactor, a pool type liquid metal fast reactor. One of the objectives of this project was to pilot the non-LWR PRA standard. Public domain references for this PRA are found in References [9], [63], [64], and [65].

- A PRA was performed using the non-LWR standard to meet licensing requirements for the HTR-PM under construction in China. This reactor is a pebble bed type HTGR. A preliminary PRA was performed and included in the Preliminary Safety Analysis Report which was required to obtain a construction permit, and a more comprehensive PRA is currently being completed to meet a requirement for an operating license. ${ }^{[62]}$

- TerraPower is performing a PRA using the non-LWR standard to support the design of the Traveling Wave Reactor, a sodium-cooled fast reactor that is designed to utilize spent 
LWR fuel as a fuel source. Feedback from this PRA was incorporated into the trial use standard and continues to support the development of the next edition of the standard.

- Argonne National Laboratory has participated in the development of the trial use standard and has incorporated experience in supporting the design of another liquid metal fast reactor being developed in Korea. Argonne National Laboratory has also participated in the GE-PRISM PRA upgrade and has used the requirements in the standard for mechanistic source terms to guide the development of source term technology for SFRs.

- The trial use standard was sponsored in part by the PBMR project in South Africa and the DOE NGNP project and reflected the lessons learned from those PRA projects.

- PRAs using the standard have been recently initiated for the X-energy pebble bed reactor, the Molten Chloride Fast Reactor, as well as HTGRs and sodium reactors under development in Japan.

At the September 2016 meeting of the JCNRM, it was decided to move forward with the development of an ANSI standard for non-LWR PRAs. The schedule to prepare the draft for ballot review is December 2018. By the time Phase 2 of this LMP is completed, it is quite likely that the next edition of this standard will be available to support future non-LWR PRAs. Hopefully, circumstances will permit NRC's continued involvement in the JCNRM project team responsible for this standard and for NRC to endorse this standard as it has endorsed the LWR PRA standards in RG 1.200. ${ }^{[33]}$

To provide a suitable PRA standard for HTGRs, SFRs, and a wide variety of prospective advanced reactor concepts, a reactor technology neutral approach to writing the PRA requirements was adopted. Approximately $80 \%$ of the technical requirements in this non-LWR standard are the same as or similar to PRA requirements in LWR PRA standards including ASME/ANS-RA-Sb-2013, ${ }^{[45]}$ and the ANS PRA standards that have been and are being developed for low power and shutdown PRAs, and Level 2 and Level 3 PRAs. The requirements in the non-LWR PRA standard have been organized into 18 PRA elements, which are defined in Table 4-2. This table identifies similarities and differences with corresponding LWR PRA standards. 
Modernization of Technical Requirements for Licensing of Advanced Non-Light Water Reactors:

Probabilistic Risk Assessment Approach

\section{Table 4-2. Elements of ASME/ANS Non-LWR PRA Standard and Comparison with LWR PRA Standards}

\section{ASME/ANS-RA-S-1.4-2013 ${ }^{[46]}$}

Plant Operating State Analysis (POS)

Initiating Event Analysis (IE)

Event Sequence Analysis (ES)

Success Criteria Development (SC)

Systems Analysis (SY)

Human Reliability Analysis (HR)

Data Analysis (DA)

Internal Flood PRA (FL)

Internal Fire PRA (FI)

Seismic PRA (S)

Other Hazards Screening Analysis (EXT)

High Winds PRA (W)

External Flooding PRA (XF)

Other Hazards PRA (X)

Event Sequence Quantification (ESQ)

Mechanistic Source Term Analysis (MS)

Radiological Consequence Analysis (RC)

Risk Integration (RI)

\section{Corresponding LWR PRA Standard}

Similar to POS in ANS Low Power and Shutdown PRA standard ${ }^{[47]}$ to support PRA models covering operating and shutdown modes

Similar to IE in ASME/ANS-RA-Sb-2013 ${ }^{[45]}$ except that LWR IE categories are replaced by reactor technology neutral categories and both single unit and multi-unit initiators are included

Similar to AS in ASME/ANS-RA-Sb-2013 except that event sequences are developed to user defined intermediate end states and release categories

Similar to SC in ASME/ANS-RA-Sb-2013 except that safe stable end states are defined to prevent user defined end states rather than to prevent core damage and large early release

Similar to SY in ASME/ANS-RA-Sb-2013

Similar to HR in ASME/ANS-RA-Sb-2013

Similar to DA in ASME/ANS-RA-Sb-2013

Similar to FL in ASME/ANS-RA-Sb-2013

Similar to FI in ASME/ANS-RA-Sb-2013

Similar to $S$ in ASME/ANS-RA-Sb-2013

Similar to EXT in ASME/ANS-RA-Sb-2013

Similar to $W$ in ASME/ANS-RA-Sb-2013

Similar to XF in ASME/ANS-RA-Sb-2013

Similar to $X$ in ASME/ANS-RA-Sb-2013

Similar to QU in ASME/ANS-RA-Sb-2013 except that the event sequences are mapped to user defined end states and release categories and cover anticipated events, and events within and beyond the design basis, and accidents involving single reactor units and multiple reactor units

Similar to source term requirements in ANS Level 2 PRA standard ${ }^{[48]}$ except that source terms cover both single unit and multiple reactor units

Similar to the requirements in the ANS Level 3 PRA standard ${ }^{[77]}$ except that there is an option to limit the scope to the performance of site boundary dose calculations rather than a full Level 3 analysis

This PRA element is unique to the non-LWR PRA standard and includes requirements to combine the results of the ESQ and RC elements to affect an integrated risk assessment with options to combine the information in different ways. This includes requirements to establish the risk significant release categories which is then used in ESQ to decompose the risk significant accident sequences and basic events. 
The key differences between the non-LWR and the supporting LWR standards are listed below.

- When the non-LWR PRA is developed to its fullest scope, the event sequences are developed sufficiently to establish a comprehensive set of release categories each with a mechanistic source term, a quantification of radiological consequences, frequencies, and risk.

- Core damage frequency is not used because existing definitions of CDF are in terms of LWR characteristics (liquid level in the reactor vessel, oxidation temperature of zircalloy cladding, metallic fuel melting, etc.) that may not have a counterpart in the non-LWR plant. As explained more fully in Section 3.7, this standard includes technology neutral risk metrics including frequency and site boundary dose consequences for each accident family or LBE, the individual risk metrics for the NRC Safety Goal QHO comparisons, and complementary cumulative distribution curves (frequency of exceeding selected consequence metrics). The standard includes provisions and requirements for user defined reactor-specific metrics as well as the technology inclusive metrics of LBE frequency and dose, the QHO metrics, the 10 CFR 20 metric, and the metrics embodied with the F-C target.

- The non-LWR standard includes requirements to support a multi-unit PRA for multi-unit and modular reactor designs. These requirements are included to enable the PRA to provide risk insights to design features to effectively manage the risks of accidents involving multiple reactor modules.

- To support PRAs performed for a range of sites rather than a specific site as may be required to support a design certification application, the technical requirements for probabilistic hazards analysis for seismic events, high winds and wind generated missiles, external flooding, and other external hazards have been written to support hazard analyses for a set of site parameters that envelope those intended to be covered by the design certification. A seismic PRA that covered a range of Eastern U.S. sites was performed as part of the MHTGR PRA. Guidance for establishing design assumptions for a range of sites and establishing the corresponding plant parameter envelope is available in References [78] and [79].

- PRA peer reviews for advanced non-LWRs are expected to confirm that technical requirements used in the PRA are met as will the current LWR PRA peer reviews. An emphasis of these reviews will focus on elements that are different than LWR PRAs arising from fundamental differences in the safety design approach as well as limitations of PRAs that are performed during preoperational phases. The major elements that are different include the event sequence end states and risk metrics, approach to evaluating success criteria, treatment of technology specific phenomena, and treatment of uncertainty due to lack of experience with the reactor technology. Consideration should be given to "in process" reviews rather than reviews applied near the completion of the PRA. 


\subsubsection{Role of PRA Standard in Supporting LMP Methodology}

The ASME/ANS PRA Standard for Advanced non-LWRs was developed to support a broad range of PRA applications that are envisioned for advanced non-LWRs. These applications include new licensing applications not previously done for operating or advanced LWRs. This is reflected in the following statement in the forward of the standard:

The expected applications of such PRAs include input to licensing and design decisions such as selection of licensing basis events and safety classification of equipment, satisfaction of NRC PRA requirements for advanced non-LWRs, and support of risk-informed applications for advanced non-LWR nuclear power plants. With the concurrence of JCNRM, the non-LWR working group decided early on that a new PRA standard was needed to support a broad range of applications for advanced reactor designs.

The LMP methodology has adopted this standard to support a similar set of applications. The standard is not tied to a specific licensing approach such as that considered within the LMP methodology. From the point of view of the LMP, the purpose of the PRA standard is to support the development of baseline PRAs that will provide information to support RIPB design and licensing decisions such as those listed above from the forward of the standard. The scope of the PRA standard covers the capabilities of the PRA to provide the necessary risk inputs to RIPB decisions for a spectrum of non-LWR designs.

The PRA Standard for advanced non-LWRs was developed with the specific intent of supporting PRAs being developed early in the design and in any pre-operational design, construction and licensing stage. There are specific requirements in the standard to identify assumptions and source of uncertainty associated with lack of as-built and as-operated design and operational details. In addition, the PRA applications process described in the standard calls for the user to determine the appropriate scope of the PRA requirements to apply in early stages of the design.

- If the PRA is introduced at an early stage of design, it is expected that there will be a number of iterations involving changes to plant design, PRA upgrades and revisiting of the tasks in the LMP methodology involving LBE selection and evaluation, SSC safety classification, and selection of special treatment requirements. The impact of changes made through these iterations can be minimized if the following guidance is followed.

- In the initial performance of the PRA prior to the first attempt at safety classification, the PRA should be performed based on a conservative assumption that all modeled SSCs are commercial grade.

- The non-LWR PRA standard requires that uncertainties be properly assessed in each iteration of PRA development. Guidance for uncertainty treatment is provided in Reference [68].

\footnotetext{
* In early 2020, this standard is being revised to account for feedback from PRAs that have been done to pilot the Reference [46] version of the standard. In the next edition, there will be more guidance on how to apply the standard to PRAs early in the design.
} 
- As the plant design evolves and the PRA is upgraded, conservative assumptions such as assuming commercial grade SSCs will be replaced with more realistic assumption which will tend to reduce frequencies of LBEs as well as reduce uncertainties.

- As the defense-in-depth aspects of LMP are applied special treatments will be specified for Safety Related (SR) and Non-Safety Related with Special Treatment (NSRST) SSCs that at a minimum will involve the selection of performance targets for reliability and capability and specifications of a performance monitoring program.

- As the above guidance is followed, the PRA results will be become progressively more realistic, reducing the magnitude of uncertainties, which in turn will reduce the mean frequencies and consequences. This should greatly reduce the potential for changes later in the design process that would increase the classification and special treatments of SSCs classified as NSRST. The determination of RSFs and the selection of SR SSCs is expected to be highly stable through these iterations.

\subsubsection{Additional Guidance for PRA Technical Adequacy}

Useful guidance in developing PRA models for advanced non-LWRs is found in NUREG-1860. ${ }^{[35]}$ This document includes a good summary of the safety characteristics of nonLWRs, guidance on how to use the PRA to inform the selection of LBEs and SSC special treatment requirements, and high level requirements for PRA technical adequacy that parallel and supplement the requirements in the ASME/ANS RA-S-1.4-2013. ${ }^{[46]}$ The Writing Group responsible for the non-LWR standard plans to review the PRA material in NUREG-1860 for consideration as input in the revised non-LWR PRA standard.

The IAEA has published attributes of a full scope Level 1 PRA in Reference [51]. Although this reference was developed for currently operating LWR plants, it includes attributes for supporting a multi-reactor PSA which are similar to those in ASME/ANS RA-S-1.4-2013. Additional references to support PRA modeling of multi-reactor module plants are listed in Section 4.1.1.

PRAs are required to support Generic Design Reviews for new facilities and periodic safety reviews for operating plants licensed in the United Kingdom. These reviews are similar to Design Certifications Applications reviews performed by the NRC. The Safety Assessment Principles (SAPs) used by the United Kingdom licensing authorities ${ }^{[57]}$ include specific requirements for the required PRAs and also serve as useful guidance for technical adequacy of a PRA. Importantly, the SAPs are reactor technology neutral because they support the licensing of currently operating gas-cooled reactors and LWRs and future licensing of advanced non-LWRs.

\subsection{Insights from B. John Garrick Institute for the Risk Sciences}

The LMP team includes the B. John Garrick Institute for the Risk Sciences at the University of California, Los Angeles. To support the development of the LMP reports on RIPB decision making, the Garrick Institute was tasked with reviewing the NGNP white papers on PRA, LBE selection, SSC safety classification, and DID. The Garrick Institute review scope included the review of earlier drafts of this LMP paper on PRA development as well as the LMP report on 
LBE selection and evaluation. Insights from these reviews have been incorporated into this report and include the following key points:

- The Garrick review was generally supportive of the approaches reflected in the NGNP and PRA white papers and recognize advancements beyond the NGNP papers.

- It was noted in this review that the examples provided for PRA development and LBE selection are from modular HTGRs including pebble bed reactors and sodium cooled fast reactors, which benefit from a long and rich history of design and PRA development. Additional guidance is needed for other reactor concepts such as molten salt reactors which are at an earlier stage of design development and lack a significant body of PRA case studies. An effort was made in preparation of this report to provide more guidance on how to begin the PRA development, which is found in Section 3 of this report.

- It was noted that some molten salt reactor concepts have radioactive waste processing systems with much greater radionuclide inventories including tritium than those for operating LWR plants. Releases from these systems may pose greater risks than those from reactor-based source terms. In addition, some of the coolants used in these reactors may pose non-radiological and toxic hazards which need to be addressed.

- Use of plant-year vs. reactor-year based frequency metrics and the explicit inclusion of multiple reactor and multi-source accident sequences are recognized as a strength of the LMP approach.

- Lessons from the Fukushima Daiichi accident need to be addressed including the important role of recovery actions and realistic treatment of accident management. It is not clear whether mitigation strategies (such as the "FLEX" capabilities developed by the U.S. power industry in response to the accident) will be used and how these will be addressed in the PRA.

- Risk metrics may need to be modified for plants located near industrial facilities providing process heat. In addition, there are risk metrics beyond those used to select and evaluate LBEs that greatly expand the capabilities of PRA for risk management. Examples are facility investment risk, plant production risks, and land contamination-based risk metrics.

- Additional guidance on the treatment of uncertainty in estimating frequencies and consequences for new reactors would be beneficial.

- More guidance on the necessary tools for thermo-fluid and neutronic response of plants to event sequences as well as the prediction of mechanistic source terms would be beneficial.

- John Garrick, recognized as one of the pioneers of PRA technology, has provided comments that are provided as part of the Garrick Institute review. He offers counsel not to use the PRA standards in prescriptive manner which may inhibit the creative work needed to fully develop the PRA technology for new reactors. He reminds us that the risk triplet,

\footnotetext{
* The risk triplet, according to the definition of Kaplan and Garrick, is comprised of a structured set of scenarios, quantitative estimates of the frequency and consequences of each scenario, and a probabilistic representation of the uncertainty in these estimates. The risk assessment results from answering three fundamental safety questions: "What can go wrong?", "How likely is it?", and "What are the Consequences?"
} 
defined in his landmark paper with Stan Kaplan, "On the Quantitative Definition of Risk,"[76] has been successfully applied to many different reactor and non-reactor technologies unencumbered by prescriptive standards. Finally, he recommends that treatment of uncertainty and external events be introduced at an early stage and objects to the artificial separation of PRA models by hazard group. Rather, he advocates the concept of a fully integrated risk assessment as having the best opportunity to yield the most effective risk management strategies early in the design process.

\subsection{NRC Roles in Ensuring PRA Technical Adequacy}

Successful RIPB licensing decisions within the LMP methodology will require active participation by the NRC. This participation is recommended to include the following:

- Continued NRC staff participation on the ASME/ANS JCNRM Writing Group responsible for the Advanced non-LWR PRA standard (This recommendation has been adopted. ${ }^{[83]}$ )

- Review and endorsement of the ANSI version of the non-LWR PRA standard scheduled for balloting in 2020 (This recommendation has been adopted. ${ }^{[96]}$ )

- Participation on PRA peer review teams required by the PRA standards

Review of licensing documents in which information from the PRA is used to support RIPB decisions such as selection of LBEs, safety classification and special treatment requirements of SSCs, principal design criteria informed by the PRA, and use of the PRA to affect a riskinformed evaluation of DID. NRC has continued to support the JCNRM writing group responsible for the next edition of the non-LWR PRA standard and has committed to the review and endorsement of the standard as evidenced in Reference [96]. 


\subsection{REPORT SUMMARY}

The information provided in this report was prepared to support interactions with the NRC and to prepare industry guidance for implementing the LMP methodology which may be endorsed in a future regulatory guide. NRC provided comments on a draft of this report in Reference [1]. LMP responses to those comments have been incorporated into the industry guidance in NEI $18-04^{[2]}$ and in this report.

This report documents the elements of the LMP approach to PRA below.

- A set of PRA objectives to support the LMP methodology is outlined in Section 1.3 and 3.3 to support the following PRA applications:

- Supporting and evaluating the development of the design

- Identifying the spectrum of LBEs to be considered

- Evaluating the risk significance of LBEs against Frequency-Consequence (F-C) Targets derived from Top Level Regulatory Criteria (TLRC)

o Performing an integrated risk assessment of advanced non-LWR plants that may be comprised of two or more reactor modules and associated non-core sources of radioactive material

- Safety classification of SSCs

- Development of performance targets for the reliability and capability of SSCs in the prevention and mitigation of accidents

- Determining integrated plant performance margins compared to TLRC performancebased objectives

- Exposing and evaluating sources of uncertainty in the identification of LBEs and in the estimation of their frequencies and consequences, and providing key input to the evaluation of the adequacy of DID

- Providing risk and performance-based insights into the evaluation of the design DID adequacy

○ Supporting other risk-informed and performance-based (RIPB) decisions

- Attributes of advanced non-LWR PRAs that are needed to support the LMP methodology are summarized in Section 3.2 and the necessary PRA scope in Sections 3.4 and 3.6.

- A flexible roadmap for introducing PRA early in the design and for expanding the level of detail of the PRA models and the scope of hazards as the design matures is covered in Section 3.5.

- Technology inclusive risk metrics for advanced non-LWR PRAs are discussed in Section 3.7.

- Example PRA models for HTGRs, SFRs, and MSRs are provided in Sections 3.8, 3.9, and 3.10 , respectively. 
- Guidance on the treatment of technical issues that will need to be addressed to support LMP PRA applications such as lack of service data, treatment of passive and inherent safety features, treatment of uncertainties, and PRA modelling of accidents involving two or more reactor modules is provided in Section 4.1.

- The approach to establishing fit-for-purpose PRA technical adequacy using the ASME/ANS PRA standard for advanced non-LWRs is covered in Section 4.2. 
Modernization of Technical Requirements for Licensing of Advanced Non-Light Water Reactors:

Probabilistic Risk Assessment Approach

\subsection{GLOSSARY OF TERMS}

\begin{tabular}{|c|c|c|c|}
\hline LMP Term & Acronym & Definition & Source \\
\hline \multicolumn{4}{|c|}{ Terms Associated with Functions } \\
\hline $\begin{array}{l}\text { Fundamental } \\
\text { Safety Function }\end{array}$ & FSF & $\begin{array}{l}\text { Safety functions common to all reactor technologies and designs; includes control heat } \\
\text { generation, control heat removal and confinement of radioactive material }\end{array}$ & IAEA-TECDOC-1570 \\
\hline $\begin{array}{l}\text { PRA Safety } \\
\text { Function }\end{array}$ & PSF & $\begin{array}{l}\text { Reactor design specific SSC functions modeled in a PRA that serve to prevent and/or } \\
\text { mitigate a release of radioactive material or to protect one or more barriers to release. } \\
\text { In ASME/ANS-Ra-S-1.4-2013 these are referred to as "safety functions." The modifier } \\
\text { PRA is used in the LMP GD to avoid confusion with safety functions performed by Safety- } \\
\text { Related SSCs. }\end{array}$ & $\begin{array}{l}\text { LMP, } \\
\text { ASME/ANS-Ra-S-1.4-2013 }\end{array}$ \\
\hline $\begin{array}{l}\text { Prevention } \\
\text { Function }\end{array}$ & -- & $\begin{array}{l}\text { An SSC function that, if fulfilled, will preclude the occurrence of an adverse state. The } \\
\text { reliability of the SSC in the performance of such functions serves to reduce the } \\
\text { probability of the adverse state. }\end{array}$ & LMP \\
\hline $\begin{array}{l}\text { Mitigation } \\
\text { Function }\end{array}$ & -- & $\begin{array}{l}\text { An SSC function that, if fulfilled, will eliminate or reduce the consequences of an event in } \\
\text { which the SSC function is challenged. The capability of the SSC in the performance of } \\
\text { such functions serves to eliminate or reduce any adverse consequences that would occur } \\
\text { if the function were not fulfilled. }\end{array}$ & LMP \\
\hline $\begin{array}{l}\text { Required Safety } \\
\text { Function }\end{array}$ & RSF & $\begin{array}{l}\text { A PRA Safety Function that is required to be fulfilled to maintain the consequence of one } \\
\text { or more DBEs or the frequency of one or more high-consequence BDBEs inside the F-C } \\
\text { Target }\end{array}$ & LMP \\
\hline $\begin{array}{l}\text { Required } \\
\text { Functional } \\
\text { Design Criteria }\end{array}$ & RFDC & $\begin{array}{l}\text { Reactor design-specific functional criteria that are necessary and sufficient to meet the } \\
\text { RSFs }\end{array}$ & LMP \\
\hline $\begin{array}{l}\text { Safety-Related } \\
\text { Design Criteria }\end{array}$ & SRDC & $\begin{array}{l}\text { Design criteria for SR SSCs that are necessary and sufficient to fulfill the RFDCs for those } \\
\text { SSCs selected to perform the RSFs }\end{array}$ & LMP \\
\hline \multicolumn{4}{|c|}{ Terms Associated with Licensing Basis Events } \\
\hline $\begin{array}{l}\text { Anticipated } \\
\text { Operational } \\
\text { Occurrence }\end{array}$ & AOO & $\begin{array}{l}\text { Anticipated event sequences expected to occur one or more times during the life of a } \\
\text { nuclear power plant, which may include one or more reactor modules. Event sequences } \\
\text { with mean frequencies of } 1 \times 10^{-2} / \text { plant-year and greater are classified as AOOs. AOOs } \\
\text { take into account the expected response of all SSCs within the plant, regardless of safety } \\
\text { classification. }\end{array}$ & LMP \\
\hline
\end{tabular}


Modernization of Technical Requirements for Licensing of Advanced Non-Light Water Reactors: Probabilistic Risk Assessment Approach

\begin{tabular}{|c|c|c|c|}
\hline LMP Term & Acronym & Definition & Source \\
\hline $\begin{array}{l}\text { Design Basis } \\
\text { Event }\end{array}$ & DBE & $\begin{array}{l}\text { Infrequent event sequences that are not expected to occur in the life of a nuclear power } \\
\text { plant, which may include one or more reactor modules, but are less likely than AOOs. } \\
\text { Event sequences with mean frequencies of } 1 \times 10^{-4} / \text { plant-year to } 1 \times 10^{-2} / \text { plant-year are } \\
\text { classified as DBEs. DBEs take into account the expected response of all SSCs within the } \\
\text { plant regardless of safety classification. The objective and scope of DBEs form the safety } \\
\text { design basis of the plant. }\end{array}$ & LMP \\
\hline $\begin{array}{l}\text { Beyond Design } \\
\text { Basis Event }\end{array}$ & BDBE & $\begin{array}{l}\text { Rare event sequences that are not expected to occur in the life of a nuclear power plant, } \\
\text { which may include one or more reactor modules, but are less likely than a DBE. Event } \\
\text { sequences with frequencies of } 5 \times 10^{-7} / \text { plant-year to } 1 \times 10^{-4} / \text { plant -year are classified as } \\
\text { BDBEs. BDBEs take into account the expected response of all SSCs within the plant } \\
\text { regardless of safety classification. }\end{array}$ & LMP \\
\hline $\begin{array}{l}\text { Design Basis } \\
\text { Accident }\end{array}$ & DBA & $\begin{array}{l}\text { Postulated accidents that are used to set design criteria and performance objectives for } \\
\text { the design of Safety-Related SSCs. DBAs are derived from DBEs based on the capabilities } \\
\text { and reliabilities of Safety-Related SSCs needed to mitigate and prevent accidents, } \\
\text { respectively. DBAs are derived from the DBEs by prescriptively assuming that only SR } \\
\text { SSCs classified are available to mitigate postulated accident consequences to within the } \\
10 \text { CFR } 50.34 \text { dose limits. }\end{array}$ & LMP \\
\hline $\begin{array}{l}\text { Licensing Basis } \\
\text { Event }\end{array}$ & LBE & $\begin{array}{l}\text { The entire collection of event sequences considered in the design and licensing basis of } \\
\text { the plant, which may include one or more reactor modules. LBEs include normal } \\
\text { operation, AOOs, DBEs, BDBEs, and DBAs. }\end{array}$ & LMP \\
\hline $\begin{array}{l}\text { Frequency- } \\
\text { Consequence } \\
\text { Target }\end{array}$ & F-C Target & $\begin{array}{l}\text { A target line on a frequency-consequence chart that is used to evaluate the risk } \\
\text { significance of LBEs and to evaluate risk margins that contribute to evidence of adequate } \\
\text { defense-in-depth }\end{array}$ & LMP \\
\hline $\begin{array}{l}\text { Risk-Significant } \\
\text { LBE }\end{array}$ & -- & $\begin{array}{l}\text { An LBE whose frequency and consequence meet a specified risk significance criterion. In } \\
\text { the LMP framework, an AOO, DBE, or BDBE is regarded as risk-significant if the } \\
\text { combination of the upper bound ( } 95^{\text {th }} \text { percentile) estimates of the frequency and } \\
\text { consequence of the LBE are within } 1 \% \text { of the F-C Target AND the upper bound 30-day } \\
\text { TEDE dose at the EAB exceeds } 25 \text { mrem. }\end{array}$ & LMP \\
\hline \multicolumn{4}{|c|}{ Terms Associated with Plant Design and Structures, Systems, and Components } \\
\hline $\begin{array}{l}\text { Design Basis } \\
\text { External Hazard } \\
\text { Level }\end{array}$ & DBEHL & $\begin{array}{l}\text { A design specification of the level of severity or intensity of an external hazard for which } \\
\text { the Safety-Related SSCs are designed to withstand with no adverse impact on their } \\
\text { capability to perform their RSFs }\end{array}$ & LMP \\
\hline
\end{tabular}


Modernization of Technical Requirements for Licensing of Advanced Non-Light Water Reactors: Probabilistic Risk Assessment Approach

\begin{tabular}{|c|c|c|c|}
\hline $\begin{array}{l}\text { Multi-Reactor } \\
\text { Module Plant }\end{array}$ & -- & $\begin{array}{l}\text { A plant comprising multiple reactor modules that are designed and constructed using a } \\
\text { modular design approach. Modular design means a nuclear power plant that consists of } \\
\text { two or more essentially identical nuclear reactors (modules) and each reactor module is } \\
\text { a separate nuclear reactor capable of being operated independent of the state of } \\
\text { completion or operating condition of any other reactor module co-located on the same } \\
\text { site, even though the nuclear power plant may have some shared or common systems. }\end{array}$ & $\begin{array}{l}\text { Multi-module plant adapted } \\
\text { from ASME/ANS-Ra-S-1.4- } \\
2013 \text {, modular design from } \\
\text { 10CFR52.1 }\end{array}$ \\
\hline $\begin{array}{l}\text { Safety-Related } \\
\text { SSCs }\end{array}$ & SR SSCS & $\begin{array}{l}\text { SSCs that are credited in the fulfillment of RSFs and are capable to perform their RSFs in } \\
\text { response to any Design Basis External Hazard Level }\end{array}$ & LMP \\
\hline $\begin{array}{l}\text { Non-Safety- } \\
\text { Related with } \\
\text { Special } \\
\text { Treatment SSCs }\end{array}$ & NSRST SSCS & $\begin{array}{l}\text { Non-safety-related SSCs that perform risk-significant functions or perform functions that } \\
\text { are necessary for defense-in-depth adequacy }\end{array}$ & LMP \\
\hline $\begin{array}{l}\text { Risk-Significant } \\
\text { SSC }\end{array}$ & -- & $\begin{array}{l}\text { An SSC that meets defined risk significance criteria. In the LMP framework, an SSC is } \\
\text { regarded as risk-significant if its PRA Safety Function is: a) required to keep one or more } \\
\text { LBEs inside the F-C Target based on mean frequencies and consequences; or b) if the } \\
\text { total frequency LBEs that involve failure of the SSC PRA Safety Function contributes at } \\
\text { least } 1 \% \text { to any of the LMP cumulative risk targets. The LMP cumulative risk targets } \\
\text { include: (i) maintaining the frequency of exceeding } 100 \text { mrem to less than } 1 / \text { plant-year; } \\
\text { (ii) meeting the NRC safety goal QHO for individual risk of early fatality; and (iii) meeting } \\
\text { the NRC safety goal QHO for individual risk of latent cancer fatality. }\end{array}$ & LMP \\
\hline $\begin{array}{l}\text { Safety- } \\
\text { Significant SSC }\end{array}$ & -- & $\begin{array}{l}\text { An SSC that performs a function whose performance is necessary to achieve adequate } \\
\text { defense-in-depth or is classified as Risk-Significant (see Risk-Significant SSC). }\end{array}$ & LMP \\
\hline
\end{tabular}


Modernization of Technical Requirements for Licensing of Advanced Non-Light Water Reactors:

Probabilistic Risk Assessment Approach

\begin{tabular}{|c|c|c|c|}
\hline LMP Term & Acronym & Definition & Source \\
\hline $\begin{array}{l}\text { Safety Design } \\
\text { Approach }\end{array}$ & -- & $\begin{array}{l}\text { The strategies that are implemented in the design of a nuclear power plant that are } \\
\text { intended to support safe operation of the plant and control the risks associated with } \\
\text { unplanned releases of radioactive material and protection of the public and plant } \\
\text { workers. These strategies normally include the use of robust barriers, multiple layers of } \\
\text { defense, redundancy, and diversity, and the use of inherent and passive design features } \\
\text { to perform safety functions. }\end{array}$ & LMP \\
\hline \multicolumn{4}{|c|}{ Terms Associated with Risk-Informed and Performance-Based Regulation and Decision-Making } \\
\hline $\begin{array}{l}\text { Defense-in- } \\
\text { Depth }\end{array}$ & DID & $\begin{array}{l}\text { "An approach to designing and operating nuclear facilities that prevents and mitigates } \\
\text { accidents that release radiation or hazardous materials. The key is creating multiple } \\
\text { independent and redundant layers of defense to compensate for potential human and } \\
\text { mechanical failures so that no single layer, no matter how robust, is exclusively relied } \\
\text { upon. Defense-in-depth includes the use of access controls, physical barriers, redundant } \\
\text { and diverse key safety functions, and emergency response measures." }\end{array}$ & NRC Glossary \\
\hline $\begin{array}{l}\text { Layers of } \\
\text { Defense }\end{array}$ & -- & $\begin{array}{l}\text { Layers of defense are those plant capabilities and programmatic elements that provide, } \\
\text { collectively, independent means for the prevention and mitigation of adverse events. } \\
\text { The actual layers and number are dependent on the actual source and hazard posing the } \\
\text { threat. See Defense-in-Depth. }\end{array}$ & LMP \\
\hline $\begin{array}{l}\text { Performance- } \\
\text { Based }\end{array}$ & PB & $\begin{array}{l}\text { An approach to decision-making that focuses on desired objective, calculable or } \\
\text { measurable, observable outcomes, rather than prescriptive processes, techniques, or } \\
\text { procedures. Performance-based decisions lead to defined results without specific } \\
\text { direction regarding how those results are to be obtained. At the NRC, performance- } \\
\text { based regulatory actions focus on identifying performance measures that ensure an } \\
\text { adequate safety margin and offer incentives and flexibility for licensees to improve } \\
\text { safety without formal regulatory intervention by the agency. }\end{array}$ & $\begin{array}{l}\text { Adapted from NRC Glossary } \\
\text { definition of performance- } \\
\text { based regulation in order to } \\
\text { apply to both design decisions } \\
\text { and regulatory decision- } \\
\text { making }\end{array}$ \\
\hline Risk-Informed & $\mathrm{RI}$ & $\begin{array}{l}\text { An approach to decision-making in which insights from probabilistic risk assessments are } \\
\text { considered with other sources of insights }\end{array}$ & $\begin{array}{l}\text { Adapted from NRC Glossary } \\
\text { definition of performance- } \\
\text { based regulation in order to } \\
\text { apply to both design decisions } \\
\text { and regulatory decision- } \\
\text { making }\end{array}$ \\
\hline
\end{tabular}


Modernization of Technical Requirements for Licensing of Advanced Non-Light Water Reactors:

Probabilistic Risk Assessment Approach

\section{LMP Term}

Acronym

Definition

Source

Risk-Informed

and

Performance-

Based

RIPB-DM

The union of risk information and performance information to achieve performancebased objectives

LMP

Integrated

Decision-

Making

Terms Associated with Probabilistic Risk Assessment

A perturbation to the plant during a plant operating state (POS) that challenges plant control and safety systems whose failure could potentially lead to an undesirable end state and/or radioactive material release. An Initiating Event could degrade the reliability of a normally operating system, cause a standby mitigating system to be challenged, or require that the plant operators respond in order to mitigate the event or to limit the extent of plant damage caused by the Initiating Event. These events include human-caused perturbations and failure of equipment from either internal plant causes

Initiating Event

IE

Event

Sequence

(such as hardware faults, floods, or fires) or external plant causes (such as earthquakes or high winds). An Initiating Event is defined in terms of the change in plant status that results in a condition requiring shutdown or a reactor trip (e.g., loss of main feedwater system, small reactor coolant pressure boundary [RCPB] breach) when the plant is at power, or the loss of a key safety function (e.g., decay heat removal system) for nonpower modes of operation. A specific type of Initiating Event may be identified as originating from a specific cause as defined in terms such as "flood-induced transient" or "seismically-induced RCPB breach."

A representation of a scenario in terms of an Initiating Event defined for a set of initial plant conditions (characterized by a specified POS) followed by a sequence of system, safety function, and operator failures or successes, with sequence termination with a specified end state (e.g., prevention of release of radioactive material or release in one of the reactor-specific release categories. An event sequence may contain many unique variations of events (minimal cut sets) that are similar in terms of how they impact the performance of safety functions along the event sequence. 
Modernization of Technical Requirements for Licensing of Advanced Non-Light Water Reactors: Probabilistic Risk Assessment Approach

\begin{tabular}{|c|c|c|c|}
\hline LMP Term & Acronym & Definition & Source \\
\hline $\begin{array}{l}\text { Event } \\
\text { Sequence } \\
\text { Family }\end{array}$ & - & $\begin{array}{l}\text { A grouping of event sequences with a common or similar POS, Initiating Event, hazard } \\
\text { group, challenges to the plant safety functions, response of the plant in the performance } \\
\text { of each safety function, response of each radionuclide transport barrier, and end state. } \\
\text { An event sequence family may involve a single event sequence or several event } \\
\text { sequences grouped together. Each release category may include one or more event } \\
\text { sequence families. Event sequence families are not required to be explicitly modeled in } \\
\text { a PRA. Each event sequence family involving a release is associated with one and only } \\
\text { one release category. }\end{array}$ & ASME/ANS-Ra-S-1.4-2013 \\
\hline End State & & $\begin{array}{l}\text { The set of conditions at the end of an Event Sequence that characterizes the impact of } \\
\text { the sequence on the plant or the environment. In most PRAs, end states typically } \\
\text { include success states (i.e., those states with negligible impact) and Release Categories. }\end{array}$ & ASME/ANS-Ra-S-1.4-2013 \\
\hline $\begin{array}{l}\text { PRA Technical } \\
\text { Adequacy }\end{array}$ & -- & $\begin{array}{l}\text { A set of attributes that define the technical suitability of a PRA capability to provide fit- } \\
\text { for-purpose insights to risk-informed decision-making. It includes consideration of } \\
\text { realism, completeness, transparency, PRA model-to-plant as-designed and as-built } \\
\text { fidelity state, and identification and evaluation of uncertainties relative to risk levels. } \\
\text { Strategies to achieve technical adequacy include conformance to consensus PRA } \\
\text { standards, performance of PRA peer reviews, and structured processes for PRA model } \\
\text { configuration control, maintenance and updates, and incorporation of new evidence that } \\
\text { comprises the state of knowledge reflected in the PRA model development and its } \\
\text { quantification. }\end{array}$ & LMP \\
\hline $\begin{array}{l}\text { Plant Operating } \\
\text { State }\end{array}$ & POS & $\begin{array}{l}\text { A standard arrangement of the plant during which the plant conditions are relatively } \\
\text { constant, are modeled as constant, and are distinct from other configurations in ways } \\
\text { that impact risk. POS is a basic modeling device used for a phased-mission risk } \\
\text { assessment that discretizes the plant conditions for specific phases of a Low Power and } \\
\text { Shutdown evolution. Examples of such plant conditions include core decay heat level, } \\
\text { primary coolant level, primary temperature, primary vent status, reactor building status, } \\
\text { and decay heat removal mechanisms. Examples of risk impacts that are dependent on } \\
\text { POS definition include the selection of Initiating Events, Initiating Event frequencies, } \\
\text { definition of accident sequences, success criteria, and accident sequence quantification. }\end{array}$ & ASME/ANS-Ra-S-1.4-2013 \\
\hline $\begin{array}{l}\text { Mechanistic } \\
\text { Source Term }\end{array}$ & MST & $\begin{array}{l}\text { A source term that is calculated using models and supporting scientific data that simulate } \\
\text { the physical and chemical processes that describe the radionuclide inventories and the } \\
\text { time-dependent radionuclide transport mechanisms that are necessary and sufficient to } \\
\text { predict the source term. }\end{array}$ & ASME/ANS-Ra-S-1.4-2013 \\
\hline
\end{tabular}




\subsection{REFERENCES}

[1] U.S. Nuclear Regulatory Commission, "NRC Staff Questions/Comments on LMP White Paper on PRA Approach," ADAMS Accession No. ML17233A187, August 18, 2017.

[2] Nuclear Energy Institute, "Risk-Informed Performance-Based Technology Inclusive Guidance for Advanced Reactor Licensing Basis Development," NEI 18-04, Revision OB, May 25, 2019.

[3] Idaho National Laboratory, "Modernization of Technical Requirements for Licensing of Advanced Non-Light Water Reactors, Selection and Evaluation of Licensing Basis Events," Revision 0, August 2019.

[4] Idaho National Laboratory, "Modernization of Technical Requirements for Licensing of Advanced Non-Light Water Reactors, Safety Classification and Performance Criteria for Structures, Systems, and Components," Revision 0, August 2019.

[5] Idaho National Laboratory, "Modernization of Technical Requirements for Licensing of Advanced Non-Light Water Reactors, Risk-Informed and Performance-Based Evaluation of Defense-in-Depth Adequacy," Revision 0, August 2019.

[6] Idaho National Laboratory, "Next Generation Nuclear Plant Probabilistic Risk Assessment White Paper," INL/EXT-11-21270, ADAMS Accession No. ML11265A082, July 2011.

[7] 10 CFR 52.1, "Licenses, Certifications, and Approvals for Nuclear Power Plants - Definitions," 2015.

[8] U.S. Department of Energy, "Probabilistic Risk Assessment for the Standard Modular High Temperature Gas-Cooled Reactor," DOE-HTGR-86-011, Revision 5, April 1988.

[9] GE Hitachi Nuclear Energy, "Final Scientific/Technical Report: Development/Modernization of an Advanced Non-LWR Probabilistic Risk Assessment," Federal Grant DE-NE0008325, 2017.

[10] Idaho National Laboratory, "Next Generation Nuclear Plant Licensing Basis Event Selection White Paper," INL/EXT-10-19521, ADAMS Accession No. ML102630246, September 2010.

[11] Idaho National Laboratory, "Next Generation Nuclear Plant Structures, Systems, and Components Safety Classification White Paper," INL/EXT-10-19505, ADAMS Accession No. ML102660144, September 2010.

[12] Idaho National Laboratory, "Next Generation Nuclear Plant Defense-in-Depth Approach," INL/EXT 09-17139, ADAMS Accession No. ML093480191, December 2009.

[13] Idaho National Laboratory, "Next Generation Nuclear Plant Mechanistic Source Terms White Paper," INL/EXT-10-17997, ADAMS Accession No. ML103050268, July 2010.

[14] 10 CFR 52, "Licenses, Certifications, and Approvals for Nuclear Power Plants," Code of Federal Regulations, Office of the Federal Register, 2007.

[15] 10 CFR 50, "Domestic Licensing of Production and Utilization Facilities," Code of Federal Regulations, Office of the Federal Register, 2007.

[16] 60 FR 158, "Use of Probabilistic Risk Assessment Methods in Nuclear Regulatory Activities; Final Policy Statement," Federal Register, U.S. Nuclear Regulatory Commission, pp. 42622-42629, August 16, 1995.

[17] 10 CFR 50, Appendix A, "General Design Criteria for Nuclear Power Plants," Code of Federal Regulations, Office of the Federal Register, 2007. 
[18] SECY 2003-0047, "Policy Issues Related to Licensing Non-Light Water Reactor Designs," U.S. Nuclear Regulatory Commission, March 28, 2003.

[19] SRM 2003-0047, "Staff Requirements Memorandum for SECY 03-0047-Policy Issues Related to Licensing Non-Light Water Reactor Designs," U.S. Nuclear Regulatory Commission, June 26, 2003.

[20] SECY-2005-0006, "Second Status Paper on the Staff's Proposed Regulatory Structure for New Plant Licensing and Update on Policy Issues Related to New Plant Licensing," January 7, 2005.

[21] Idaho National Laboratory, "Next Generation Nuclear Plant Fuel Performance and Qualification White Paper," INL/EXT-10-17686, July 2010.

[22] NUREG-1338, "Draft Preapplication Safety Evaluation Report for the Modular High Temperature Gas-Cooled Reactor," U.S. Nuclear Regulatory Commission, March 1989.

[23] Regulatory Guide 1.206, "Combined License Applications for Nuclear Power Plants," Federal Register, U.S. Nuclear Regulatory Commission, July 2007.

[24] NRC to NGNP letter "Next Generation Nuclear Plant-Assessment of White Papers on Fuel Qualification, Mechanistic Source Terms, Defense-In-Depth Approach, Licensing Basis Event Selection, and Safety Classification of Systems, Structures, And Components," (ML120240651), Section 2.1 of Enclosure 2 (ML120170084), February 15, 2012.

[25] ACRS Letter, Subject: “Next Generation Nuclear Plant (NGNP) Key Licensing Issues," May 15, 2013.

[26] NRC to ACRS Letter, Subject: "Response to Advisory Committee on Reactor Safeguards Regarding Staff Assessment of Next Generation Nuclear Plant Key Licensing Issues," June 20, 2013.

[27] ACRS Letter, Subject: "Issues Pertaining to the Advanced Reactor (PRISM, MHTGR, and PIUS) and CANDU 3 Designs and Their Relationship to Current Regulatory Requirements," ACRSR1509, February 19, 1993.

[28] 59 FR 35461, "Regulation of Advanced Nuclear Power Plants; Statement of Policy," Federal Register, U.S. Nuclear Regulatory Commission, July 12, 1994.

[29] 51 FR 149, "Safety Goals for the Operations of Nuclear Power Plants; Policy Statement," Federal Register, U.S. Nuclear Regulatory Commission, pp. 28044-28049, (51 FR 160, August 4, 1986, republished with corrections, pg. 30028-30023), August 21, 1986.

[30] NUREG-0800, Standard Review Plan, Chapter 19.0, "Probabilistic Risk Assessment and Severe Accident Evaluation for New Reactors," Revision 3, December 2015.

[31] NUREG-0800, Standard Review Plan 19.1, "Determining the Technical Adequacy of Probabilistic Risk Assessment Results for Risk-Informed Activities," Federal Register, U.S. Nuclear Regulatory Commission, Revision 3, September 2012.

[32] Regulatory Guide 1.174, "An Approach for Using Probabilistic Risk Assessment in Risk-informed Decisions on Plant Specific Changes to the Current Licensing Basis," May 2011.

[33] Regulatory Guide 1.200, "An Approach for Determining the Technical Adequacy of Probabilistic Risk Assessment Results for Risk-informed Activities," Federal Register, U.S. Nuclear Regulatory Commission, Revision 2, March 2009.

[34] SECY-93-087, "Policy, Technical, And Licensing Issues Pertaining to Evolutionary and Advanced Light-Water Reactor (ALWR) Designs," U.S. Nuclear Regulatory Commission, April 1993. 
[35] NUREG-1860, "Feasibility Study for a Risk-Informed and Performance-Based Regulatory Structure for Future Plant Licensing", U.S. Nuclear Regulatory Commission, December 2007.

[36] NUREG-2150, “A Proposed Risk Management Regulatory Framework”, U.S. Nuclear Regulatory Commission, April 2012.

[37] SECY 2015-0168, "Recommendations on Issues Related to Implementation of a Risk Management Regulatory Framework," U.S. Nuclear Regulatory Commission, December 18, 2015.

[38] SRM 2015-0168, "Staff Requirements - SECY-15-0168 - Recommendations on Issues Related to Implementation of a Risk Management Regulatory Framework," March 9, 2016.

[39] U.S. Nuclear Regulatory Commission, "The Near-Term Task Force Review of Insights from the Fukushima Dai-Ichi Accident," July 12, 2011.

[40] Exelon Generation Company Letter, Subject: "Proposed Licensing Approach for the Pebble Bed Modular Reactor in the United States," January 31, 2002.

[41] U.S. Nuclear Regulatory Commission Letter, Subject: "NRC Staff's Preliminary Findings Regarding Exelon Generation's (Exelon's) Proposed Licensing Approach for the Pebble Bed Modular Reactor (PBMR)," March 26, 2002.

[42] U.S. Department of Energy, "Preliminary Safety Information Document for the Standard MHTGR," DOE-HTGR-86-024, September 1988.

[43] NUREG-1368, "Preapplication Safety Evaluation Report for the Power Reactor Innovative Small Module (PRISM) Liquid-Metal Reactor," Final Report, U.S. Nuclear Regulatory Commission, February 1994.

[44] NUREG/CR-2300, “PRA Procedures Guide," Federal Register, U.S. Nuclear Regulatory Commission, January 1983.

[45] American Society of Mechanical Engineers and American Nuclear Society, "Standard for Probabilistic Risk Assessment for Nuclear Power Plant Applications," ASME-RA-Sb-2013.

[46] American Society of Mechanical Engineers and American Nuclear Society, "Probabilistic Risk Assessment Standard for Advanced non-LWR Nuclear Power Plants," RA-S-1.4-2013.

[47] American Nuclear Society and American Society of Mechanical Engineers, "Requirements for Low Power and Shutdown Probabilistic Risk Assessment," ANS/ASME-58.22-2014, March 25, 2015.

[48] American Society of Mechanical Engineers and American Nuclear Society, "Severe Accident Progression and Radiological Release (Level 2) PRA Standard for Nuclear Power Plant Applications for Light Water Reactors (LWRs)," ASME/ANS RA-S-1.2-2014, January 5, 2015.

[49] ANSI/ANS-53.1-2011, "Nuclear Safety Design Process for Modular Helium-Cooled Reactor Plants," American Nuclear Society, December 21, 2011.

[50] International Atomic Energy Agency, "Safety of Nuclear Power Plants: Design," IAEA Safety Standards Series No. SSR-2/1, IAEA, Vienna, 2012.

[51] IAEA TECDOC-1804, "Attributes of Full Scope Level 1 Probabilistic Safety Assessment (PSA) for Applications in Nuclear Power Plants," International Atomic Energy Agency, 2016.

[52] International Atomic Energy Agency, "Technical Approach to Multi-Unit Site Probabilistic Safety Assessment," IAEA Safety Reports Series No. 96, IAEA, Vienna, 2019. 
[53] Pickard Lowe And Garrick Inc., "Seabrook Station Probabilistic Safety Assessment -Section 13.3 Risk of Two Unit Station," Prepared for Public Service Company of New Hampshire, PLG-0300, 1983.

[54] Canadian Nuclear Safety Commission, "International Workshop on Multi-Unit Probabilistic Safety Assessment (PSA)," Ottawa, Canada (workshop summary and presentations available at http://nuclearsafety.gc.ca/eng/), November $17-20,2014$.

[55] SRM-11-0089, "Staff Requirements - SECY-11-0089 - Options for Proceeding with Future Level 3 Probabilistic Risk Assessment (PRA) Activities," U.S. Nuclear Regulatory Commission, ML112640419, September 21, 2011.

[56] U.S. Nuclear Regulatory Commission, "Technical Analysis Approach Plan for Level 3 PRA Project," Revision OB Working Draft, ML13296A064, October 2013.

[57] United Kingdom Office of Nuclear Regulation, "Safety Assessment Principles for Nuclear Facilities," Revision 0, 2014 edition.

[58] Van der Börst, and H. Shoonaker, "An Overview of Risk Importance Measures," Reliability Engineering and System Safety, 72, pp. 241-245, 2001.

[59] Fleming, K. N., et al., "HTGR Accident Initiation and Progression Analysis Status Report-Phase II Risk Assessment," General Atomic Report No. GA-A15000, April 1978.

[60] PBMR Letter, Subject: "PBMR White Paper: PRA Approach, USDC20060613-1, Pebble Bed Modular Reactor (Proprietary) Ltd.," June 13, 2006.

[61] Bengt Lydell and Karl Fleming, "PBMR Passive Component Reliability - Helium Pressure Boundary Components," Prepared by Technology Insights for PBMR (Pty) Ltd., PBMR Proprietary Data, Final Report, 2006.

[62] Zhang, S. et al., "An Integrated Modeling Approach for Event Sequence Development in MultiUnit Probabilistic Risk Assessment," Reliability Engineering and System Safety, Volume 155, pp. 147-159, November 2016.

[63] Grabaskas, D. et al., "A Methodology for the Development of a Reliability Database for An Advanced Reactor Probabilistic Risk Assessment," Proceedings of the $24^{\text {th }}$ International Conference on Nuclear Engineering, ICONE24-60760, Charlotte NC, June 26-30, 2016.

[64] Grabaskas, D. et al., "A Methodology for The Integration of a Mechanistic Source Term Analysis in a Probabilistic Framework for Advanced Reactors," Proceedings of the $24^{\text {th }}$ International Conference on Nuclear Engineering, Charlotte NC, June 26-30, 2016.

[65] Brunette, A.J., et al., "A Methodology for the Integration of Passive System Reliability with Success Criteria in a Probabilistic Framework for Advanced Reactors," Proceedings of the $24^{\text {th }}$ International Conference on Nuclear Engineering, Charlotte, NC, June 26-30, 2016.

[66] WASH-1400 (NUREG 75/014), "Reactor Safety Study," U.S. Nuclear Regulatory Commission, October 1975.

[67] NUREG-1829 "Estimating Loss-of-Coolant-Accident (LOCA) Frequencies Through the Elicitation Process," Federal Register, U.S. Nuclear Regulatory Commission (Draft for Comment), June 2005.

[68] NUREG-1855, "Guidance on the Treatment of Uncertainties Associated with PRAs in RiskInformed Decision Making," Revision 1, March 2017. 
[69] IAEA TECDOC-626, "Safety Related Terms for Advanced Nuclear Plants," International Atomic Energy Agency, 1991.

[70] NEI-00-02, "Probabilistic Risk Assessment (PRA) Peer Review Process Guidance," Revision 1, May 2006.

[71] U.S. Nuclear Regulatory Commission, "Report to Congress on Advanced Reactor Licensing," August 2012.

[72] U.S. Nuclear Regulatory Commission, Office of New Reactors, "Assessment of White Paper Submittals on Defense-In-Depth, Licensing Basis Event Selection, And Safety Classification of Structures, Systems and Components," Next Generation Nuclear Plant Project 0748, Attached to Letter from NRC to DOE, July 17, 2014.

[73] NuScale Power, "NuScale Standard Plant Design Certification Application, Chapter Nineteen Probabilistic Risk Assessment," December 2016.

[74] American Institute of Chemical Engineers, "Guidelines for Hazard Evaluation Procedures," by the Center for Chemical Process Safety, 2008.

[75] Generation IV Risk and Safety Working Group, "An Integrated Safety Assessment Methodology (ISAM) for Generation IV Nuclear Systems," June 2011.

[76] Kaplan, S. and B. John Garrick, "On the Quantitative Definition of Risk," Risk Analysis, Vol. 1, pp. 11-27, 1981.

[77] American Nuclear Society and American Society of Mechanical Engineers, "Standard for Radiological Accident Offsite Consequence Analysis (Level 3 PRA) to Support Nuclear Installation Applications," ANS/ASME-RA-S-1.3, Trial Use, 2017.

[78] Idaho National Laboratory, "Site Suitability and Hazard Assessment Guide for Small Modular Reactors," INL/EXT-13-29749, October 2013.

[79] Entergy, 2009, "Procedure for Site Hazards Evaluation and Impact Assessment," Rev. 1, NGNPLIC-ETR-RPT-001, September 2009.

[80] University of California, Berkeley, "Fluoride-Salt-Cooled, High-Temperature Reactor (FHR) Subsystems Definition, Functional Requirement Definition, and Licensing Basis Event (LBE) Identification White Paper," UCBTH-12-001, August 2013.

[81] Brandon Chisholm, et al., "Development of a Methodology for Early Integration of Safety Analysis Into Advanced Reactor Design," Proceedings of American Nuclear Society PSA-2019, May 2019.

[82] ORNL/TM-2018/788, "A New Look at Licensing Basis Events for the Molten Salt Reactor Experiment," August 2018.

[83] Letter from Brian E. Thomas, NRC Standards Executive, Office of Nuclear Regulatory Research U.S. NRC to Rich Porco, Chair, ASME Board on Nuclear Codes and Standards, and Steven Arndt, Chair, ANS Standards Board, regarding NRC priorities for completion of PRA standards, ADAMS Accession No. ML19031C904, February 7, 2019.

[84] Pyron, D.A., "Safety Analysis for the Licensing of Molten Salt Reactors," Paul Scherrer Institute, 2016.

[85] Vanderbilt University, “Molten Salt Reactor Experiment (MSRE) Case Study Using RiskInformed, Performance-Based Technical Guidance to Inform Future Licensing for Advanced 
Non-Light Water Reactors," https://www.nrc.gov./docs/ML1924/ML19249B632.pdf, September 4, 2019.

[86] A. Maioli, et al, "Westinghouse eVinciTM Micro-Reactor Licensing Modernization Project Demonstration," https://www.nrc.gov./docs/ML1922/ML19227A322.pdf, August 12, 2019.

[87] Pickard, Lowe and Garrick, Inc., "South Texas Project Probabilistic Safety Assessment," PLG0675, May 1989.

[88] Center for Chemical Process Safety, "Guidelines for Initiating Events and Independent Protection Layers in Layer of Protection Analysis," New York, NY: American Institute of Chemical Engineers, 2015.

[89] Electric Power Research Institute, "Program on Technology Innovation: Early Integration of Safety Assessment into Advanced Reactor Design, Preliminary Body of Knowledge and Methodology," EPRI Report 3002011801, 2018.

[90] Bechtel River Protection Project, "Rev 0 Low-Activity Waste Plant Nuclear Safety Model," 24590-LAW-RPT-NS-15-003, August 16, 2016.

[91] B. Chisholm, et al., "A Systematic Approach to Identify Initiating Events and Building a PRA Model Demonstrated on the Molten Salt Reactor Experiment," to be published in Progress in Nuclear Energy in 2020.

[92] Idaho National Laboratory, "Next Generation Nuclear Plant Mechanistic Source Terms White Paper," INL/EXT-10-17997, ADAMS Accession No. ML103050268, July 2010.

[93] D. Naidoo, et al., "Next Generation Nuclear Plant: Plant Level Assessments Leading to Fission Product Retention Allocations," NGNP-PLD-GEN-RPT-N-00007, October 2009.

[94] D. Grabaskas, et al., "A Methodology for the Integration of a Mechanistic Source Term Analysis in a Probabilistic Framework for Advanced Reactors," Proceedings of the $24^{\text {th }}$ International Conference on Nuclear Engineering, Charlotte, North Carolina, June 26-30, 2016.

[95] "RMPS Project: Reliability Methods for Passive Systems, Final Report," European Commission: $5^{\text {th }}$ EURATOM Framework Programme, 1998-2002.

[96] Letter from Louis Lund, NRC Standards Executive, U.S. Nuclear Regulatory Commission to C. Rick Grantom, Co-Chair and Bob Budnitz Co-Chair, ASME/ANS Joint Committee on Nuclear Risk Management, "NRC Plan for Endorsement of ASME/ANS Advanced non-LWR PRA Standard," Adams Accession Number 20045G141, March 13, 2013. 


\section{APPENDIX A LMP DOCUMENTATION AND FREQUENTLY ASKED QUESTIONS}

\section{A.1 LMP Documentation}

The LMP team prepared independent reports on each of the four major LMP elements. Additionally, the LMP team produced a narrative report describing the processes, events, and documents involved in producing the ultimate project deliverable product, NEI 18-04 "RiskInformed Performance-Based Technology Inclusive Guidance for Non-Light Water Reactor Licensing Basis Development." Finally, the LMP team produced a report based on the experiences of early adopters of the LMP RIPB process which includes best practices, lessons learned, and frequently asked questions and responses. Table A-1 lists the Southern Company document numbers of each of these reports. The documents are available via the DOE's Office of Scientific and Technical Information (OSTI) public document repository (https://www.osti.gov).

Table A-1. LMP Reports and Document Numbers

\begin{tabular}{|c|c|c|}
\hline Report Title & $\begin{array}{l}\text { Southern Company } \\
\text { Document Number }\end{array}$ & $\begin{array}{l}\text { DOE OSTI } \\
\text { Document Number }\end{array}$ \\
\hline Selection and Evaluation of Licensing Basis Events & SC-29980-100 Rev 1 & TBD \\
\hline Probabilistic Risk Assessment Approach & SC-29980-101 Rev 1 & TBD \\
\hline $\begin{array}{l}\text { Safety Classification and Performance Criteria for } \\
\text { Structures, Systems, and Components }\end{array}$ & SC-29980-102 Rev 1 & TBD \\
\hline $\begin{array}{l}\text { Risk-Informed and Performance-Based Evaluation of } \\
\text { Defense-in-Depth Adequacy }\end{array}$ & SC-29980-103 Rev 1 & TBD \\
\hline Final Project Report & SC-29980-105 Rev. 1 & TBD \\
\hline $\begin{array}{l}\text { LMP Lessons Learned, Best Practices, and Frequently } \\
\text { Asked Questions }\end{array}$ & SC-29980-106 Rev 0 & TBD \\
\hline
\end{tabular}

\section{Licensing Basis Event Selection Approach}

Inputs to the selection of LBEs are derived from a PRA of an advanced non-LWR plant. These inputs together with deterministic inputs, such as design selections and selection of SafetyRelated (SR) SSCs, are used as part of the selection and evaluation of LBEs. As part of the LBE selection and evaluation process described in the LBE report, the engineering and safety analysis effort will result in a selection of a set of SR SSCs that are necessary and sufficient to perform the PRA Safety Functions (PSFs) required to keep the Design Basis Events (DBEs) within the Frequency-Consequence (F-C) target, and to prevent any high-consequence Beyond Design Basis Event (BDBE) from migrating into the DBE region and exceeding the F-C Target. The SR SSCs are then relied upon to mitigate all the Design Basis Accidents (DBAs) within the dose limits of 10 CFR 50.34 using conservative assumptions. 


\section{Probabilistic Risk Assessment Approach}

This report outlines the approach to develop a PRA for advanced non-LWR plants in support of risk-informed and performance-based (RIPB) applications. Future advanced non-LWR license applications will include a design-specific PRA that is capable of supporting the applications for NRC permit(s) or license(s). When introduced at an early stage of the design, the PRA is expected to result in a more efficient risk management process. This report outlines the relevant regulatory policy and guidance for this type of PRA, describes the approach to be followed for the development of the PRA, and sets forth PRA topics that need to be addressed in order to facilitate successful design and more safety focused preparation and review of the license application.

\section{SSC Safety Classification and Performance Requirements Approach}

Information developed from and used in the development of the PRA to define event sequences and evaluate their frequencies and consequences is an input to the SSC safety classification and development of SSC performance targets. Information from the PRA is used to establish the necessary and sufficient conditions of SSC capability and reliability in order for LBE frequencies, consequences, and uncertainties to stay within the frequency-consequence evaluation criteria derived from the TLRC and to implement risk management strategies to control the total integrated risk of the plant. Reliability targets for SSCs are determined based on the need to maintain each LBE within its LBE category (Anticipated Operational Occurrence, Design Basis Event, or Beyond Design Basis Event). RIPB SSC capability targets are defined in part by the selected design margins between the LBE frequencies and dose limits for that LBE category. Special treatment requirements for SSCs are derived to achieve the necessary and sufficient degree of reliability and capability of the SSCs. This is discussed in a companion report on the LMP SSC safety classification approach.

\section{Defense-in-Depth Adequacy}

The PRA models and supporting assumptions are based in part on the plant capabilities for DID reflected in the design, as well as assumptions about the limits placed on design and operation of the plant by assumed programmatic DID measures. Information developed in the PRA is used to help evaluate the SSCs responsible for preventing and mitigating accidents. The PRA also plays an important role in the identification of key sources of uncertainty, and this supports a feedback loop to identify possible enhancements to plant capability and programmatic aspects of DID. Hence, the PRA provides important input to the risk-informed evaluation of DID, complements the NRC's deterministic approach and traditional DID philosophy, and provides a more objective, RIPB means to systematically demonstrate DID adequacy and preservation. This is discussed in a companion report on the LMP approach to evaluating DID adequacy.

\section{LMP Final Report}

The LMP team produced a narrative report describing the processes, events, and documents involved in producing the ultimate Project deliverable product, NEI 18-04 "Risk-Informed Performance-Based Technology Inclusive Guidance for Non-Light Water Reactor Licensing Basis Development." This report contains a wealth of references to documents that future users of the LMP RIPB process may find useful. Tables within the report provide references to the 
NRC Agencywide Document Management System (ADAMS) Accession Numbers of many industry and NRC documents that future permit and license applicants may wish to reference in their own applications.

\section{LMP Lessons Learned, Best Practices, and Frequently Asked Questions and Responses}

The LMP team produced a report based on the experiences of early adopters of the LMP RIPB process which includes best practices, lessons learned, and frequently asked questions and responses. This report provides guidance to reactor designers on how to efficiently implement the LMP RIPB processes within their own organization and answers to 32 frequently asked questions from reactor designers.

\section{A.2 Frequently Asked Questions}

\section{Probabilistic Risk Assessment Frequently Asked Questions}

PRAQ1. How can the use of PRA technology to risk-inform the licensing of advanced nonLWRs be justified given the lack of operating experience with these reactors?

PRAQ2. How to develop adequate PRA data for initiating events and frequencies, component failure rates, maintenance unavailability, and other PRA data needs?

PRAQ3. What is the role of the PRA in the SSC safety classification process and how does safety classification influence the PRA models and data?

PRAQ4. What is the role of absolute and relative risk significance criteria in the LMP methodology?

PRAQ5. What is the applicability of 10 CFR 50 Appendix B to PRA in the LMP methodology?

PRAQ6. What is the available guidance for the systematic search for initiating events for the PRA on advanced non-LWRs?

PRAQ7. How does the LMP methodology identify and evaluate "cliff edge" effects?

PRAQ8. How does the structure of the PRA event tree logic impact the identification of the Required Safety Functions and the selection of the SR SSCs?

PRAQ9. How can the PRA standard requirements be met during the design stage when as-built and as-operated information is not available?

PRAQ10. What is the available guidance on how RSFs are determined, how they relate to FSFs?

PRAQ11. What guidance is available on the PRA treatment of safety functions provided via passive means and utilizing inherent reactor features?

PRAQ12. How can the LMP methodology be applied using dynamic PRA method? 
PRAQ13. How does LMP address events that are not modeled in the PRA?

\section{Licensing Basis Events Frequently Asked Questions}

LBEQ1. What is the available guidance for how to develop mechanistic source terms using the PRA and supporting deterministic processes?

LBEQ2. How is the safety classification and special treatment of SSCs influenced by the placement of LBEs as AOOs vs. DBEs or BDBE?

LBEQ3. Is there additional information available on the selection of the F-C Target anchor points for evaluating the risk-significance of LBEs?

LBEQ4. What insights were obtained for using the F-C charts from the LMP tabletop exercises and from discussions with the NRC Staff regarding DG-1353 and SECY-19-0117?

\section{SSC Classification Frequently Asked Questions}

SSCQ1. What guidance is available on how to select among candidates for SR SSCs and possible conflicts with ARDCs?

SSCQ2. What guidance is available for how to classify NSRST SSCs and how to come up with STs.

SSCQ3. What guidance is available for how to consider whether an SSC is classified as NSRST as necessary for adequate DID?

SSCQ4. What guidance is available for how to address the full scope of SSCs in a plant including I\&C, support systems, active SSCs, passive SSCs relying on inherent features, and SSCs necessary to implement safety significant operator actions?

SSCQ5. What guidance is available for how to consider the need to protect SR SSCs against DBEHLs and how to consider the requirements for NSR and NSRST SSCs?

SSCQ6. What guidance is available to discuss how SSC classification flows down from RSFs to major components and subcomponents to establish SRDC at the lowest level?

SSCQ7. What guidance is available on how to set reliability and capability targets for safety significant SSCs?

SSCQ8. What is the relationship between the Maintenance Rule scope and the LMP SSC approach to assuring reliability and capability targets for NSRST and NSR components?

SSCQ9. IEEE standards for I\&C design only consider two safety classifications, 1E or non-1E. $1 \mathrm{E}$ is for safety functions or supporting systems that perform safety functions. Software QA for $1 \mathrm{E}$ is very complex and expensive. $1 \mathrm{E} \mathrm{V} \& \mathrm{~V}$ is also complex and difficult (i.e. exploration for unintended functions and behavior). The same concept of existing industrial codes and standards having binary rules for safety-related and non-safety-related SSC, but not addressing the 
"middle" NSRST, is encountered often across standards development organizations. Should equipment classified by LMP as NSRST be treated as 1E or non-1E (or, as safety-related or nonsafety-related) and why?

\section{Defense-in-Depth Frequently Asked Questions}

DIDQ1. What guidance is available on how to examine the results, limitations, uncertainties, and omissions from the PRA for making IDP decisions that impact SSC safety classification and ST or deciding on practical compensatory actions?

DIDQ2. What guidance is available on how to organize the IDP and update the DID baseline through design iterations?

DIDQ3. What is the distinction between the IDP and the IDPP and why is it important?

DIDQ4. What additional guidance is there regarding the evaluation of Plant Capability DID for low dose or no dose (zero consequences) LBEs and the determination of NSRST SSCs?

\section{Project Management Frequently Asked Questions}

PMQ1. What guidance is available for how to manage the iterative process of design development, PRA development, and selection of codes and standards for SSCs?

PMQ2. How does a designer know that they are completely done implementing the LMP RIPB process with a reactor design? What is the definitive "pencils down" "finish line" event? 